\title{
EVALUATION OF HANDS-FREE COMMUNICATION SYSTEMS
}

\section{Barry A. Bell Arnold G. Perrey}

\author{
U.S. DEPARTMENT OF COMMERCE \\ Natlonal Instltute of Standards \\ and Technology \\ Center for Electronles and \\ Electrical Englneering \\ ElectrIcIty DIvision \\ Galthersburg, MD 20899
}

\section{Marshall J. Treado}

U.S. DEPARTMENT OF COMMERCE Natlonal Instltute of Standards and Technology

Natlonal EngIneerIng Laboratory Law Enfor cement Standards Laboratory Galthersburg, MD 20899

\section{Prepared for}

National Instltute of Justlce U.S. Department of Justlce WashIngton, DC 20531

U.S. DEPARTMENT OF COMMERCE Robert A. Mosbacher, Secretary NATIONAL INSTITUTE OF STANDARDS AND TECHNOLOGY

John W. Lyons, Director 



\section{EVALUATION OF HANDS-FREE COMMUNICATION SYSTEMS}

\author{
Barry A. Bell \\ Arnold G. Perrey
}

U.S. DEPARTMENT OF COMMERCE Natlonal Institute of Standards and Technology Center for Electronlcs and Electrlcal Englneorlng Electriclty Division Galthersburg, MD 20899

Marshall J. Treado

U.S. DEPARTMENT OF COMMERCE Natlonal Instltute of Standards and Technology Natlonal Englneerlng Laboratory Law Enforcement Standards Laboratory Galthersburg, MD 20899

Prepared for Natlonal Institute of Justlce U.S. Department of Justice Washington, DC 20531

January 1990

Issued August 1990

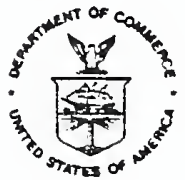

U.S. DEPARTMENT OF COMMERCE Robert A. Mosbacher, Secretary NATIONAL INSTITUTE OF STANDARDS AND TECHNOLOGY John W. Lyons, Director 


\section{Table of Contents}

page

List of Figures . . . . . . . . . . . . . . . . . . . . . . . . . iv

Abstract . . . . . . . . . . . . . . . . . . . . . . . 1

1. Introduction . . . . . . . . . . . . . . . . . . . . . 1

2. Commonly Used Terms and Acronyms . . . . . . . . . . . . . . . . 2

3. Basic HFCS Operational Considerations . . . . . . . . . . . . . . . 3

4. Brief Description of the Various HFCSs . . . . . . . . . . . . . . . 9

5. The HFCS Evaluation Tests . . . . . . . . . . . . . . . . . . 11

5.1 Interface/Control Unit Tests... . . . . . . . . . . . . . . 11

5.2 Tests of the System Transducers . . . . . . . . . . . . . . 15

6. Summary . . . . . . . . . . . . . . . . . . 23

7. References... . . . . . . . . . . . . . . . . . . 24

Appendix A - Units and Their Relationships . . . . . . . . . . . . . . . 25

Appendix B - Equipment Used for the Evaluation Tests . . . . . . . . . . 30

Appendix C - Test Data on all Four HFCSs . . . . . . . . . . . . . . . 33 



\section{List of Figures}

page

Figure 1. Figure 2 . Figure 3 .

Figure 4. Figure 5. Figure 6. Figure 7 .

Figure 8 .

Figure 9. Figure 10. Figure 11.

Figure 12.

Figure 13. Figure 14.

Figure 15.

Figure 16. Figure 17.

Figure 18.

Figure 19.

Figure 20.

Figure 21.

Figure 22.

Figure 23.

Figure 24.
A Hands Free Communication System (HFCS) . . . . . . . . . . . 3

Typical types of transducer configurations for HFCSs... . . . 4 Typical amplitude-frequency characteristic of an Interface/Control Unit amplifier circuit . . . . . . . . . . . . . . 4 Typical electrical response of an FM radio transmitter. . . . 5 Acoustical response of a typical boom microphone . . . . . . . 5 Acoustical response of a typical ear pickup . . . . . . . . . 5 Composite plot of three amplitude-frequency characteristics of a typical headphone at three different loudness levels . 7 Composite plot of three amplitude-frequency characteristics of a typical earphone at three different loudness levels . 7 Four examples of types of headset mountings for earphones . . 8 Block diagram of the basic HFCS test setup . . . . . . . . . . 11 Test setup for measuring the voltage gain, distortion, signal-to-noise ratio, and output impedance of the Interface/Control Unit . . . . . . . . . . . . . . . . 12

Test setup for measuring the input impedance of the Interface/Control Unit . . . . . . . . . . . . . . . 12

Simplified block diagram of the sound-level meter . . . . . . 16

Amplitude-frequency characteristic curves of the sound-level meter for different weighting networks . . . . . . . . . . 16

Cross-sectional view of the in-line axial sound source-tosound-level meter adaption scheme . . . . . . . . . . . 17

Test setup for calibrating the sound source . . . . . . . . . 19

Lower plot: Amplitude-frequency characteristic of the sound source relative to $74 \mathrm{~dB}$ SPL @ $1000 \mathrm{~Hz}$ (drive signal held constant at $0.04 \mathrm{~V}$ )

Upper plot: Amplitude-frequency characteristic of the sound source relative to $95 \mathrm{~dB}$ SPL @ $1000 \mathrm{~Hz}$ (drive signal held constant at $0.204 \mathrm{~V}$ )

Test setup for testing microphones with the calibrated sound source ....................... . . 20

Block diagram showing the test setup for headphones and other receiving type transducers . . . . . . . . . . . 20

Cross-sectional view of the in-line axial headphone-to-soundlevel meter adaption scheme . . . . . . . . . . . . . .

Cross-sectional view of the in-line axial earphone-to-soundlevel meter adaption scheme . . . . . . . . . . . . . . . .

Chart for the conversion of loudness level in dB SPL to sound pressure level in dynes $/ \mathrm{cm}^{2}$. . . . . . . . . . . . . . 27

Sound pressure levels for normal, raised, and loud male and female voices, relative to transducer distance . . . . . 28

Microphone sensitivity evaluation chart . . . . . . . . . . 29 

Evaluation of Hands-Free Communication Systems

Barry A. Bell, Arnold G. Perrey, and Marshall J. Treado

National Institute of Standards and Technology

Gaithersburg, MD 20899

Abstract

Hands-Free Communication Systems (HFCS) are used by law enforcement agencies, fire departments, rescue squads, and the Armed Forces, where tasks require the communications operator's hands to be free. Four such HFCSs were tested to measure their operational characteristics of voltage gain/frequency response, signal-to-noise ratio, total harmonic distortion, and sensitivity.

Key words: acoustic; amplification; communication; distortion;

emf; frequency; interface; noise; operation; sensitivity; signal; transceiver.

\section{Introduction}

Several manufacturers have developed components and devices to be used in conjunction with a personal transceiver (walkie-talkie radio set). A typical hands-free communication system (HFCS) consists of a personal transceiver, a microphone, a headphone or earphone, and an interface/control unit between these items. The interface/control unit activates the transmit and receive modes of operation and amplifies the microphone output when transmitting. The transmitting transducers may or may not be built into helmets and can include either a throat-, bone conduction-, or boom-type microphone, or an ear pickup. The HFCSs vary somewhat in configuration since they are manufactured as pressto-talk (PTT) and voice operated (VOX) units. The latter operating mode is utilized when it is necessary to have both hands free.

At the request of the National. Institute of Justice (NIJ), the National Institute of Standards and Technology (NIST), through its Law Enforcement Standards Laboratory (LESL) and the Electricity Division, has evaluated the performance of HFCSs with an emphasis on the main operational characteristics of such systems. Four manufacturers of HFCSs were contacted and each submitted their system components to NIST for evaluation and testing ${ }^{1}$. Basic operational characteristics of the HFCSs were measured, e.g., the voltage gain/frequency response, signal-to-noise ratio, total harmonic distortion, and input/output impedance of their interface/control units. Similarly, the acoustical response and sensitivity of the transmitting transducers and the frequency response and sensitivity of the receiving transducers were characterized.

1 In order to describe the systems and tests discussed in this report adequately, commercial equipment and instruments are identified by manufacturer's name and/or model number. In no case does such identification imply recommendation or endorsement by the National Institute of Standards and Technology, the National Institute of Justice, or any other government agency. 


\section{Commonly Used Terms and Acronyms}

(NOTE: See Appendix A for a description of units and their relationships)

Attack time - The time it takes for an interface/control unit to attain its operational state.

$\mathrm{dB}$

- Decibel; one tenth of a Bel, the number of decibels denoting the ratio of two amounts of power being ten times the logarithm to the base 10 of this ratio.

dB SPL

- A unit of pressure level in decibels referenced to a sound pressure of $2 \times 10^{-4}$ dynes $/ \mathrm{cm}^{2}$, or $20 \times 10^{-6}$ Pascal $(\mathrm{Pa})$. By definition, $74 \mathrm{~dB}$ SPL $=0.1 \mathrm{~Pa}=1 \mathrm{dyne} / \mathrm{cm}^{2}$.

$\mathrm{dBm}$

- A unit of signal level in decibels with reference to $1 \mathrm{~mW}$.

$\mathrm{dBV}$

- A unit of voltage level in decibels with reference to $1 \mathrm{~V}$.

Emf - Electromotive force; a measure of electrical potential, typically given in millivolt (mV) units.

Efficiency - For a speaker (headphone or earphone), the ratio of the mechanical power delivered to the vibrating mass relative to the electrical power applied to the drive coil.

Hold time - The time an interface/control unit remains operational after the last syllable spoken.

$\mathrm{Pa}$

- Pascal; the international system (SI) unit for pressure. By definition, $1 \mathrm{~Pa}=1$ newton $/ \mathrm{m}^{2}$.

PTT - Press to talk, switch operated (activated) transmission.

Sensitivity - For a microphone, the ratio of the output emf generated to the applied pressure. This output/input relationship is also used for speakers (headphones/earphones), i.e., the ratio of the sound pressure level generated from the applied electrical power.

$S / N$, SNR - Signal-to-noise ratio; a measure of the signal range available above the inherent noise level in an amplifier, for example.

Transceiver - The combination of radio transmitting and receiving equipment in a common housing, usually for portable or mobile use (often referred to as a walkie-talkie).

VOX

- Voice operated/activated transmission (sometimes referred to as TOX (talk operated/activated transmission). 


\section{Basic HFCS Operational Considerations}

Figure 1 below shows a typical configuration of the components used in an HFCS. Essentially, these systems are simply an extension of the familiar walkie-talkie radio communications transceiver. However, to adapt the personal transceiver to a "hands-free" application, the receiving and transmitting operations are extended to utilize transducers purposely located near the head for better acoustical coupling and ease of operation. Figure 2 (overleaf) illustrates some typical types of transducer configurations for HFCSs.

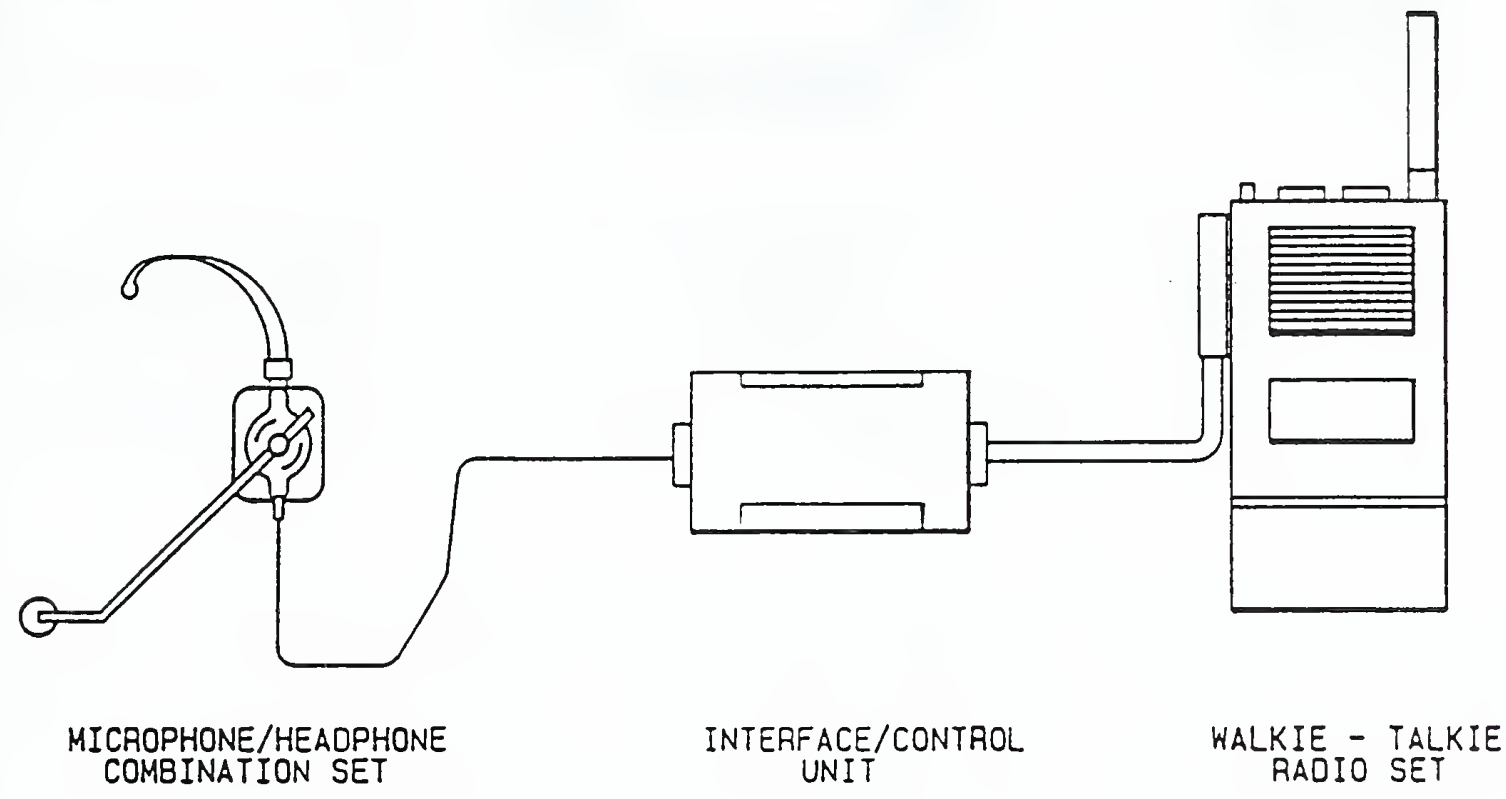

Figure 1. A Hands Free Communication System (HFCS)

The operating modes must be controlled when using these microphone/headphone combinations in conjunction with the radio set, and the connections to the circuits in the radio set must be properly interfaced electrically. This is the function of the interface/control unit. Consequently, testing the operational characteristics of such an HFCS involves measurements of the input and output impedances of the interface/control unit as well as the nominal signal levels, gain, signal-to-noise ratio $(S / N)$, and distortion associated with the amplifier circuitry in this unit. Also, the sensitivity of the system transducers and the flatness of their amplitude-frequency characteristic are principal performance considerations.

For instance, figure 3 shows the typical amplitude-frequency characteristic of an interface/control unit amplifier circuit. Over a frequency range from $100 \mathrm{~Hz}$ through $6000 \mathrm{~Hz}$, a total of sixteen discrete frequencies were used to measure the corresponding amplitudes in order to show the flatness over the frequency range of interest adequately. This range has been defined as the voice communication band with frequencies from $300 \mathrm{~Hz}$ through $3000 \mathrm{~Hz}$, which 


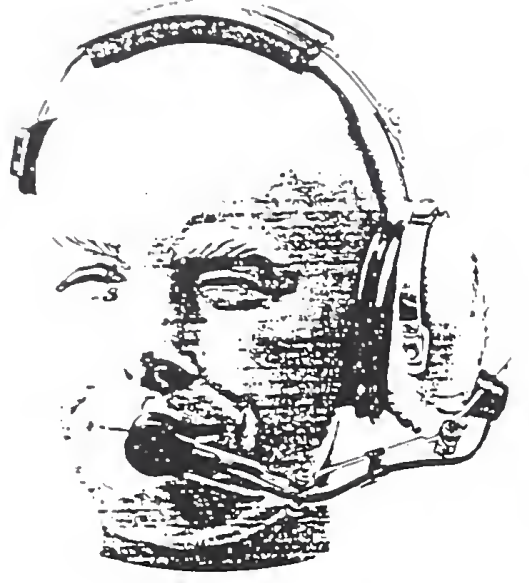

(a) Headphone/boom microphone combination

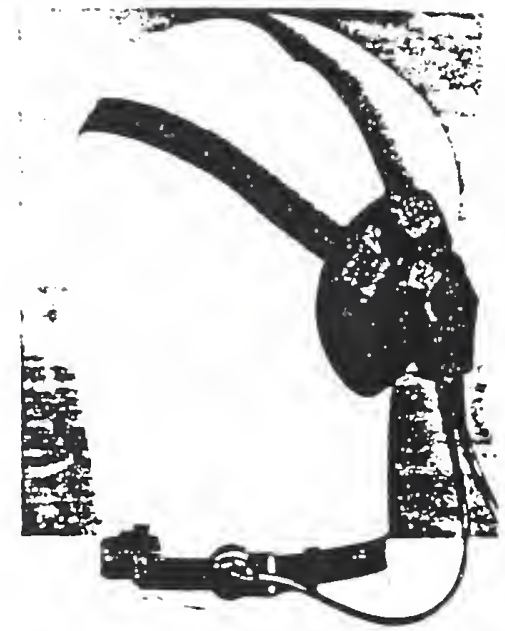

(b) Headphone/throat microphone combination

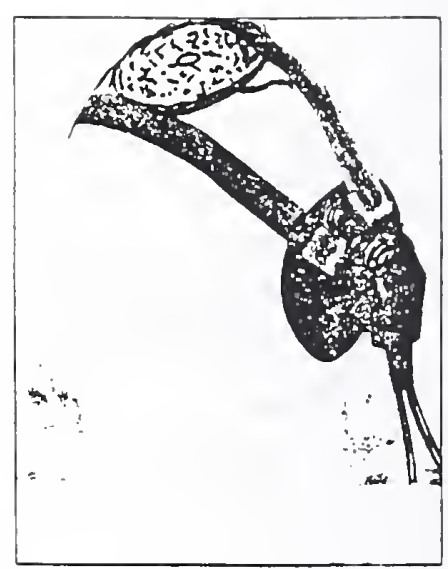

(c) Headphone/bone conduction microphone combination

Figure 2. Typical types of transducer configurations for HFCSs

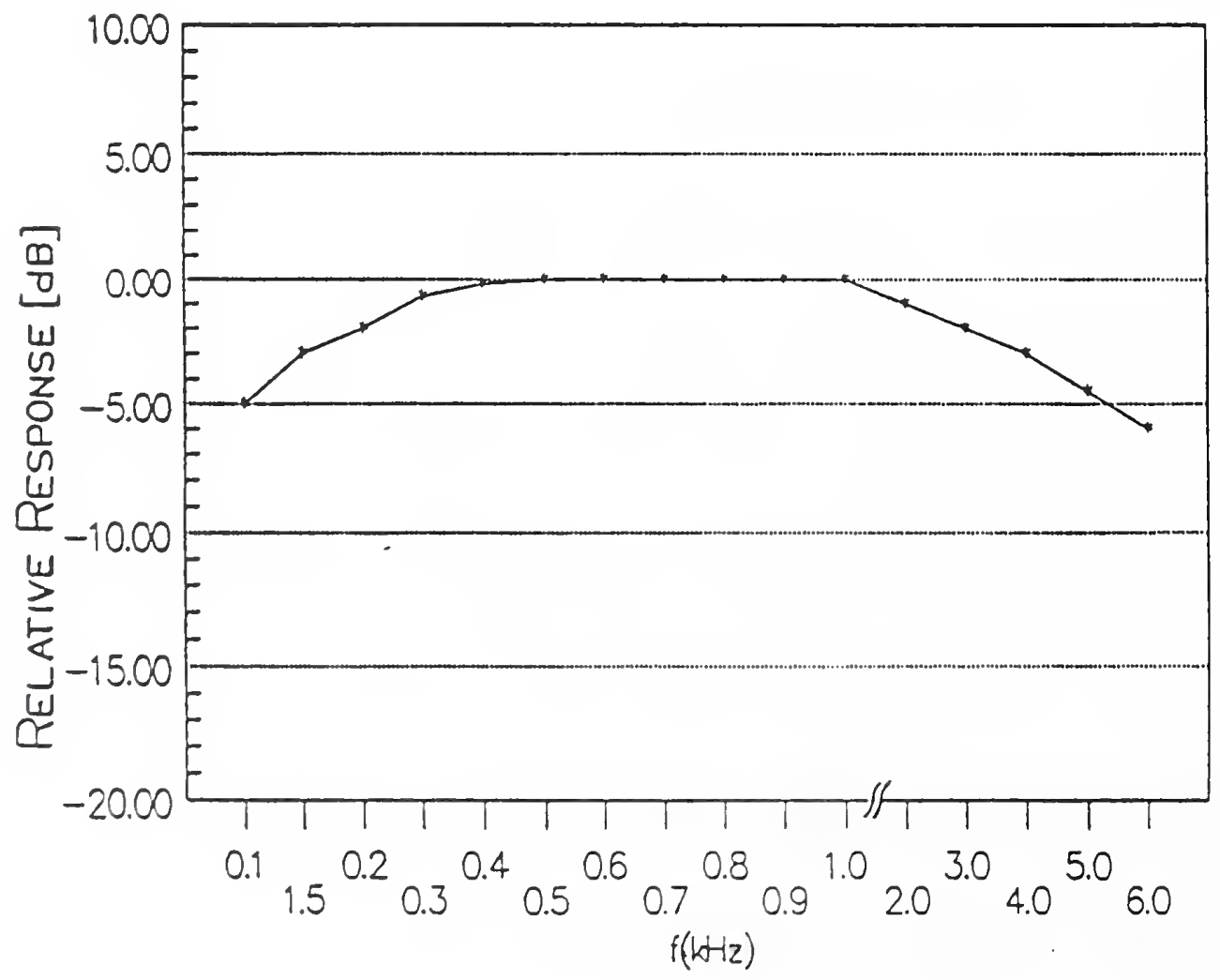

Reference Level: $-22.6 \mathrm{dBV}$ $(74 \mathrm{mV})$ at $1000 \mathrm{~Hz}$

Figure 3. Typical amplitude-frequency characteristic of an Interface/Control Unit amplifier circuit 


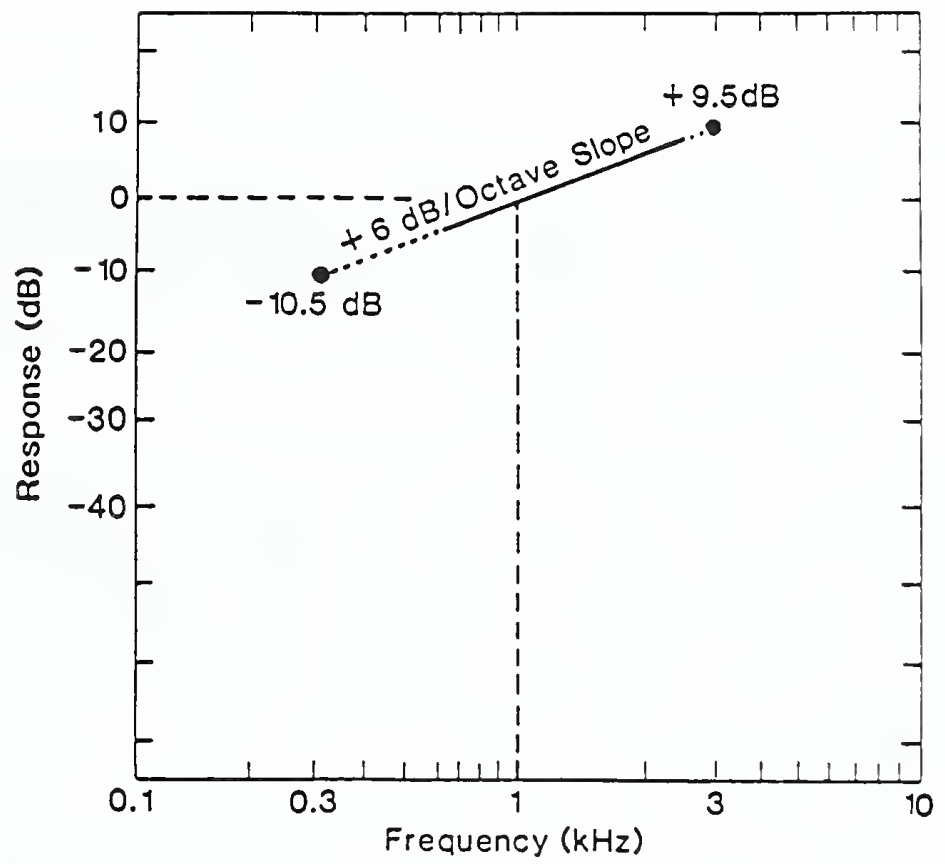

Figure 4. Typical electrical response of an FM radio transmitter

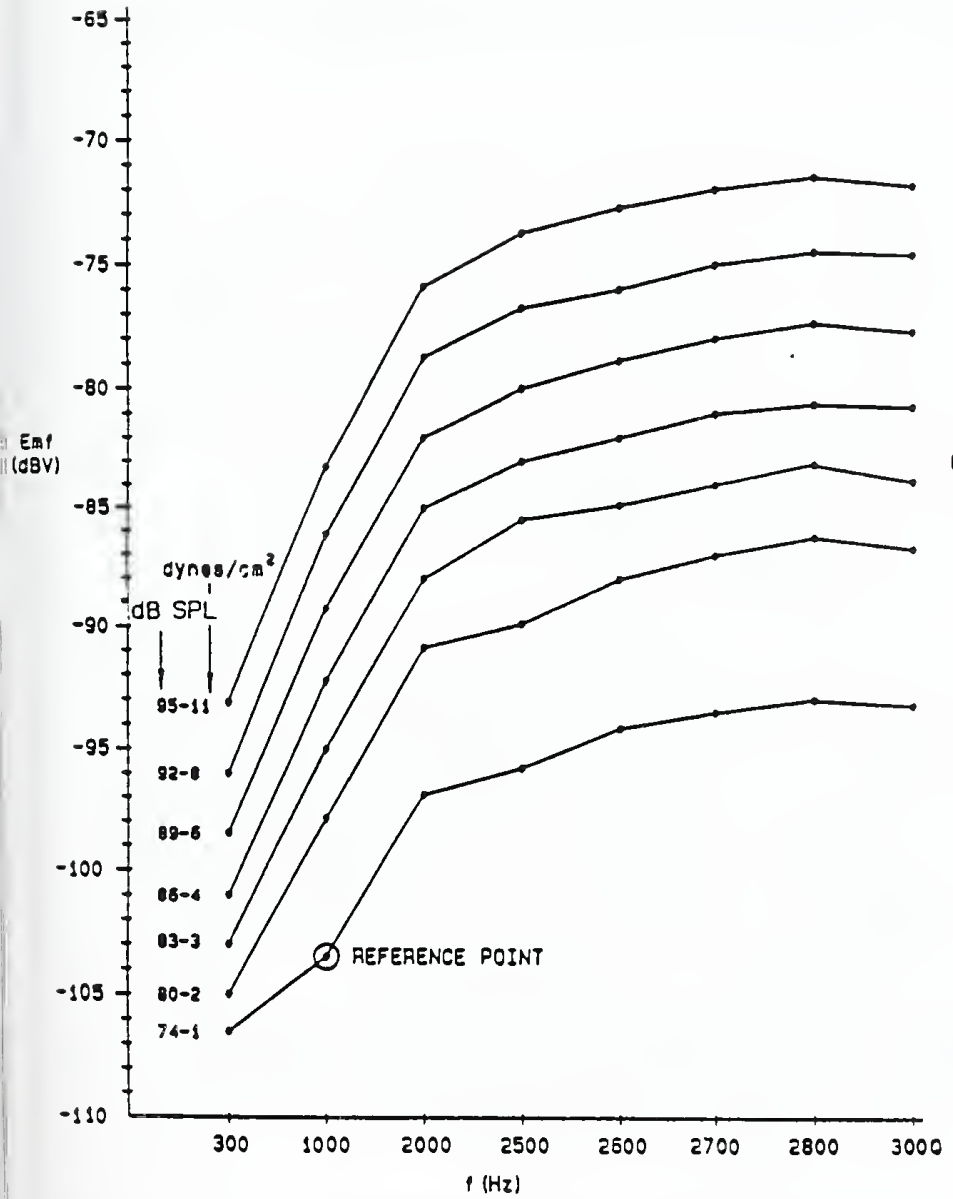

Figure 5. Acoustical response of a typical boom microphone

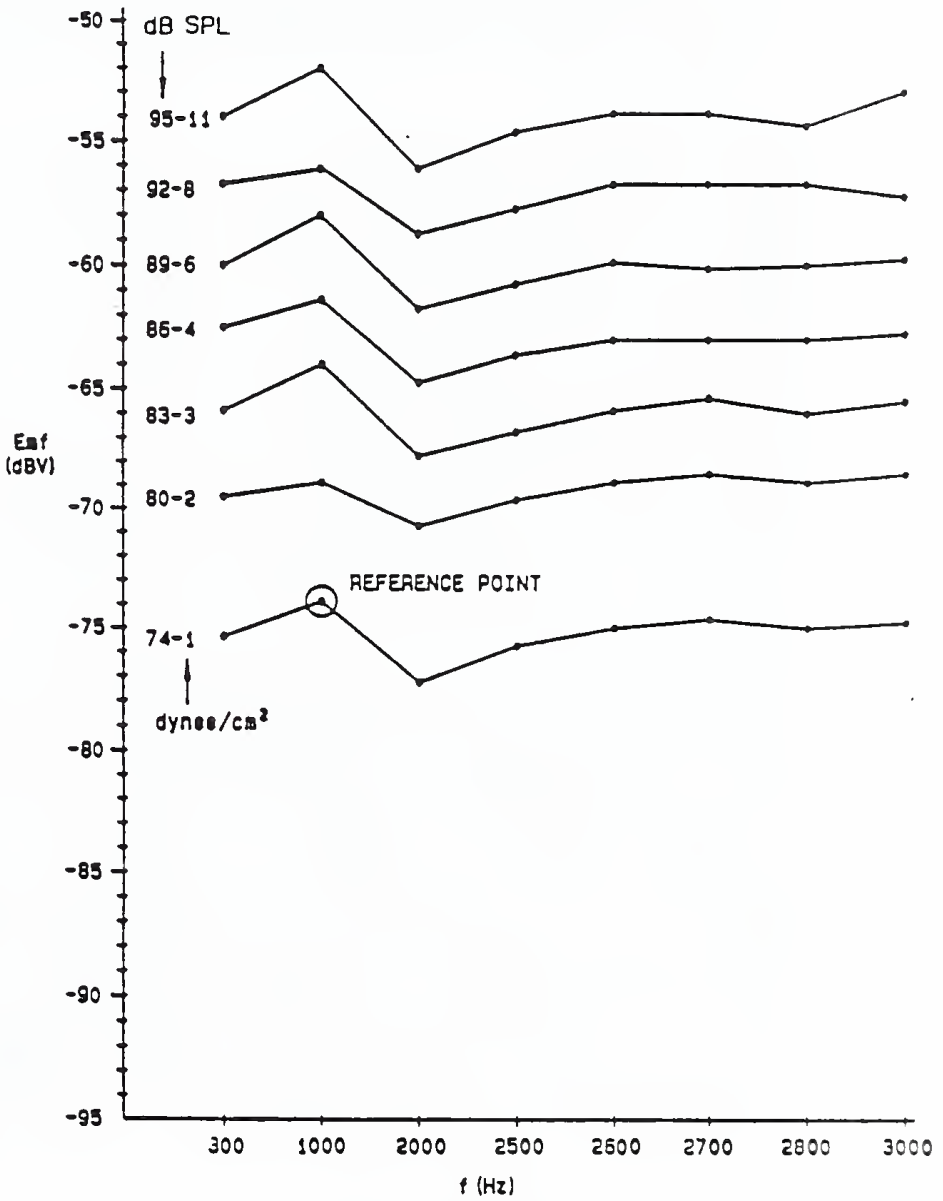

Figure 6. Acoustical response of a typical ear pickup 
matches the modulation frequency range of most radio transmitters. A typical electrical response of an FM radio transmitter is shown in figure 4 . This figure shows a $6 \mathrm{~dB}$ per octave pre-emphasis from $300 \mathrm{~Hz}$ through $3000 \mathrm{~Hz}$, relative to the $1000 \mathrm{~Hz}$ level. The dotted extensions of the solid line are indicative of an additional $6 \mathrm{~dB}$ per octave attenuation from $600 \mathrm{~Hz}$ to $300 \mathrm{~Hz}$, and $6 \mathrm{~dB}$ per octave gain from $2500 \mathrm{~Hz}$ to $3000 \mathrm{~Hz}$, which are called for in cases where coded signaling is utilized [1].

Figure 5 shows the typical acoustical response of a boom microphone with its output emf (in dBV) plotted versus frequency for various sound pressure levels (dyne $/ \mathrm{cm}^{2}$ or $\mathrm{dB}$ SPL) incident on the microphone. ${ }^{2}$ The reference frequency point is $1000 \mathrm{~Hz}$ and the reference sound pressure is 1 dyne $/ \mathrm{cm}^{2}=74 \mathrm{~dB} \mathrm{SPL}$. In order to characterize the complete response of the microphone to the full range of voice levels, the various sound pressure levels shown were used. Bone conduction- and throat-type microphones, as well as ear pickups, were similarly tested, showing significant differences in their response characteristics. Figure 6 shows a typical acoustical response of an ear pickup transducer. Compared to the response of the boom microphone of figure 5, this pickup device had a much flatter response. The family of response curves is also at a considerably higher level, indicating a greater sensitivity. The reference point at $1000 \mathrm{~Hz}$ and a sound pressure of 1 dyne $/ \mathrm{cm}^{2}$ is indicated on both figures. At these points the sensitivity is -104 and $-74 \mathrm{dBV} / \mathrm{dynes} / \mathrm{cm}^{2}$ for the boom microphone and the ear pickup, respectively.

Headphones and earphones were tested for their amplitude-frequency characteristic within the audio frequency range of interest. Figure 7 shows a composite plot of three amplitude-frequency characteristics obtained on a typical headphone, measured at three different input drive levels. For the tests, the input coil of the headphone received a drive voltage from an audio generator. The resulting acoustical output was measured using a standard sound-level meter (see the description of this meter under section 5.2). Again, the reference frequency used was $1000 \mathrm{~Hz}$ and the response is relative to the indicated loudness level at the reference frequency. The measured voice-coil resistance of the headphone and the drive voltages required to generate the loudness levels of interest are given in figure 7 .

As with the microphone and ear pickup responses shown in figures 5 and 6 (typical for transmitting-type transducers), the head/earphone responses can show considerable variations. Figure 8 shows the composite plot of three amplitude-frequency characteristics obtained on a typical earphone, measured at three different input drive levels. Compared with the response of the headphone shown in figure 7, this earphone has increased sensitivity at the higher audio frequencies, in order to improve the reception of speech consonants having frequency components in this range. Voice coil resistance and drive voltage data are also given so that one can determine the approximate electrical power applied to the device under test (i.e., $\left.\mathrm{P}-\mathrm{V}^{2} / \mathrm{R}\right)$. The reference point at $1000 \mathrm{~Hz}$ and a loudness level of $74 \mathrm{~dB} \mathrm{SPL}$ is indicated on both figures. With applied power of approximately

2 See Appendix A for a discussion of units and their relationships. 

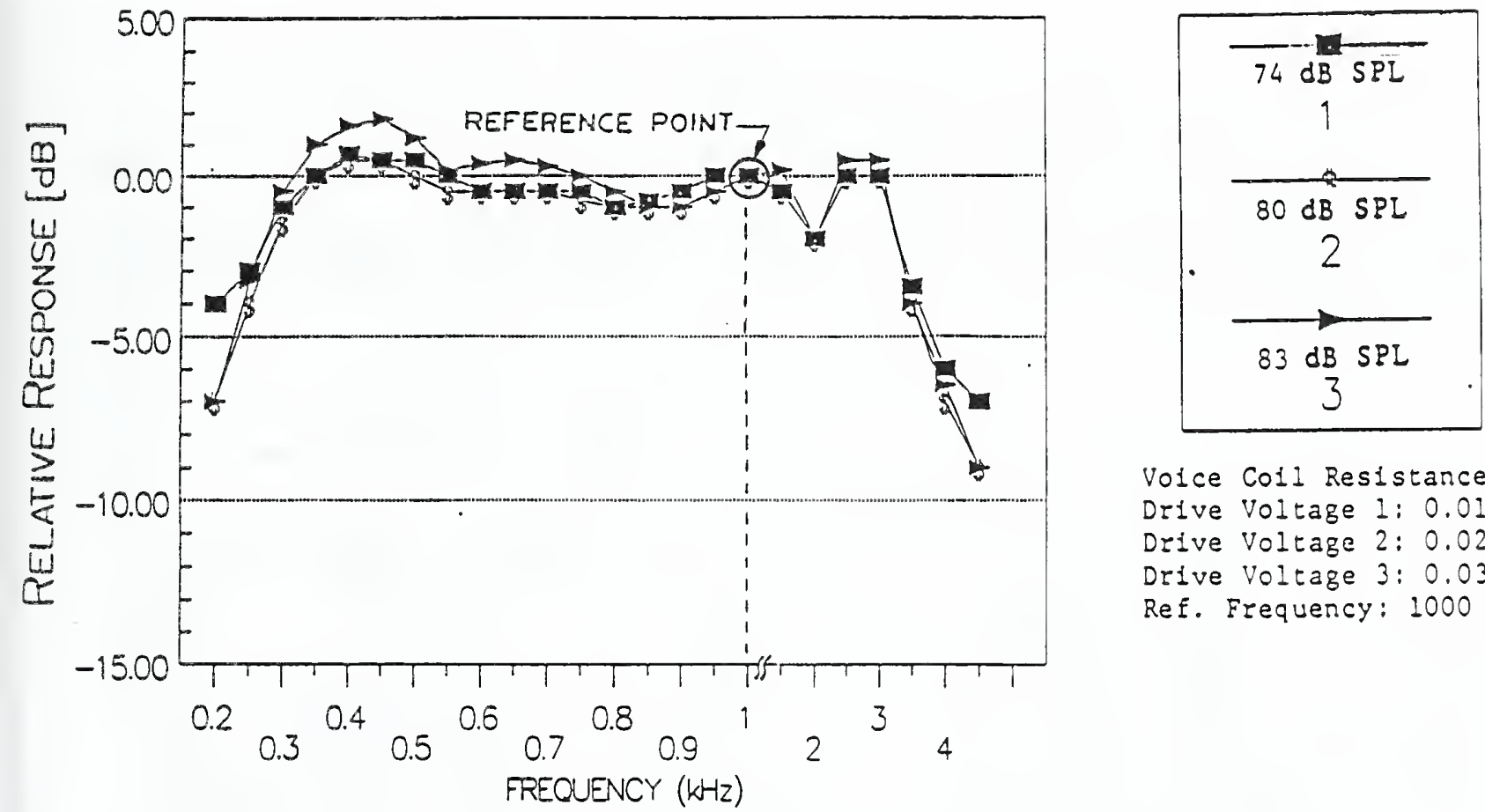

Volce Coil Resistance: $80 \hat{n}$ Drive Voltage 1: $0.013 \mathrm{~V}$ Drive Voltage 2: $0.027 \mathrm{~V}$ Drive Voltage 3: $0.039 \mathrm{~V}$ Ref. Frequency: $1000 \mathrm{~Hz}$

Figure 7. Composite plot of three amplitude-frequency characteristics of a typical headphone for three different drive levels

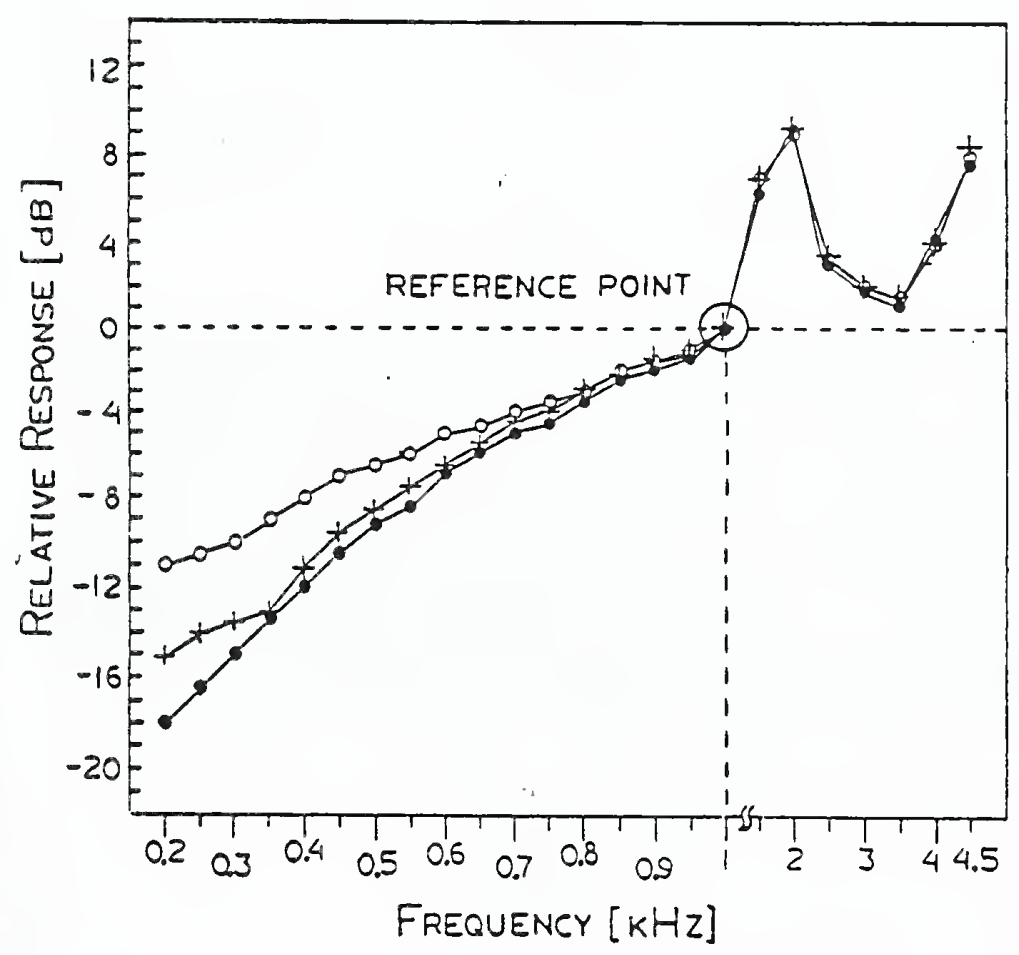

$1 \cdot 0 \cdot 74 \mathrm{~dB} \mathrm{SPL}$

$2 \cdot+.80 \mathrm{~dB} \mathrm{SPL}$

3 - $-83 \mathrm{~dB}$ SPL

Voice Coll Resistance: 300.8

Drive Voltage 1: $0.0598 \mathrm{~V}$

Defve Voltage 2: $0.122 \mathrm{~V}$

Drive Voltage 3: $0.164 \mathrm{~V}$

Ref. Frequency: $1000 \mathrm{~Hz}$

Figure 8. Composite plot of three amplitude-frequency characteristics of a typical earphone for three different drive levels 
$(0.013 \mathrm{~V})^{2} / 80 \Omega=2.1 \times 10^{-6} \mathrm{~W}$ for the headphone and $(0.0598 \mathrm{~V})^{2} / 300 \Omega=$ $11.9 \times 10^{-6} \mathrm{~W}$ for the earphone, the sensitivities at these reference points are 35.2 and $6.22(\mathrm{~dB} \mathrm{SPL}) / \mu \mathrm{W}$, respectively.

In many headphone/earphone applications such as HFCSs, wearer comfort is also important. Figure 9 below (from [3]) shows four examples of types of headset mountings for earphones.
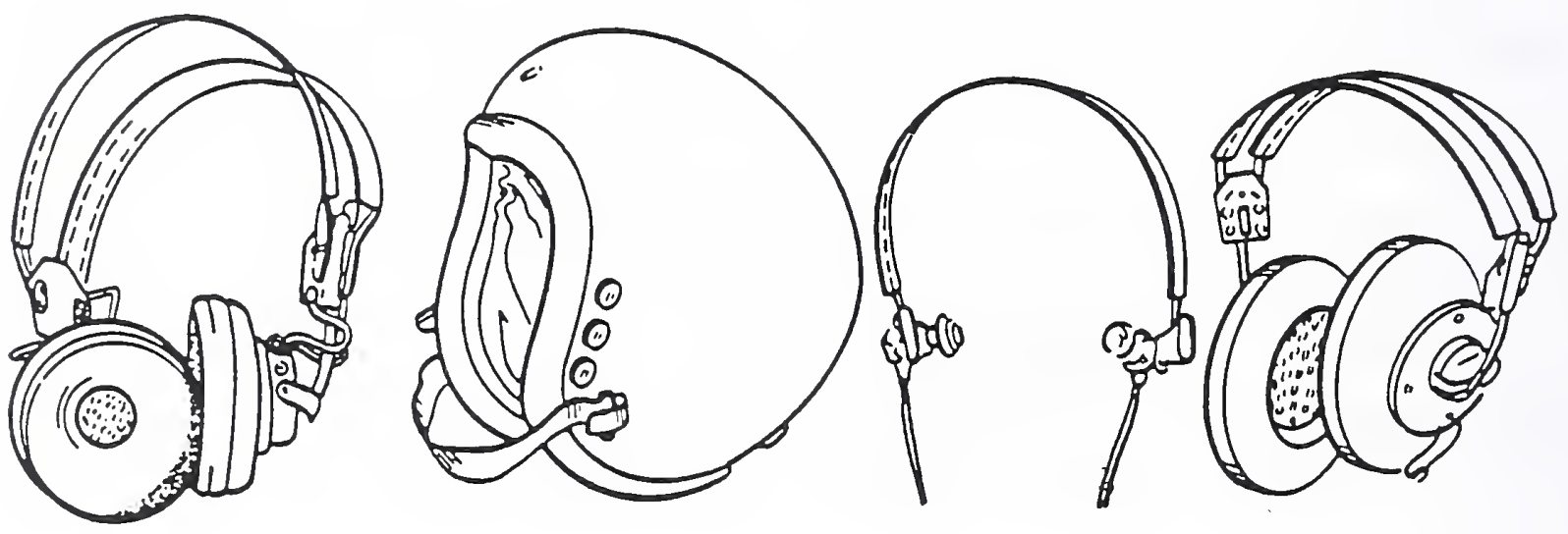

(a) Ear cushion

(b) Helmet

(c) Semi-insert

(d) Circumaural earmuff

Figure 9. Four examples of types of headset mountings for earphones

Insert type earphones need less driving power than external headphones because the enclosed volume is much smaller; however, they require moderate efficiency in order to save on the life of amplifier batteries. On the other hand, circumaural earmuffs are often driven by amplifiers that are otherwise used for loudspeakers. Here, efficiency is less important than the required sound level delivering capacity (i.e., the sensitivity). One mw of electrical power to an earphone typically produces 100 to $110 \mathrm{~dB}$ SPL when mounted in a standard $6 \mathrm{~cm}^{3}$ acoustical coupler [2]. The same earphone will produce less sound level in an earmuff (100 to $300 \mathrm{~cm}^{3}$ ) than in an ear cushion $\left(-6 \mathrm{~cm}^{3}\right)$, and will produce more sound level when coupled to an ear insert $\left(-2 \mathrm{~cm}^{3}\right)$. 


\section{Brief Description of the Various HFCSs}

The following four companies voluntarily submitted their HFCSs for testing:

1. Setcom Corporation (Smart Vox)

1400 Stierlin Road

Mountain View, CA 94043

2. Controlonics Corporation (Flexi Com)

49 Power Road, Box 568

Westford, MA 01886

3. Magnum Distribution, Inc. (Ear Mike)

3-245 H Street, Box 8008

Blaine, WA 98230

4. Centurion International, Inc. (Ear Com)

P.O. Box 82846

Lincoln, NE 68501

To familiarize the reader with each of these HFCSs, a short description is provided as follows:

System 1. This system consisted of four components:

a) one boom microphone (for positioning in front of the mouth) combined with a dual headphone set,

b) one bone conduction transducer (for positioning on top of the head) combined with a dual headphone set,

c) one interface/control unit, and

d) one interface cable.

The interface circuitry of this system allows completely hands-free radio communications operation (VOX operation). The unit is capable of operating with a wide range of portable and mobile radios - interchangeability of headsets or radios can be accomplished without modification of the system configuration. During VOX operation, the radio keying attack time is about 6 milliseconds and the "system on" hold time, after the end of a message, is approximately one second. The system is self-contained; it uses rechargeable. NiCad batteries. The weight of the interface unit is about $16 \mathrm{oz}$. or -450 grams. Its dimensions are $4.25 \times 3 \times 1.5$ inches or $-11 \times 7.6 \times 3.8 \mathrm{~cm}$.

System 2. This system consisted of four components:

a) one boom microphone (for positioning in front of the mouth) combined with a single headphone,

b) one throat microphone combined with an earphone device, 
c) one interface/control unit, and

d) one interface cable.

This system consists of an interface adapter that does not require batteries, together with a combination talk operated (TOX)/manual PTT switch. The set draws its operating current, $1 \mathrm{~mA}$, from the associated transceiver

(modifications are not required). When operated in the TOX mode, the turn-on attack time is 10 milliseconds and the hold time is about one second. The weight of the interface unit is -3 oz. or -85 grams, and its dimensions are $1.5 \times 2.5 \times 0.75$ inches or $-3.8 \times 6.4 \times 1.9 \mathrm{~cm}$.

System 3. This system consisted of three components:

a) one interface/control unit,

b) one combination transducer (used as ear pickup/earphone), and

c) one interface cable.

The interface module of this system is fully self-contained and is powered by a type AA battery. The operating current requirement is about $1.8 \mathrm{~mA}$ in the transmit mode. The unit comes equipped with a combination transducer which combines the functions of a microphone with that of a speaker in a unit as small as a hearing-aid earpiece. The unit can be operated in the PTT mode only, but works with transceivers that are equipped with external speaker/microphone capability. The transducer utilizes the otolaryngeal system (vibrations in the ear canal generated by the voice box and eardrum) for sound generation. In the receive mode the transducer functions as an earphone. The interface device weight is $-5.5 \mathrm{oz}$. or $-155 \mathrm{grams}$, and its dimensions are $3.1 \times 2.2 \times 1.0$ inches or $-7.7 \times 5.5 \times 2.7 \mathrm{~cm}$.

System 4 . This system consisted of three components:

a) one interface/control unit,

b) one combination transducer (used as ear pickup/earphone, and

c) one interface cable.

The interface device of the system is similar, but not identical, to that of system \#3. The unit is self-contained and powered by a $9 \mathrm{~V}$ battery. Here, too, a combination transducer is used that also works on the principle of inner ear vibration detection. In the receive mode, it also works like a basic miniature earphone. The interface unit operates in the PTT mode only and is normally in the receive mode of operation. The current draw requirement for PTT operation is $\sim 10 \mathrm{~mA}$. The interface device weight is -7.1 oz. or $\sim 200$ grams; its dimensions are $4.4 \times 2.7 \times 1.3$ inches or $-11 \times 6.8$ $\times 3.3 \mathrm{~cm}$. 


\section{The HFCS Evaluation Tests}

The following paragraphs describe the tests performed on the four sets of submitted HFCSs. The test conditions, test parameters, and test procedures conducted on all four systems were identical. (See Appendix C for a description of the equipment used for these tests).

\subsection{Interface/Control Unit Tests}

The four interface/control units from each system were tested for a) voltage gain/frequency response, b) distortion (THD), c) signal-to-noise ratio (S/N), d) input impedance $\left(Z_{\text {in }}\right)$, and e) output impedance ( $Z_{\text {out }}$ ). The test setups for the various measurements are shown in figures 10 through 12 . In figure 10 below is shown the basic test setup, which identifies the major equipment items required for these measurements.

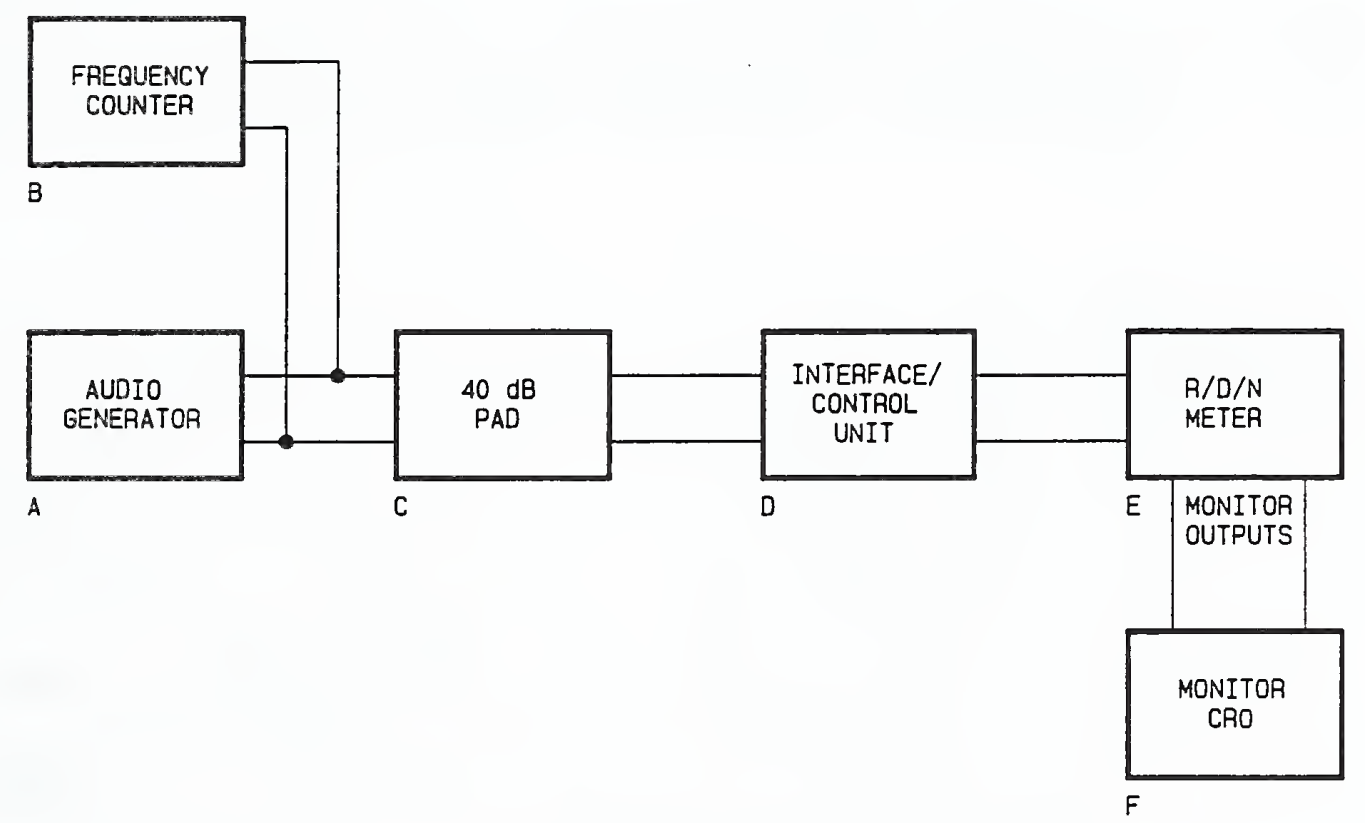

Figure 10. Block diagram of the basic HFCS test setup

An audio generator (A) is used to supply sine wave test signals at an -1 volt level to a $40 \mathrm{~dB}$ attenuator pad (C), which scales the signal down to an $-10 \mathrm{mV}$ input level for the interface/control unit (I/CU) under test (D), and provides better impedance matching between the generator and the I/CU. A frequency counter ( $B$ ) is used to conveniently monitor the frequency of the audio generator. An rms/distortion/noise $(R / D / N)$ meter $(E)$ is used to measure the rms voltage, distortion, and noise signals from the I/CU. A cathode ray tube oscilloscope - CRO (F) is used to monitor these signals via the monitor output terminals of the R/D/N meter. Fig. 11 gives additional details of the I/CU test setup that pertain to the measurements of voltage gain, distortion, signal-to-noise ratio, and output impedance. Figure 12 shows the same test 


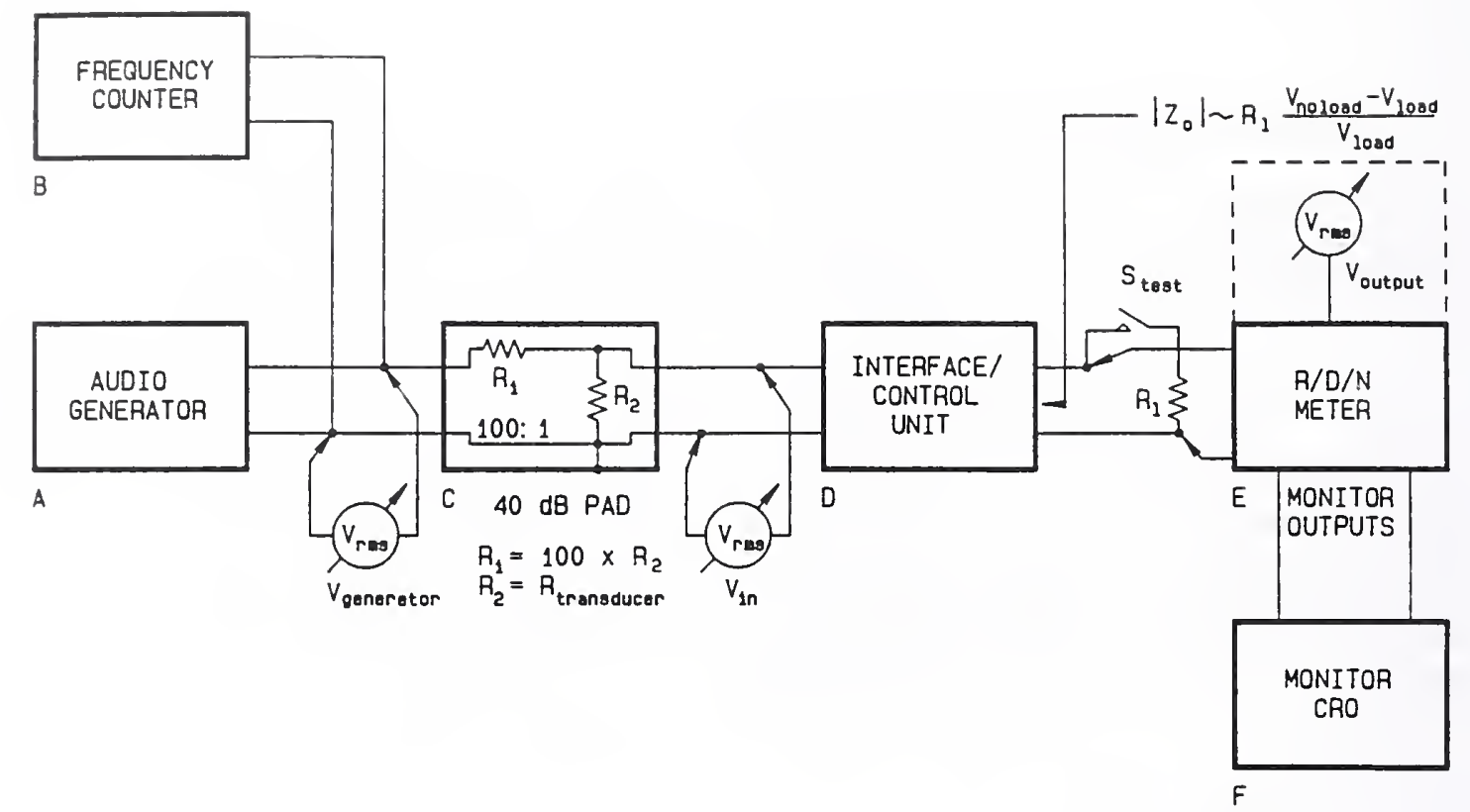

Figure 11. Test setup for measuring the voltage gain, distortion, signalto-noise ratio, and output impedance of the Interface/Control Unit

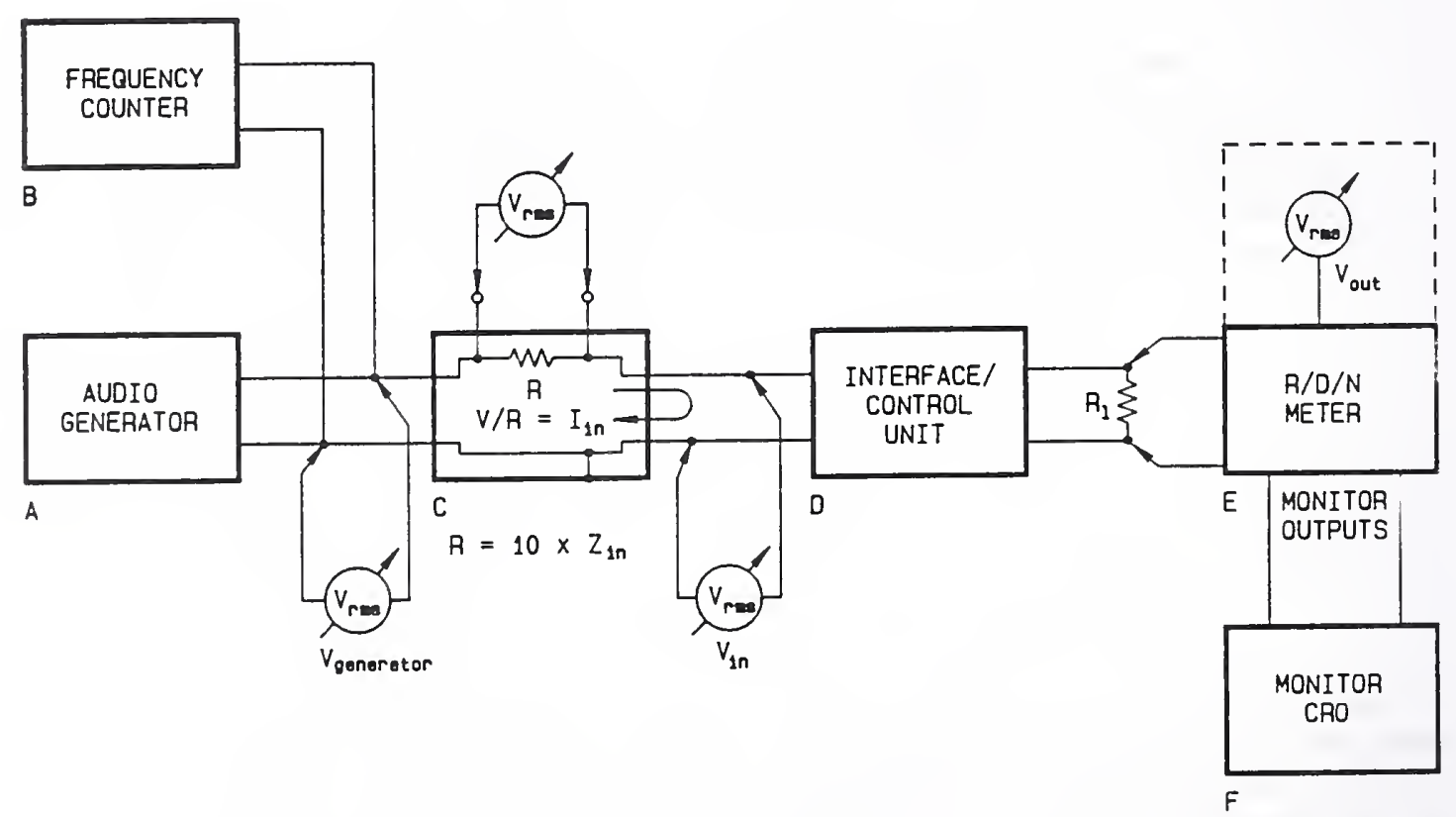

Figure 12. Test setup for measuring the input impedance of the Interface/Control Unit 
setup, except that the $40 \mathrm{~dB}$ pad has been replaced with a precision resistor, $R$, for measuring the input impedance to the $I / C U$. Table 1 in Apppendix $C$ provides a tabular summary of the data taken from measurements on the I/CU amplifiers of each HFCS tested.

\section{Voltage Gain/Frequency Response Measurements}

As indicated in figure 11, the voltage level ( $V_{\text {generator }}$ ) from an audio generator in front of a $40 \mathrm{~dB}$ pad was adjusted to provide a nominal voltage level across $R_{2}$ of the attenuator. The value of the $R_{2}$ resistor used was based on the rated output impedance of the microphone normally used with the particular I/CU. The nominal input voltage $\left(V_{i n}\right)$ was then adjusted to provide an equivalent microphone emf level to the input of the I/CU. The nominal test frequency for measuring the gain was $1000 \mathrm{~Hz}$, which was monitored by the frequency counter, and held constant to within \pm 1 percent.

Voltage measurements were then made to determine the gain of the I/CU. With the $S_{\text {test }}$ switch closed, the I/CU was terminated with its nominal $6 \mathrm{~dB}$ load resistance, $R_{1}$, and the output voltage level measured with the rms voltmeter portion of the $R / D / N$ meter. The difference measured between $V_{\text {in }}$ and $V_{\text {out }}$ is due to the voltage gain in the I/CU amplifier. The response (in $\mathrm{dB}$ ) can be calculated by the relationship,

$$
I / C U_{\text {gain }}(d B)=20 \log _{10}\left(V_{\text {out }} / N_{\text {in }}\right) \text {. }
$$

To determine the relative gain of the I/CU amplifier as a function of frequency, the nominal input signal level at $1000 \mathrm{~Hz}$ was held constant while the frequency settings of the audio oscillator were then changed, and readings taken as before of $V_{\text {out }}$. Amplitude data were collected from $100 \mathrm{~Hz}$ to $6000 \mathrm{~Hz}$ in order to cover the response characteristics adequately. Along with the numerical data, amplitude-frequency plots (relative to the gain at $1000 \mathrm{~Hz}$ ) were obtained for the I/CU amplifiers of all four HFCSs, similar to the one shown in figure 3.

\section{Distortion Measurements}

For making distortion measurements, the test setup is shown in figure 11. First, the nominal rms output voltage level was measured across the load resistor, $R_{I}$ (as above when making gain measurements). Then, by amplifying the signal internally, the distortion meter portion of the $R / D / N$ meter was adjusted for a relative setting of $0 \mathrm{dBV}$. The controls of the distortion meter were set to provide a good on-scale reading. Using internal filters, the $R / D / N$ meter automatically nulls out the fundamental frequency, and the rms value of the residual harmonics plus noise are measured by the distortion meter, relative to the 1 volt level. Typical residual waveforms were observed with the monitoring CRO, showing small amounts of second or third harmonics (or the composite of both). The typical distortion readings registered were between $-43 \mathrm{dBV}$ and $-54 \mathrm{dBV}$ for the four I/CU amplifiers tested.

\section{Signal-to-Noise Ratio ( $\mathrm{S} / \mathrm{N}$ ) Measurements}

$S / N$ ratio measurements were used to quantify the noise performance of the I/CU 
amplifiers. This test is very similar to the distortion measurement tests described above, and depicted in figure 11. Again, a nominal input signal was applied to the I/CU amplifier, an rms output voltage reading was taken, and its value used as an amplitude reference level for the signal. The distortion meter in the $\mathrm{R} / \mathrm{D} / \mathrm{N}$ instrument was again adjusted for a relative setting of $0 \mathrm{dBV}$. Then, the signal source (audio generator) was turned off, and the bandpass filter mode selected for the $R / D / N$ meter. High frequencies were attenuated beginning at $20 \mathrm{kHz}$ ( $3 \mathrm{~dB}$ upper cutoff frequency), and (to eliminate low frequency noise interference) a lower $3 \mathrm{~dB}$ cutoff frequency set at $500 \mathrm{~Hz}$. Readings of the distortion meter are then indicative of the noise floor from the amplifier over this frequency range. The typical $S / N$ values thus measured were in the range of $43 \mathrm{~dB}$ through $52 \mathrm{~dB}$ for the four I/CU amplifiers tested.

\section{Output Impedance ( $z_{\text {out }}$ ) Measurements}

To measure the output impedance ( $z_{\text {out }}$ ) of the I/CU amplifier, the test setup is once again as shown in figure 11. Switch $S_{\text {test }}$ was first closed and the $I / C U$ amplifier output terminated by the nominal $6 \mathrm{~dB}$ load resistor, $R_{1}$. The signal level from the audio generator was then adjusted to provide a nominal input voltage level to the I/CU amplifier from the output of the $40 \mathrm{~dB}$ pad. The output voltage level of the I/CU amplifier was monitored, and not allowed to exceed its nominal value. This output level ( $V_{\text {load}}$ ) was then measured and recorded. Without changing any of the control settings, the load resistor, $R_{1}$, was then disconnected by opening switch $S_{\text {test, }}$ and the open-circuit output voltage level ( $V_{\text {noload}}$ ) was measured and recorded. The voltage levels measured were then used to calculate the magnitude of the output impedance, $\left|z_{\text {out }}\right|$, with the simple voltage divider relationship:

$$
\left|z_{\text {out }}\right|(\text { at } 1 \mathrm{kHz})=\mathrm{R}_{1} \cdot\left(\mathrm{V}_{\text {noload }}-\mathrm{V}_{\text {load }}\right) / \mathrm{V}_{\text {load }} \text {. }
$$

\section{Input Impedance $\left(Z_{\text {in }}\right)$ Measurements}

Figure 12 shows the test setup used for making measurements of the input impedance, $Z_{i n}$, of the $I / C U$ amplifiers. For this test, one minor modification was made in the configuration of the input attenuator of figure 11 . Instead of using the previously utilized $40 \mathrm{~dB}$ pad, a precision series resistor (approximately 10 times the value of the specified $Z_{\text {in }}$ ) was used to provide a measure of the input current, $I_{i n}$. This current is measured by making a meajurement of the voltage drop across $R$, where it is assumed that the rms voltmeter used has reasonably good comron mode voltage rejection (as is the case with the rms voltmeter in the $R / I$. $N$ meter). By making $R$ large relative to $Z_{i n}$, the $I / C U$ amplifier input is driven by nearly a constant current source, independent of its input impedance. A signal level from the audio

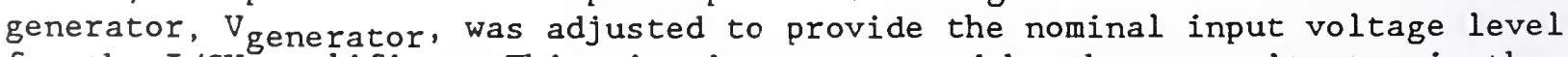
for the I/CU amplifier. This signal was measured by the rms voltmeter in the $\mathrm{R} / \mathrm{D} / \mathrm{N}$ meter as $\mathrm{V}_{\text {in }}$. (At the same time, the output voltage, $\mathrm{V}_{\text {out }}$, across $\mathrm{R}_{1}$ was monitored in order to verify the functioning of the amplifier circuitry). The measured values of $V_{j n}$ and $I_{i n}$ were then used to calculate the magnitude of the input impedance, $\left|z_{\text {in }}\right|$, as

$$
\left|z_{\text {in }}\right|(\text { at } 1 \mathrm{kHz})-\mathrm{V}_{\text {in }} / \mathrm{I}_{\text {in }} \text {. }
$$




\subsection{Tests of the System Transducers}

Both the transmitting and receiving transducers of the four HFCSs were tested for determining theix overall sensitivity and relative amplitude-frequency characteristics. For this purpose it was necessary to establish a known sound source that could conveniently be used for testing microphones, ear pickups, and other transmitting devices. Similarly, a standard sound-level meter was employed (calibrated by the Acoustic Measurements Group at NIST) to measure accurately the sound level pressure from the sound source, as well as from the various head/earphone tranducers. Table 2 in Appendix $C$ provides a tabulated summary of the transducer complement of each of the four HFCSs that were evaluated.

\section{A Brief Description of the Sound-Level Meter}

A simplified block diagram of the sound-level meter is shown in figure 13. The microphone in this instrument is normally of the high-quality capacitor or piezoelectric type. The attenuators prevent the amplifiers from over-loading when the sound level is too high for a given range. The weighting networks $(A, B$, and $C$ ) are inserted when the frequency response characteristic is changed from relatively uniform to predetermined standard curves. The amplified signal is then rectified for driving the indicating meter, which responds logarithmically over a range of $-4 \mathrm{~dB}$ to $+10 \mathrm{~dB}$, relative to a switch-selected multiple of $10 \mathrm{~dB}$ SPL. The typical meter response time is $-0.5 \mathrm{~s}$, and integration times can be changed from fast to slow (20 ms to $1 \mathrm{~s}$ ).

The overall amplitude-frequency characteristic curves of the standard soundlevel meter are shown in figure 14. Curve "C" is essentially unweighted (flat) and is used for measuring wideband sound (or noise) measurements. Weighting networks "B" and "C" are normally used for substantial or moderate attenuation of low frequency noise interference. The "A" weighting network is useful in connection with testing noise exposure levels and other special applications. Curve "C" was used with all of the testing done on the HFCS tranducers.

\section{Description and Calibration of the Sound Source}

Figure 15 illustrates a side view of the ty, ef loudspeaker and mounting that was used to produce a relatively well-known source of sound, particularly in the axial direction immediately in front of the cone of the speaker. The sound-level meter described above was used to calibrate the sound-level pressure produced by the source at this point, in conjunction with the acoustofoam adapter used to confine the microphone input of the sound-level meter to the (near-field) test region. To prevent undesired vibrations, the sound source was supported on foam padding that was about $0.5 \mathrm{in}$. thick, and the sound-level meter was supported by a stacked foam column.

This source was configured as one that could be constructed easily and maintained by personnel in an HFCS support laboratory. The sound source consisted of a small-sized, high-quality loudspeaker capable of generating various sound levels over a frequency range from $-200 \mathrm{~Hz}$ through $-5000 \mathrm{~Hz}$. The loudspeaker was equipped with a high quality magnet made of AlNiCo 


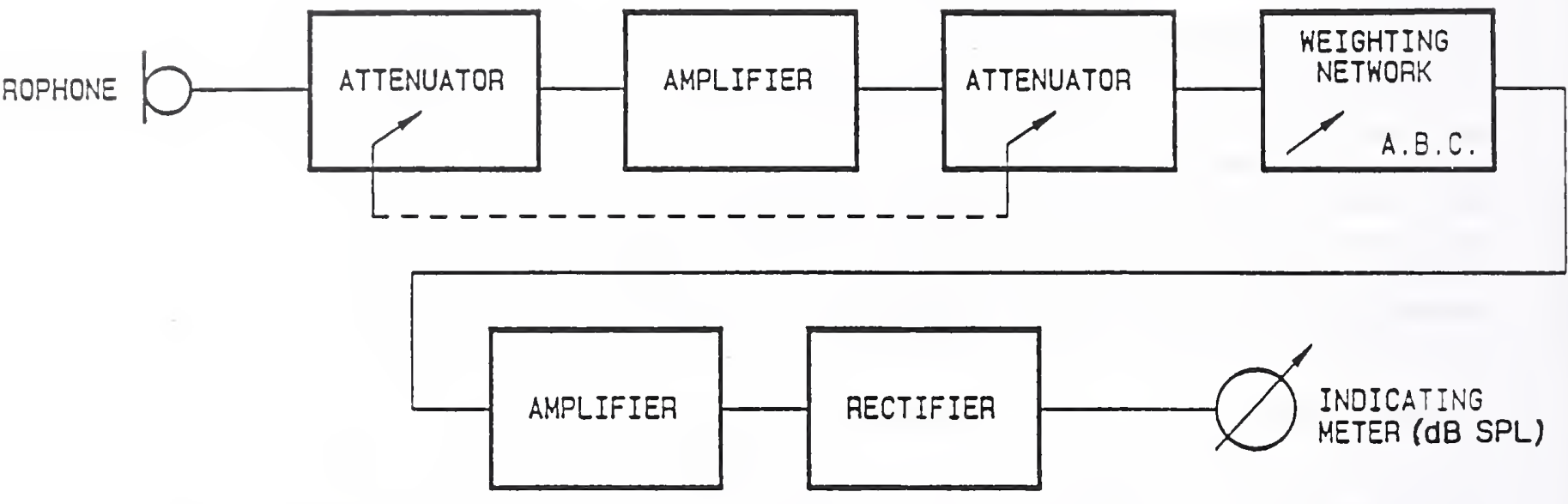

Figure 13. Simplified block diagram of the sound-level meter

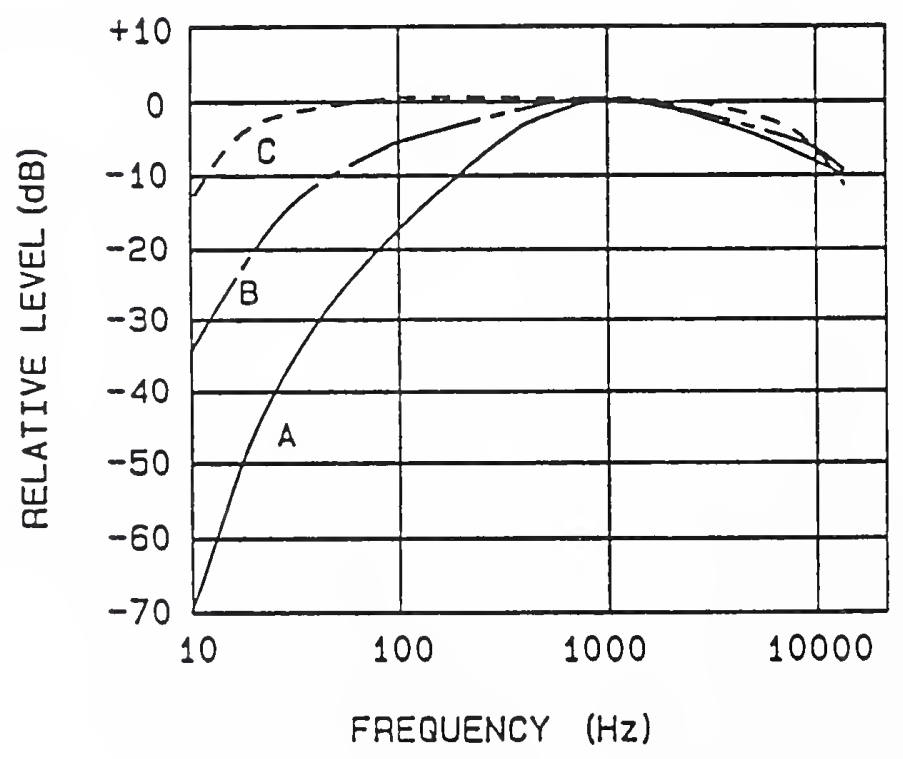

Figure 14. Amplitude-frequency characteristic curves of the sound-level meter for different weighting networks 


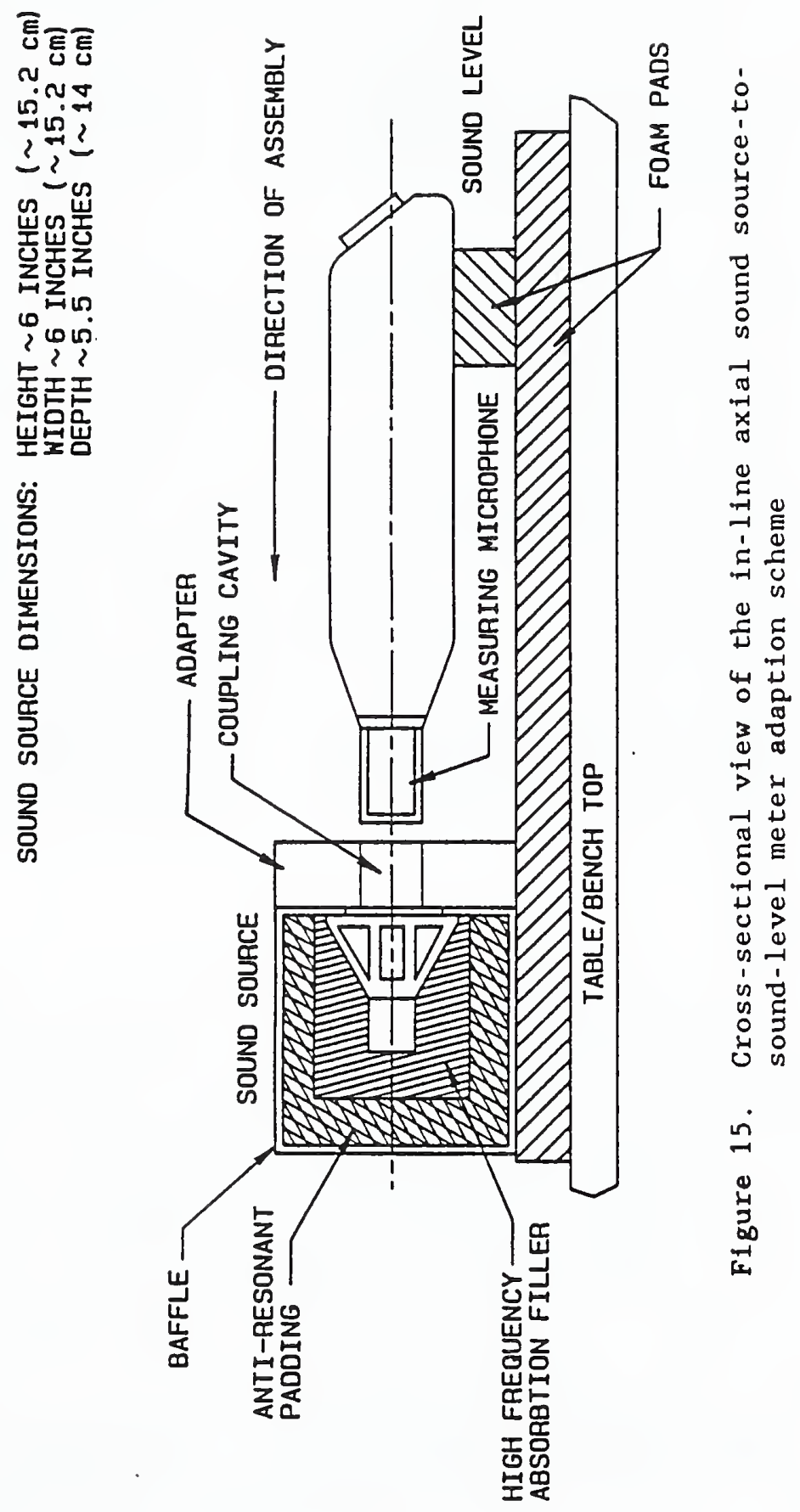


(Aluminum, Nickel, Cobalt) with an air gap flux density of -10000 gauss ( 1 tesla), and its voice coil impedance was $-8 \Omega$. Its rated power handling capacity was approximately $5 \mathrm{~W}$. The loudspeaker was mounted inside an enclosed baffle whose inner walls were covered by adhesive foam padding. The thickness of this material was about $0.5 \mathrm{in}$. The remaining inner space was filled with sheets of soft foam. Wall padding and soft foam filler were used in order to prevent low frequency resonances and to nullify high frequency reflections. The sound-source adapters were made to match the outer dimensions of the sound-scurce baffle with the interface cavity located at the geometric center of the loudspeaker.

Figure 16 shows the test setup for calibrating the sound source. A drive signal from the audio generator was fed to the input voice-coil terminals of the source. The test frequency of $1000 \mathrm{~Hz}$ was adjusted and maintained to be within \pm 1 percent. The sound-level meter weighting network selector was set to "C" and its integration speed was set to "slow". The audio drive signal level was varied until a sound level reading of $74 \mathrm{~dB}$ SPL was obtained on the $70 \pm 10 \mathrm{~dB}$ range setting of the sound-level meter. The drive level was then measured and recorded. From this point on, the drive level was held constant and the frequency was changed to $200 \mathrm{~Hz}, 400 \mathrm{~Hz}, 800 \mathrm{~Hz}, 1000 \mathrm{~Hz}$ (repeat), $1500 \mathrm{~Hz}, 2000 \mathrm{~Hz}$, and $3000 \mathrm{~Hz}$. Thus, the relative amplitude-frequency characteristic of the sound source was established at $74 \mathrm{~dB}$ SPL, as indicated by the dashed curve in figure 17 . The measurements were repeated for loudness levels of $80,83,86,89,92$, and $95 \mathrm{~dB}$ SPL. Figure 17 also shows the relative amplitude-frequency characteristic of the sound source at $95 \mathrm{~dB}$ SPL, indicating that there was no significant change in the response from that at $74 \mathrm{~dB}$ SPL. The flatness in the response over the $200 \mathrm{~Hz}$ to $3000 \mathrm{~Hz}$ range is approximately $\pm 2 \mathrm{~dB}$, which was adequate for the purposes of testing the transmitting transducers.

\section{Microphone Measurements}

Figure 18 shows how the microphones and other transmitting transducers in the HFCSs were tested in conjunction with the calibrated sound source. Typically, the sound source was located about $0.6 \mathrm{~cm}(-0.25 \mathrm{in}$.$) from the microphone to$ be tested, approximately at the axial point where the sound source was calibrated, as described above (see figure 15). The audio generator, frequency counter, and rms voltmeter were connected together in parallel and the junction point connected to the voice-coil input terminals of the sound source. With the source generating various sound pressure levels, measurements of the microphone amplitude-frequency characteristic were obtained (using acoustofoam adapters, similar to the approach used to calibrate the sound source). The output terminals of the microphone under test were terminated by an impedance matching resistor, $R_{t},(e . g ., 50 \Omega)$ and the generated output emf was measured across this resistor using the $R / D / N$ meter. The meter ranges used were $1 \mathrm{mV}(-60 \mathrm{~dB}), 3 \mathrm{mV}(-50 \mathrm{~dB})$, and $10 \mathrm{mV}$ ($40 \mathrm{~dB}$ ), depending on the nominal emf level generated by the make and type of microphore (or other type of transmitting transducer) under test.

It should be noted that the method used above for determining the relative amplitude-frequency characteristic works best for microphones and other transmitting transducers that are pressure sensitive. However, the method 


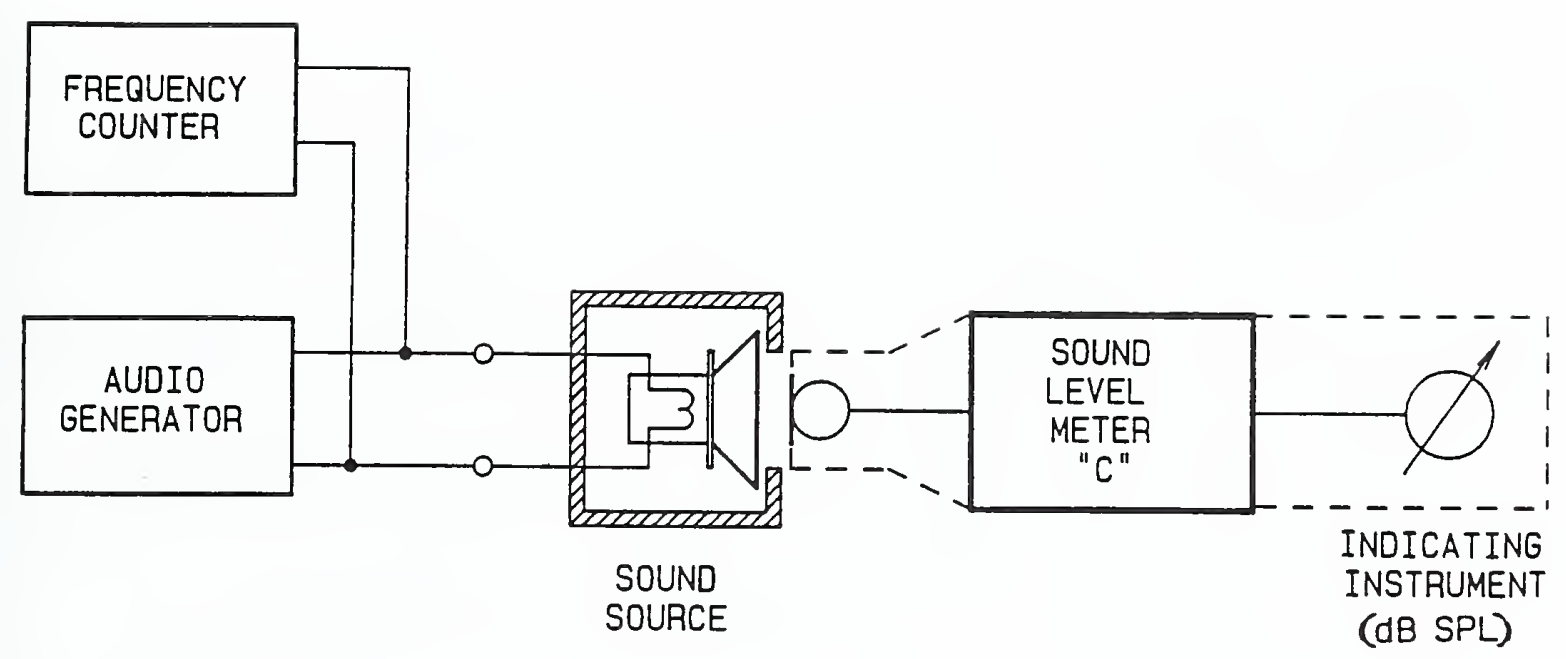

Figure 16. Test setup for calibrating the sound source dB SPL

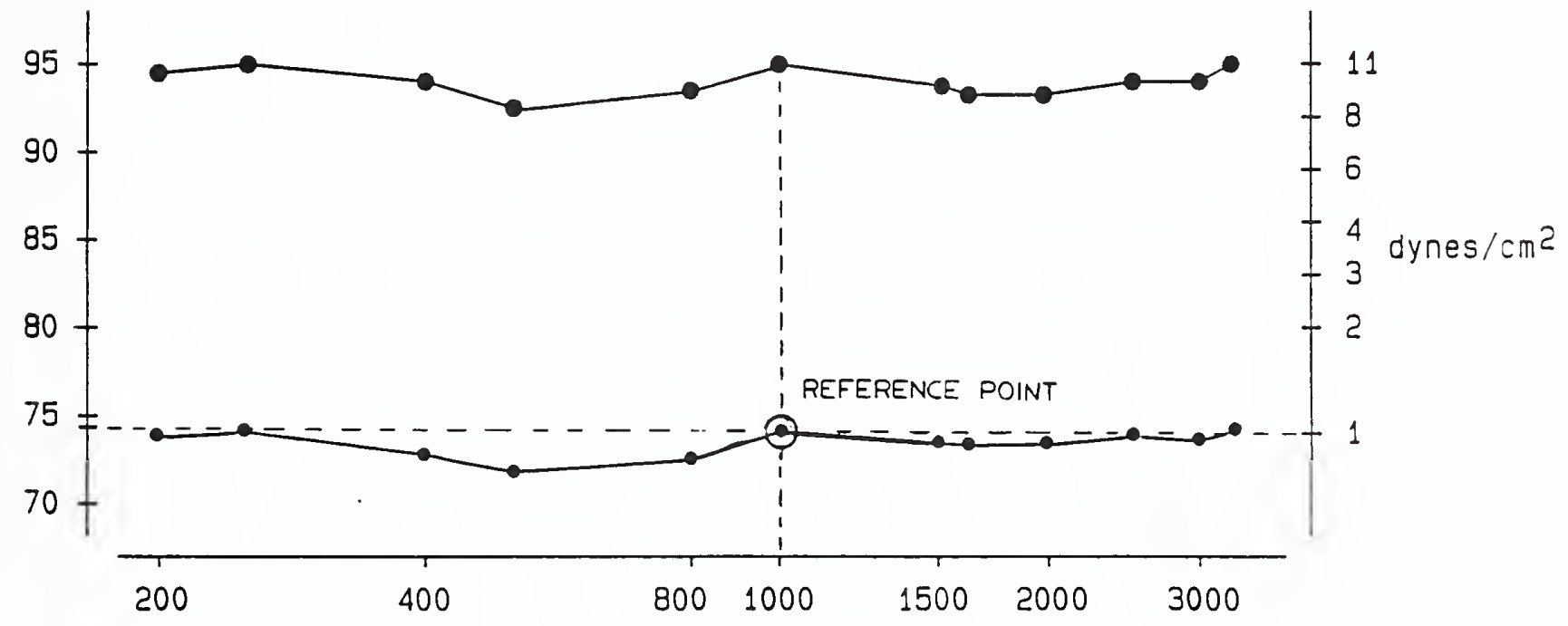

FREQ $(H z)$

Figure 17. Lower plot: Amplitude-frequency characteristic of the sound source relative to $74 \mathrm{~dB}$ SPL (c) $1000 \mathrm{~Hz}$ (drive signal held constant at $0.04 \mathrm{~V}$ )

Upper plot: Amplitude-frequency characteristic of the sound source relative to $95 \mathrm{~dB}$ SPL ( $1000 \mathrm{~Hz}$ (drive signal held constant at $0.204 \mathrm{~V}$ ) 


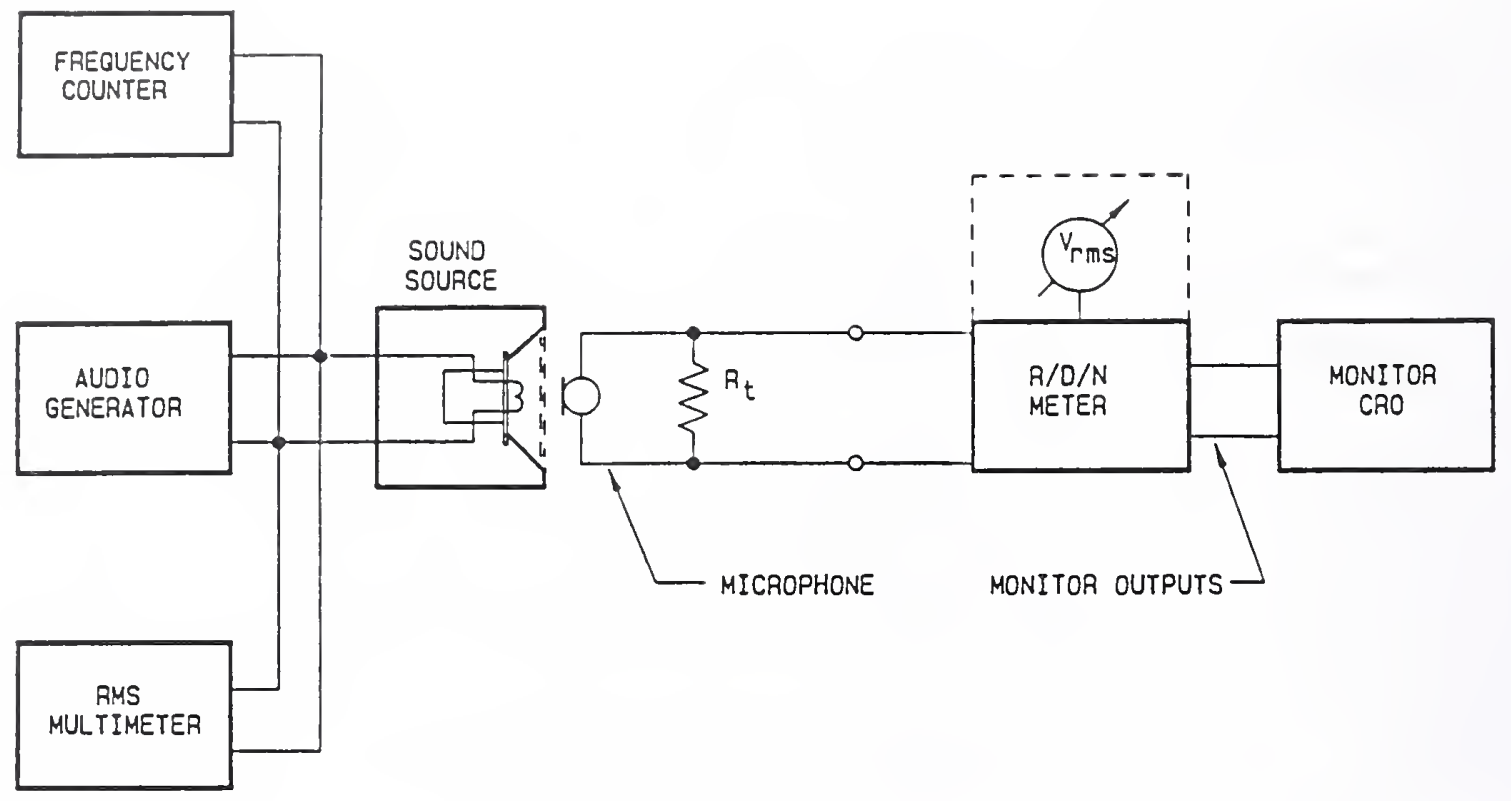

Figure 18. Test setup for testing microphones with the calibrated sound source

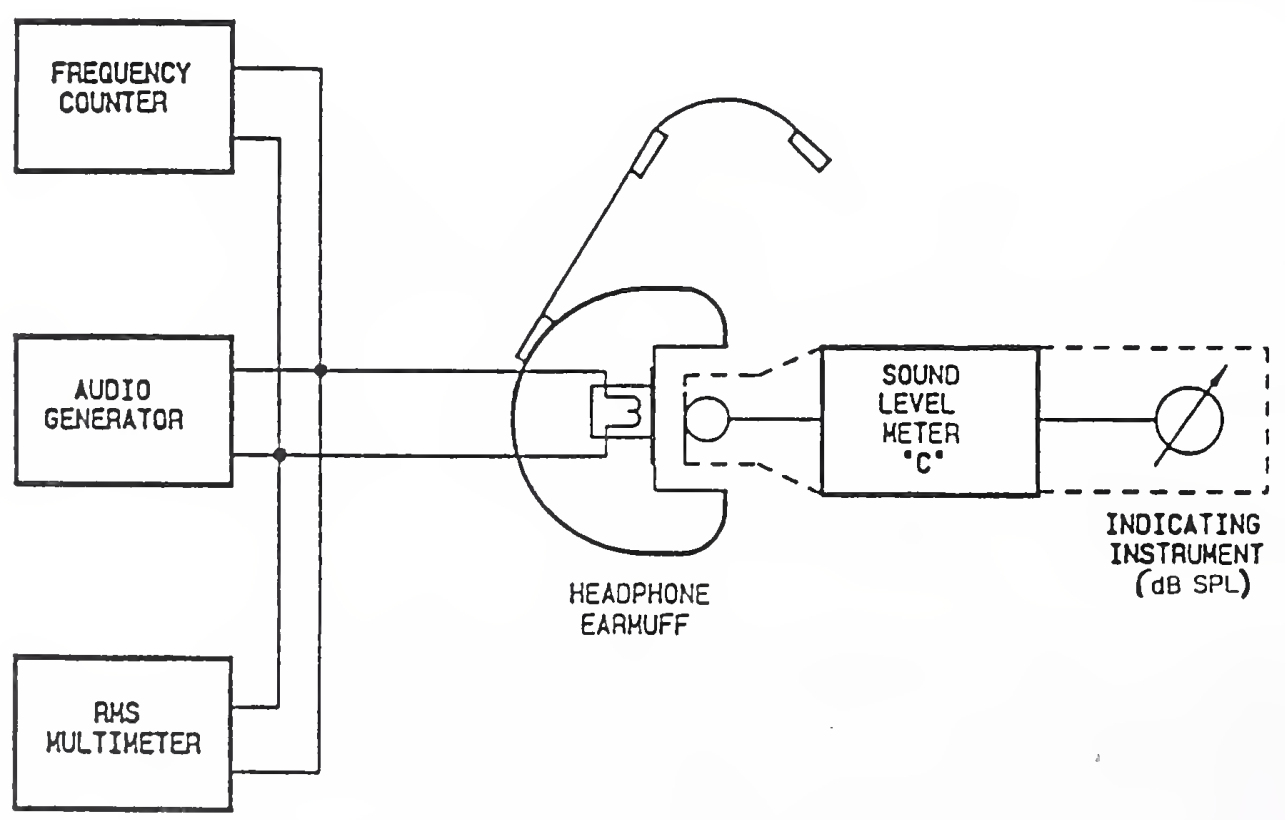

Figure 19. Block diagram showing the test setup for headphones and other receiving-type transducers 
will not give meaningful results for "noise-cancelling" types of microphones, i.e., those with more than one port. An artificial voice, which gives the proper level gradient, must be used for accurately characterizing such microphones. Similiarly, throat-and bone conduction-type microphones need special calibration techniques since the impedance of air is very different from that of the skin. However, for evaluating the relative differences of these transmitting transducers, the simple method of using a calibrated sound source works satisfactorily (with the device under test located axially, as shown in figure 18).

For testing the microphones in conjunction with the amplifier in their associated $I / C U$, terminating resistor $R_{t}$ in figure 18 was removed and replaced by the I/CU, i.e., the microphone output connected directly to the input of the $I / C U$ and the $I / C U$ output measured by the $R / D / N$ meter. Thus, the $R / D / N$ meter supplied readings determined by the emf generated by the microphone, as magnified by the gain of the amplifier in the I/CU. For instance, if the microphone generated emf was $1 \mathrm{mV}$ from an incident sound pressure of 1 dyne $/ \mathrm{cm}^{2}$ and the gain of the amplifier was $40 \mathrm{~dB}$ (a factor of 100), the $\mathrm{R} / \mathrm{D} / \mathrm{N}$ meter read $0.1 \mathrm{~V}$. Testing with the $\mathrm{I} / \mathrm{CU}$ also permited checking other operations such as PTT or VOX. In the PTT mode of operation, the PTT switch activates the amplifier and provides a control voltage that affects the transmit and receive modes of the transceiver. An output signal from the amplifier can be measured as long as the PTT switch is held down. In the voice (or tone) operated mode, the incident $1000 \mathrm{~Hz}$ test frequency (tone) activates the control circuitry of the I/CU, and maintains the "on" status of the amplifier.

\section{Headphone/Earphone Measurements}

A block diagram is given in figure 19 showing how the headphones, earphones, and other receiving transducers in the HFCSs were tested. As shown in figure 18 for driving the sound source, the audio generator, frequency counter, and rms voltmeter were connected together in parallel and the junction point connected to the voice coil input terminals of the head/earphone under test. Again, a drive signal with a reference frequency of $1000 \mathrm{~Hz} \pm 1$ o was used for this test. The signal level was varied until the sound-level meter read $74 \mathrm{~dB}$ SPL. The corresponding drive signal level was then recorded and held constant as the frequency was varied over a range from $200 \mathrm{~Hz}$ through $4000 \mathrm{~Hz}$, using a total of 25 discrete frequency points per sound level range. The sound levels (loudness levels) used for head/earphone testing were $74,80,83,86,89,92$, and $95 \mathrm{~dB} \mathrm{SPL}$, or $1,2,3,4,6,8$, and 11 dynes $/ \mathrm{cm}^{2}$, respectively.

Acoustical adapters were attached to the various types of cavities of these receiving types of transducers in order to provide for snug interfacing to the sound-level meter. Figure 20 shows a side view of the in-line axial headphone-to-sound-level meter adaption scheme that was used for the testing. On the left is located the headphone to be measured. An adapter is shown between the headphone and the sound-level meter. The direction of assembly is indicated. The adapter fits the headphone ear space, and its coupling cavity is located at the geometrical center of the headphone sound-generating element. The sound-level meter then plugs into the adapter cavity, aligning the microphone of the meter axially with the (near-field) test region of the 


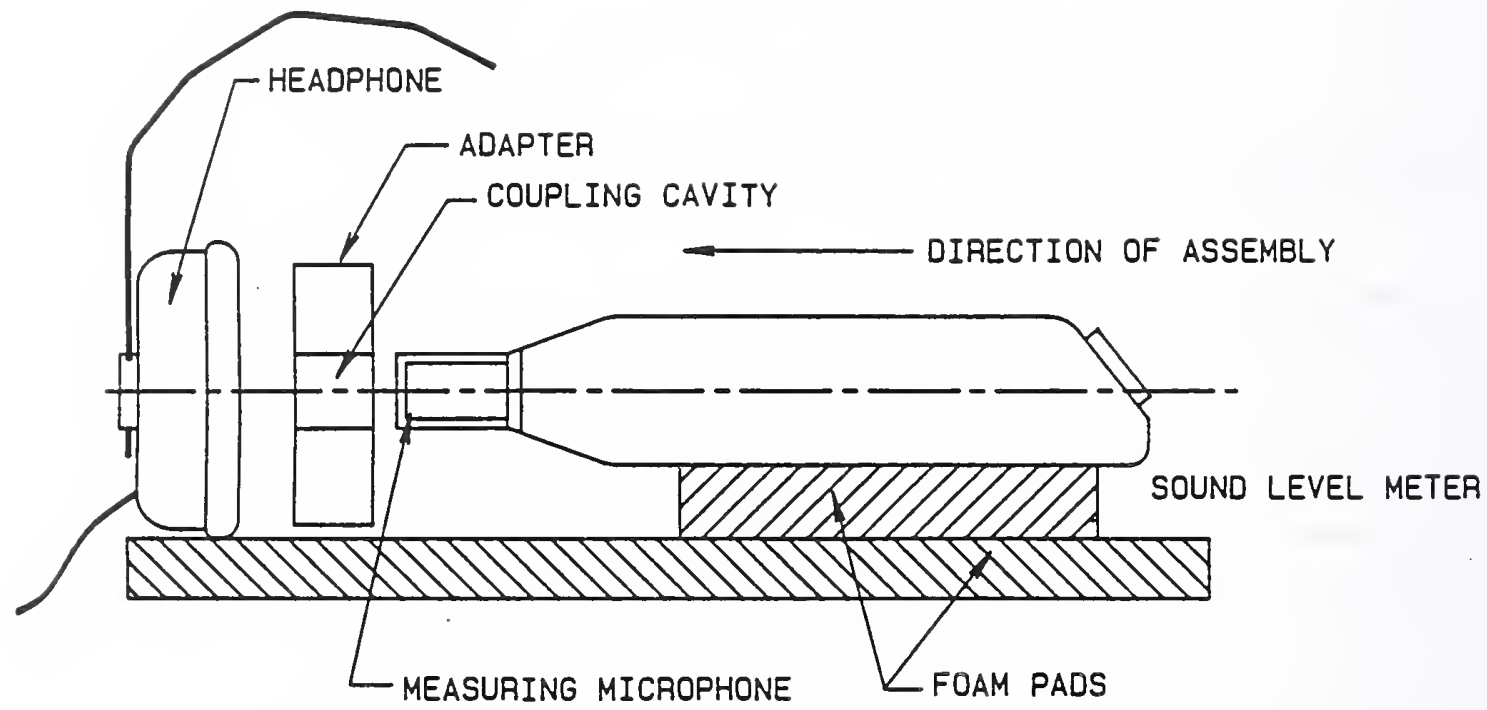

Figure 20. Cross-sectional view of the in-line axial headphone-to-soundlevel meter adaption scheme
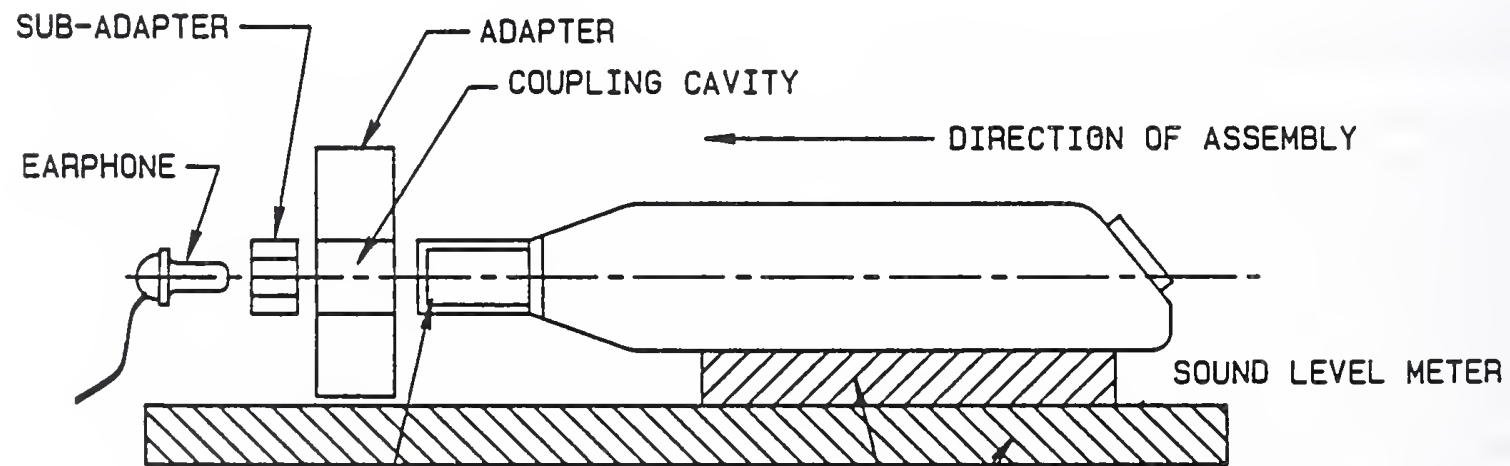

MEASURING MICROPHONE $\angle$ FOAM PADS

Figure 21. Cross-sectional view of the in-line axial earphone-to-soundlevel meter adaption scheme 
sound-generating element being tested. The entire assembly rests on foam padding (with extra padding for the sound-level meter to provide alignment with the adapter and headphone). A similar adapter technique was used to measure the response of earphones. Figure 21 shows the same in-line axial earphone-to-sound-level meter adaption scheme. A sub-adapter, which holds the earphone, plugs into the coupling cavity of the main adapter and aligns the earphone with the measuring microphone.

Again, the method described above for testing the relative amplitude-frequency characteristic of various receiving types of transducers works satisfactorily. However, it is not a rigorous calibration procedure for these devices. For the purpose of accurately performing such calibrations, methods have been developed that use standard $2-\mathrm{cm}^{3}$ and $6-\mathrm{cm}^{3}$ couplers [6].

\section{Summary}

The Hands-Free Communication Systems (HFCSs) from four companies were submitted to NIST for testing their operational characteristics. All four (similar, but not identical) HFSCs functioned well when interfaced with personal transceivers (walkie-talkie radio sets). The individual interface/control units, as well as the various transducers, such as microphones, earpickups, headphones, and earphones were found to be well suited to the HFCS application for which they were designed.

The various design approaches of the HFCS interface/control units were found to be rather diversified, e.g., circuit components varied between discrete and integrated ones. Also, the overall gain and amplitude-frequency characteristic of the four systems were different due to the electrical properties of the particular amplifiers utilized and the associated transducers. Amplifier output signal contouring was achieved by simple variable $\mathrm{R}-\mathrm{C}$ combinations, as well as by means of sophisticated equalizer networks. The use of such circuits optimizes the transmitted and received audio signals for the best possible fit to the de-emphasis/pre-emphasis slopes of the radio transceiver.

The results of tests to measure the voltage gain/frequency response, total harmonic distortion, signal-to-noise ratio, sensitivity, and other parameters of the four HFCSs submitted for evaluation are summarized in this report. 


\section{References}

1. National Institute of Justice, NIJ Standard 0210.00, Mobile FM Transceivers.

2. Daniel, Martin W.; Sound Reproduction and Recording Systems, Section 19. pp. 19-3 through 19-7; Electronic Engineers' Handbook, 1975.

3. IEEE Standard Dictionary of Electrical and Electronics Terms; ANSI/IEEE Std. 100-1984, Third Edition, pp. 853-855.

4. Neckenburger, E.; Electrical Sound Transmission - Section B, PP. 44 45 (in German).

5. Petzoldt, H.; Electroacoustics, Vol. 4, pp. 12-17, 1957 (in German).

6. American National Standard Method for Coupler Calibration of Earphones; ANSI S3.6-1969 (Revised 1986), Standards Secretariat, Acoustical Society of America, 335 East 45th Street, New York, NY $10017-3483$. 
$\underline{\mathrm{dBm}}$

The microphone output level is often referenced to a power level of 1 milliwatt $(\mathrm{mW})$. For a fixed load resistance of $600 \Omega$, this corresponds to a voltage of $0.775 \mathrm{~V}$ (rms). In other words, $\mathrm{V}_{\mathrm{ref}}=\left(10^{-3} \mathrm{~W} \times 600 \Omega\right)^{3 / 2}=0.775 \mathrm{~V}$ or $0 \mathrm{dBm}$ ( $\mathrm{dB}$ referenced to $1 \mathrm{~mW}$ ). Other voltage levels for the same $600 \Omega$ load resisitance may then be expressed in $\mathrm{dB}$ referenced to $0 \mathrm{dBm}$ and calculated from the relationship,

$$
\mathrm{dBm}=20 \log _{10}\left(\mathrm{~V}_{\text {volt }} / \mathrm{V}_{\text {ref }}\right)=20 \log _{10}\left(\mathrm{~V}_{\text {volts }} / 0.775\right)
$$

Thus, for example, a microphone output emf of $2.5 \mathrm{mV}$ has a corresponding level of $-49.8 \mathrm{dBm}$, or $49.8 \mathrm{~dB}$ below $0 \mathrm{dBm}$.

\section{$\underline{\mathrm{dBV}}$}

Emf levels may also be referenced to the $1 \mathrm{~V}$ level, i.e.,

$$
\mathrm{dBV}=20 \log _{10}\left(\mathrm{~V}_{\text {volts }} / 1.0\right) \text {. }
$$

For the example of $2.5 \mathrm{mV}$, the corresponding value with a $1 \mathrm{~V}$ reference is then $-52 \mathrm{dBV}$.

\section{$\underline{\mathrm{dB} \text { SPL }}$}

In order to establish a uniform measure of transducer sensitivity, a sound pressure level (SPL) of 1 dyne $/ \mathrm{cm}^{2}$ is used as standard excitation pressure. 3 By definition, $\mathrm{dB}$ SPL = level referenced to a sound pressure of $2 \times 10^{-4}$ dyne $/ \mathrm{cm}^{2}$, which is approximately the lowest level the human ear can perceive [4]. Thus, higher sound pressure levels can be determined from the logarithmic relationship,

$$
d B S P L=20 \log _{10}\left(P / P_{\text {ref }}\right)=20 \log _{10}\left(P /\left(2 \times 10^{-4}\right)\right),
$$

where $P$ is the sound level pressure in dynes $/ \mathrm{cm}^{2}$. Alternatively, for using the SI units,

$$
\left.d B S P L=20 \log _{10}\left(P / 20 \times 10^{-6}\right)\right)
$$

where $P$ is the sound level pressure in pascal.

3 The correct SI unit for pressure is the pascal ( $\mathrm{Pa}$ ). Since the industry still uses dynes $/ \mathrm{cm}^{2}$, these units have been given throughout this report. To convert to $\mathrm{Pa}$ units, 1 dyne $/ \mathrm{cm}^{2}=0.1 \mathrm{~Pa}$, and $1 \mathrm{~Pa}=94 \mathrm{~dB} \mathrm{SPL}$. 


\section{Reference and Conversion Charts}

In figures 22 through 24, some acoustic parameter conversion data and acoustic level data have been provided for quick reference.

Figure 22 graphically provides a convenient conversion for the relationship between loudness level ( $d B$ SPL) and sound pressure (dynes $/ \mathrm{cm}^{2}$ ).

In figure 23 (from [5]) one can find that a male speaker, $100 \mathrm{~cm}$ ( 40 in) from a transducer (microphone) generates a loudness level of $74 \mathrm{~dB}$ SPL or the sound pressure equivalent of 1 dyne $/ \mathrm{cm}^{2}$. When closer to the microphone, i.e., $10 \mathrm{~cm}$ $(\sim \mathrm{in})$, the same male voice, when raised, generates a loudness level of $\sim 103$ $\mathrm{dB}$ SPL (an equivalent sound pressure of -30 dynes $/ \mathrm{cm}^{2}$ ).

Figure 24 shows a chart that is useful in the evaluation of microphones. The chart relates the following parameters: a) along the top scales, the electrical output in millivolts (or $\mathrm{dBm}$ ); b) along the bottom scales, the applied sound pressure (measured in dynes $/ \mathrm{cm}^{2}$, or loudness level measured in $\mathrm{dB}$ SPL); and $\mathrm{c}$ ) along the vertical scale, the sensitivity of the microphone (measured in $\mathrm{mV} /$ dynes $/ \mathrm{cm}^{2}$ ). A sensitivity given as $1 \mathrm{mV} /$ dynes $/ \mathrm{cm}^{2}$ means that the microphone yields $1 \mathrm{mV}$ when subjected to a sound pressure of $1 \mathrm{dyne} / \mathrm{cm}^{2}$. Using the chart to verify the rating, one first finds the value of $1 \mathrm{mV} /$ dynes $/ \mathrm{cm}^{2}$ on the (vertical) sensitivity scale. This line is traced to the right where it intersects with the first diagonal line (corresponding to the 1 dyne $/ \mathrm{cm}^{2}$ (74 dB SPL) applied pressure line). At this point, the vertical line extended to the upper scales gives the microphone emf in $\mathrm{dBm}$ and $\mathrm{mV}$, and reads $1 \mathrm{mV}$ (or $-57.7 \mathrm{dBm}$ ). Similarly, microphones with lower or higher sensitivities would provide correspondingly lower or higher output emfs. 


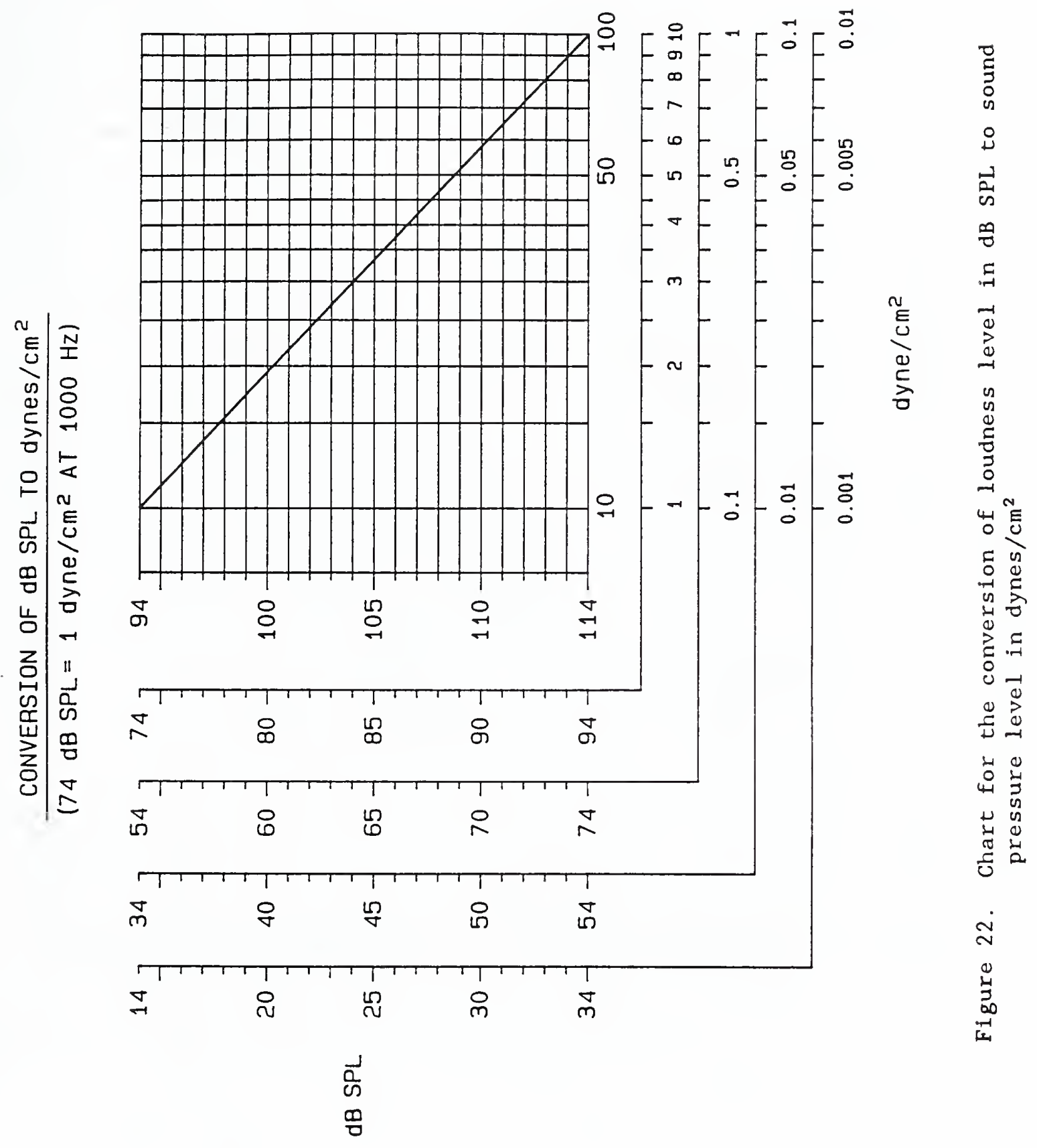




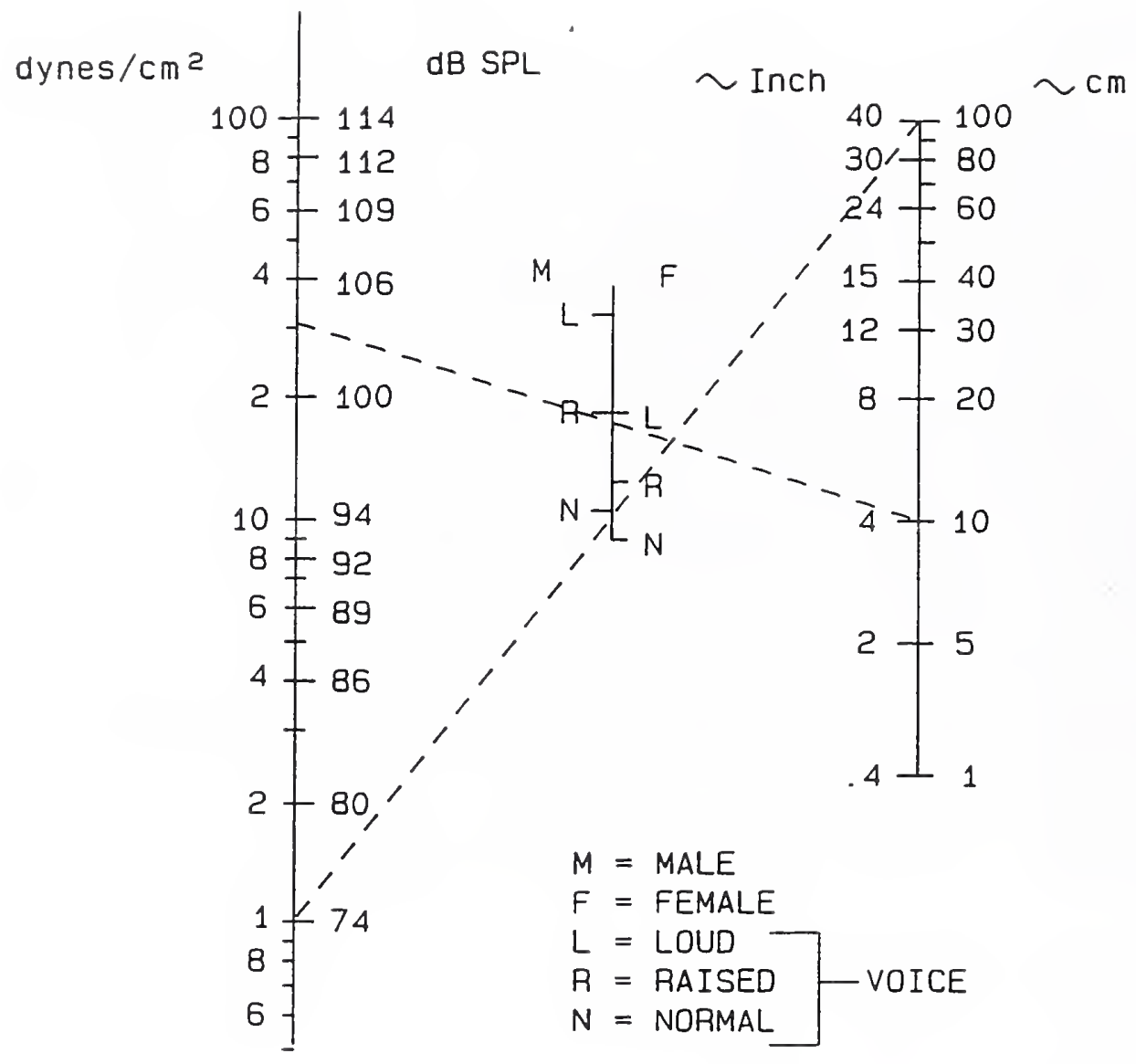

Figure 23. Sound pressure levels for normal, raised, and loud male and female voices, relative to transducer distance 


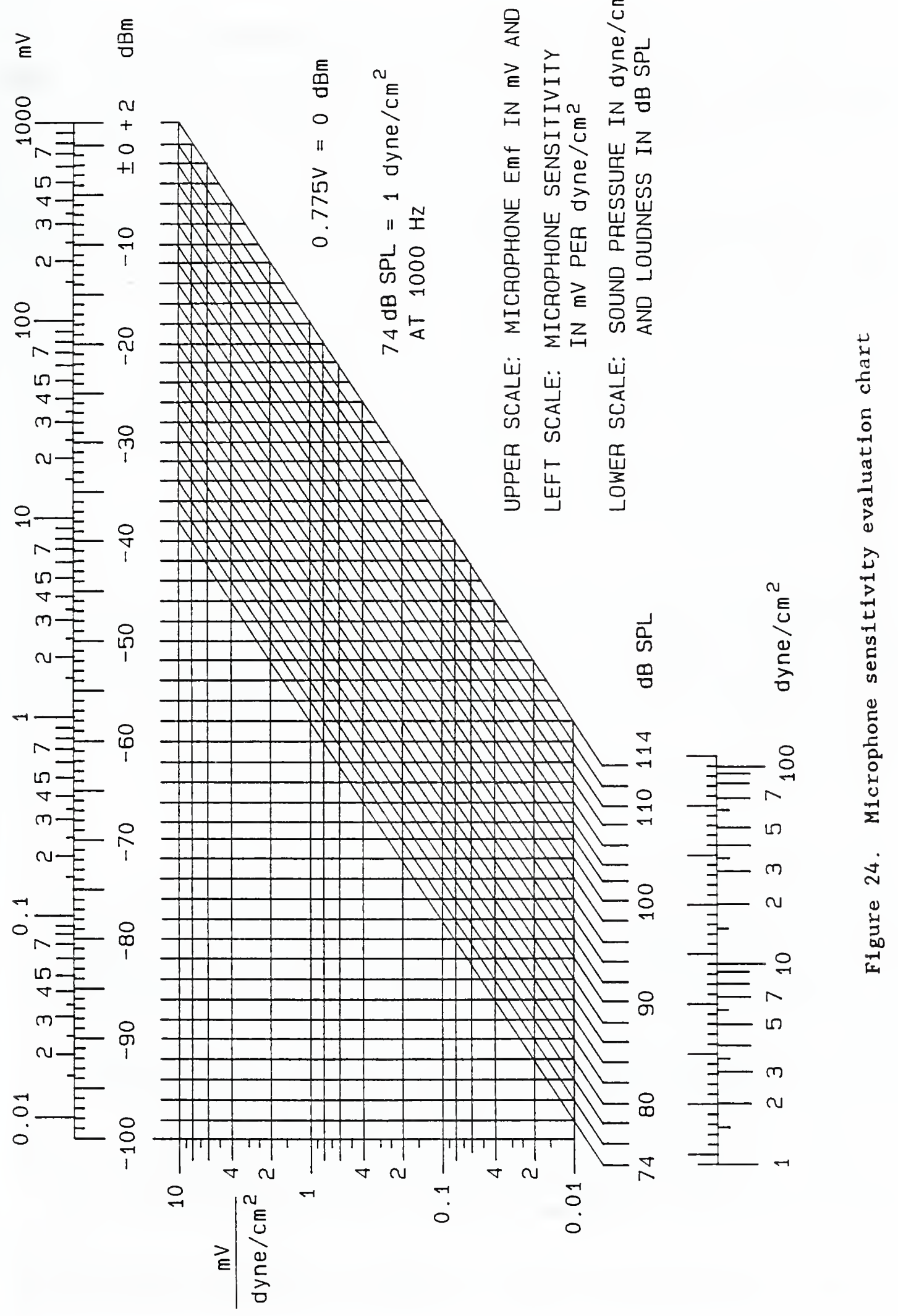


Appendix B - Equipment Used for the Evaluation Tests

The test equipment used at NIST for the evaluation of the four HFCSs consisted of the items described below: ${ }^{4}$

- Function Generator, Tektronix FG503

Although a good audio generator would suffice, this function generator provided a convenient source of audio test signals in its sine wave mode of operation. The following set of specifications were applicable for the tests described herein:

Frequency Range: $1.0 \mathrm{~Hz}$ to $3 \mathrm{MHz}$ ( 0.01 to $5 \mathrm{MHz}$ usable)

Frequency Stability: $\leq 0.5 \%$ of full scale for $24 \mathrm{hr}$ (const. temp.)

Output Amplitude: $\geq 20 \mathrm{~V}$ p-p open circuit; $\geq 10 \mathrm{~V}$ p-p into $50 \Omega$

Sine Wave Distortion: $\leq 0.5 \&(1 \mathrm{~Hz} \text { to } 30 \mathrm{kHz})^{5}$

Amplitude Flatness: $\pm 0.5 \mathrm{~dB}(20 \mathrm{~Hz}$ to $20 \mathrm{kHz})$

- Frequency Counter, Tektronix DC504

Since the exact values of the testing frequencies are not critical, this laboratory counter/timer served the purpose of displaying the frequency of the audio source in convenient digital form. It has the basic specification of:

Frequency Resolution: $0.1 \mathrm{~Hz}$ (10 $\mathrm{Hz}$ to $1 \mathrm{MHz}$, AC coupled)

- Distortion and Noise Meter, Amber 3501

This was one of the critical instruments used for the evaluation tests described in this report. For the evaluation tests described in this report, this instrument has three measurement modes: 1) rms voltage, 2) total harmonic distortion, and 3) noise (SNR). In the rms (level) mode,

In order to describe the systems and tests discussed in this report adequately, commercial equipment and instruments are identified by manufacturer's name and/or model number. In no case does such identification imply recommendation or endorsement by the National Institute of Standards and Technology, the National Institute of Justice or any other government agency, nor does it imply that the material or equipment identified is necessarily the best available for the purpose.

The necessary distortion of $\leq 0.15 \&(-56 \mathrm{dBV})$ was measured for this instrument. 
the meter employs a precision rms detector (that can accomodate signals with crest factors as high as 10 , assuring accurate indication of signals having distortion and noise). Three types of internal filters provide a high pass $(400 \mathrm{~Hz}, 3 \mathrm{~dB}$ point,) and two low pass ( $30 \mathrm{kHz}$ and $80 \mathrm{kHz}, 3 \mathrm{~dB}$ point) functions that have $18 \mathrm{~dB} /$ octave ( $60 \mathrm{~dB} /$ decade) slopes. The following specifications were pertinent for the evaluation tests:

Maximum/minimum input levels: $100 \mathrm{~V} \mathrm{rms} / 0.3 \mu \mathrm{V} \mathrm{rms}$

RMS level accuracy: $\pm 2 \&( - \pm 0.17 \mathrm{~dB}), 20 \mathrm{~Hz}$ to $20 \mathrm{kHz}$

$60 \mathrm{~Hz}$ power frequency rejection: $>40 \mathrm{~dB}$ (high pass filter)

Common Mode Rejection: $\geq 40 \mathrm{~dB}(50 / 60 \mathrm{~Hz})$

THD/SNR accuracy: $\pm 1 \mathrm{~dB}(\sim \pm 128), 20 \mathrm{~Hz}$ to $20 \mathrm{kHz}$

THD/SNR range: 0 to $-70 \mathrm{dBV}$

\section{- Oscilloscope, Tektronix 465}

This instrument was used in conjunction with the Amber $3501 \mathrm{R} / \mathrm{D} / \mathrm{N}$ meter, by connecting it to the monitor outputs of the 3501. The purpose of this scope was simply to observe the signals that were being measured by the $\mathrm{R} / \mathrm{D} / \mathrm{N}$ meter. The basic specifications of this dual channel unit are:

Frequency range: dc to $100 \mathrm{MHz}$

Deflection accuracy: \pm 3 \%

Input resistance: $1 \mathrm{M} \Omega$ in parallel with $20 \mathrm{pF}$

- Sound-Level Meter, Bruel \& Kjaer, Type 2205 with weighting network setting "C"

This was one of the critical instruments used for calibrating the sound pressure readings of the sound source, as well as testing the sound pressures generated by the various headphones, earphones, and other receiving type transducers used in the four HFCSs. The dB scale on this unit was calibrated (in conjunction with its built-in microphone) by the Acoustic Measurements Group at NIST. The basic specifications are:

Dynamic Range: 20 to $130 \mathrm{~dB}$ SPL

Reading Accuracy: $\pm 2 \mathrm{~dB}$ ("C" weighting filter)

Further details of this equipment can be found in manufacturers' operating manuals and technical literature. 

Appendix C - Test Data on all Four HFCSs 
TABLE 1

Amplifier Data

\begin{tabular}{|c|c|c|c|c|}
\hline Unit & System 1 & System 2 & System 3 & System 4 \\
\hline $\begin{array}{c}\text { Input } \\
\text { Impedance } \\
\text { Z(in) }\end{array}$ & $\begin{array}{l}-15 \mathrm{k} \Omega \\
\text { at } 1000 \mathrm{~Hz}\end{array}$ & $\begin{array}{l}-13 \mathrm{k} \Omega \\
\text { at } 1000 \mathrm{~Hz}\end{array}$ & $\begin{array}{l}-12 \mathrm{k} \Omega \\
\text { at } 1000 \mathrm{~Hz}\end{array}$ & $\begin{array}{l}-12 \mathrm{k} \Omega \\
\text { at } 1000 \mathrm{~Hz}\end{array}$ \\
\hline $\begin{array}{c}\text { Output } \\
\text { Impedance } \\
\mathrm{Z} \text { (out) }\end{array}$ & $\begin{array}{l}-1.5 \mathrm{k} \Omega \\
\text { at } 1000 \mathrm{~Hz}\end{array}$ & $\begin{array}{l}-1.4 \mathrm{k} \Omega \\
\text { at } 1000 \mathrm{~Hz}\end{array}$ & $\begin{array}{l}-1 \mathrm{k} \Omega \\
\text { at } 1000 \mathrm{~Hz}\end{array}$ & $\begin{array}{l}-1 \mathrm{k} \Omega \\
\text { at } 1000 \mathrm{~Hz}\end{array}$ \\
\hline $\begin{array}{l}\text { Gain } \\
(\mathrm{dB})\end{array}$ & $\begin{array}{l}-46 \mathrm{~dB}(200) \\
\text { at } 1000 \mathrm{~Hz}\end{array}$ & $\begin{array}{l}-22 \mathrm{~dB}(13.6) \\
\text { at } 1000 \mathrm{~Hz}\end{array}$ & $\begin{array}{l}-36 \mathrm{~dB}(63) \\
\text { at } 1000 \mathrm{~Hz}\end{array}$ & $\begin{array}{l}-24 \mathrm{~dB}(16) \\
\text { at } 1000 \mathrm{~Hz}\end{array}$ \\
\hline $\begin{array}{l}\text { Distortion } \\
\text { THD } \\
\% \text { ref. } 1 \mathrm{~V}\end{array}$ & $\begin{array}{l}0.7 \% \\
\text { at } 1000 \mathrm{~Hz}\end{array}$ & $\begin{array}{l}0.358 \\
\text { at } 1000 \mathrm{~Hz}\end{array}$ & $\begin{array}{l}0.478 \\
\text { at } 1000 \mathrm{~Hz}\end{array}$ & $\begin{array}{l}0.198 \\
\text { at } 1000 \mathrm{~Hz}\end{array}$ \\
\hline $\begin{array}{c}\text { Distortion } \\
\text { THD } \\
\text { (dBV) }\end{array}$ & at $\begin{array}{l}-43 \\
1000 \mathrm{~Hz}\end{array}$ & $\begin{array}{l}-49 \\
\text { at } 1000 \mathrm{~Hz}\end{array}$ & $\begin{array}{l}-46 \\
\text { at } 1000 \mathrm{~Hz}\end{array}$ & $\begin{array}{l}-54 \\
\text { at } 1000 \mathrm{~Hz}\end{array}$ \\
\hline $\begin{array}{l}\text { Signal to } \\
\text { Noise Ratio } \\
\text { (dB) }\end{array}$ & +43.4 & +50 & +49 & +51.7 \\
\hline $\begin{array}{c}\text { Max Level } \\
\text { for } 38 \\
\text { THD } \\
(\mathrm{dBV})\end{array}$ & $\begin{array}{l}+4.2 \\
\text { at } 1000 \mathrm{~Hz}\end{array}$ & $\begin{array}{l}+3.2 \\
\text { at } 1000 \mathrm{~Hz}\end{array}$ & $\begin{array}{l}+2.8 \\
\text { at } 1000 \mathrm{~Hz}\end{array}$ & $\begin{array}{l}+7.7 \\
\text { at } 1000 \mathrm{~Hz}\end{array}$ \\
\hline $\begin{array}{l}\text { Frequency } \\
\text { Range } \\
\text { approx. } \\
\text { 3dB points }\end{array}$ & $150-4000 \mathrm{~Hz}$ & $600-4000 \mathrm{~Hz}$ & $400-6000 \mathrm{~Hz}$ & $300-2500 \mathrm{~Hz}$ \\
\hline
\end{tabular}




\begin{tabular}{|c|c|c|c|c|c|c|c|}
\hline 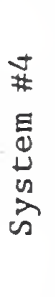 & $\begin{array}{l}0 \\
0 \\
0 \\
0 \\
\nu \\
\dot{0} \\
\dot{z}\end{array}$ & 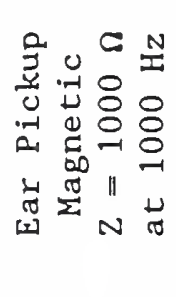 & $\begin{array}{l}0 \\
0 \\
0 \\
0 \\
\dot{0} \\
0 \\
z\end{array}$ & $\begin{array}{l}0 \\
0 \\
0 \\
0 \\
D \\
\ddot{0} \\
0 \\
z\end{array}$ & $\begin{array}{l}0 \\
0 \\
0 \\
0 \\
\nu \\
0 \\
z\end{array}$ & 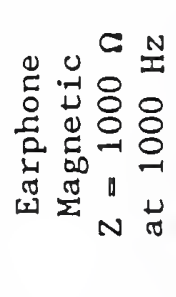 & 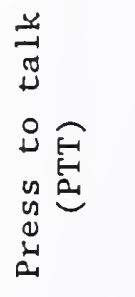 \\
\hline 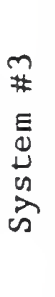 & $\begin{array}{l}0 \\
0 \\
U \\
0 \\
\ddot{D} \\
\ddot{0} \\
\dot{z}\end{array}$ & 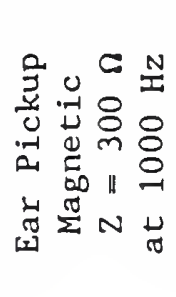 & $\begin{array}{l}0 \\
0 \\
0 \\
D \\
\ddot{D} \\
0 \\
z\end{array}$ & $\begin{array}{l}\overrightarrow{0} \\
0 \\
0 \\
D \\
\overrightarrow{0} \\
0 \\
0\end{array}$ & $\begin{array}{l}\overrightarrow{0} \\
0 \\
\text { D2 } \\
\vec{\nu} \\
\ddot{0} \\
\dot{z}\end{array}$ & 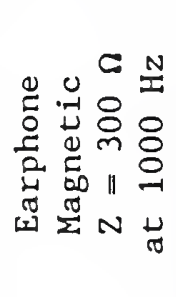 & 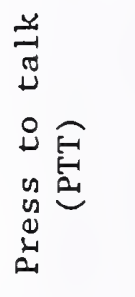 \\
\hline 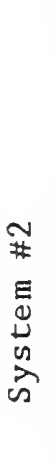 & 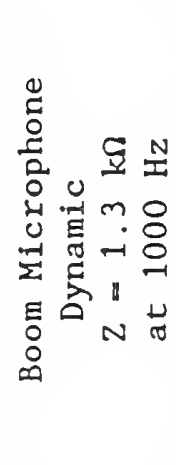 & $\begin{array}{l}\overrightarrow{0} \\
0 \\
\text { OD } \\
\vec{u} \\
\ddot{0} \\
\dot{z}\end{array}$ & 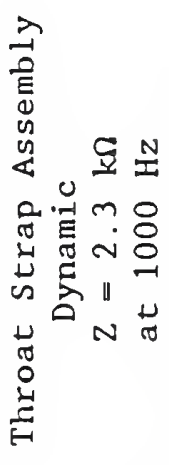 & $\begin{array}{l}0 \\
0 \\
0 \\
0 \\
\nu \\
0 \\
0\end{array}$ & 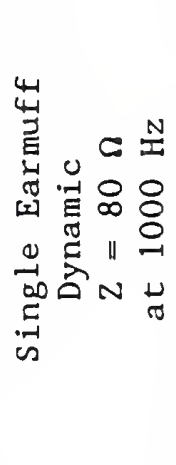 & 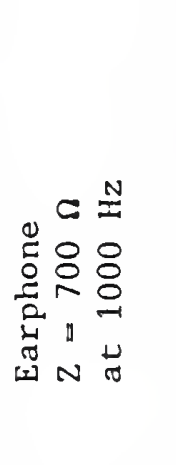 & 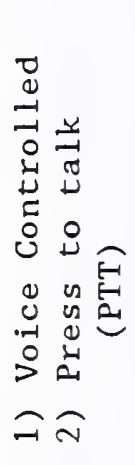 \\
\hline 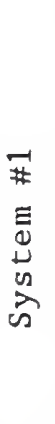 & 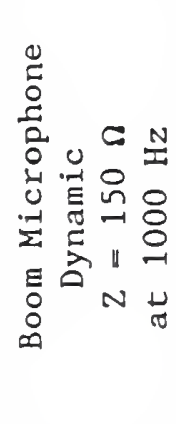 & $\begin{array}{l}\overrightarrow{0} \\
0 \\
0 \\
D \\
\ddot{0} \\
0 \\
z\end{array}$ & $\begin{array}{l}0 \\
0 \\
0 \\
0 \\
\nu \\
0 \\
0\end{array}$ & 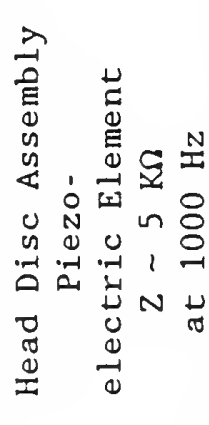 & 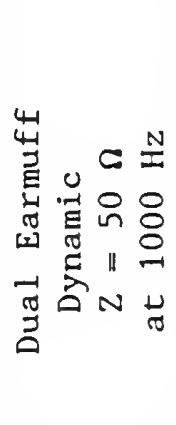 & $\begin{array}{l}0 \\
0 \\
0 \\
0 \\
\nu \\
\ddot{0} \\
\dot{z}\end{array}$ & 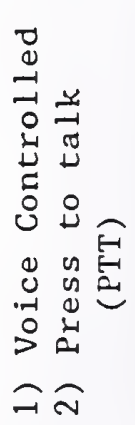 \\
\hline . & 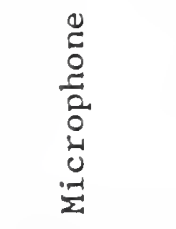 & 产 & 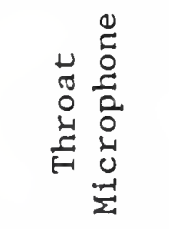 & 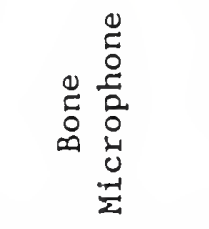 & 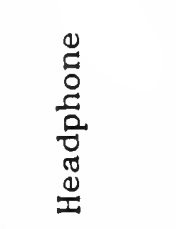 & 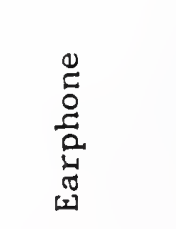 & 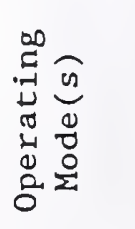 \\
\hline
\end{tabular}


System 1 Test Data 

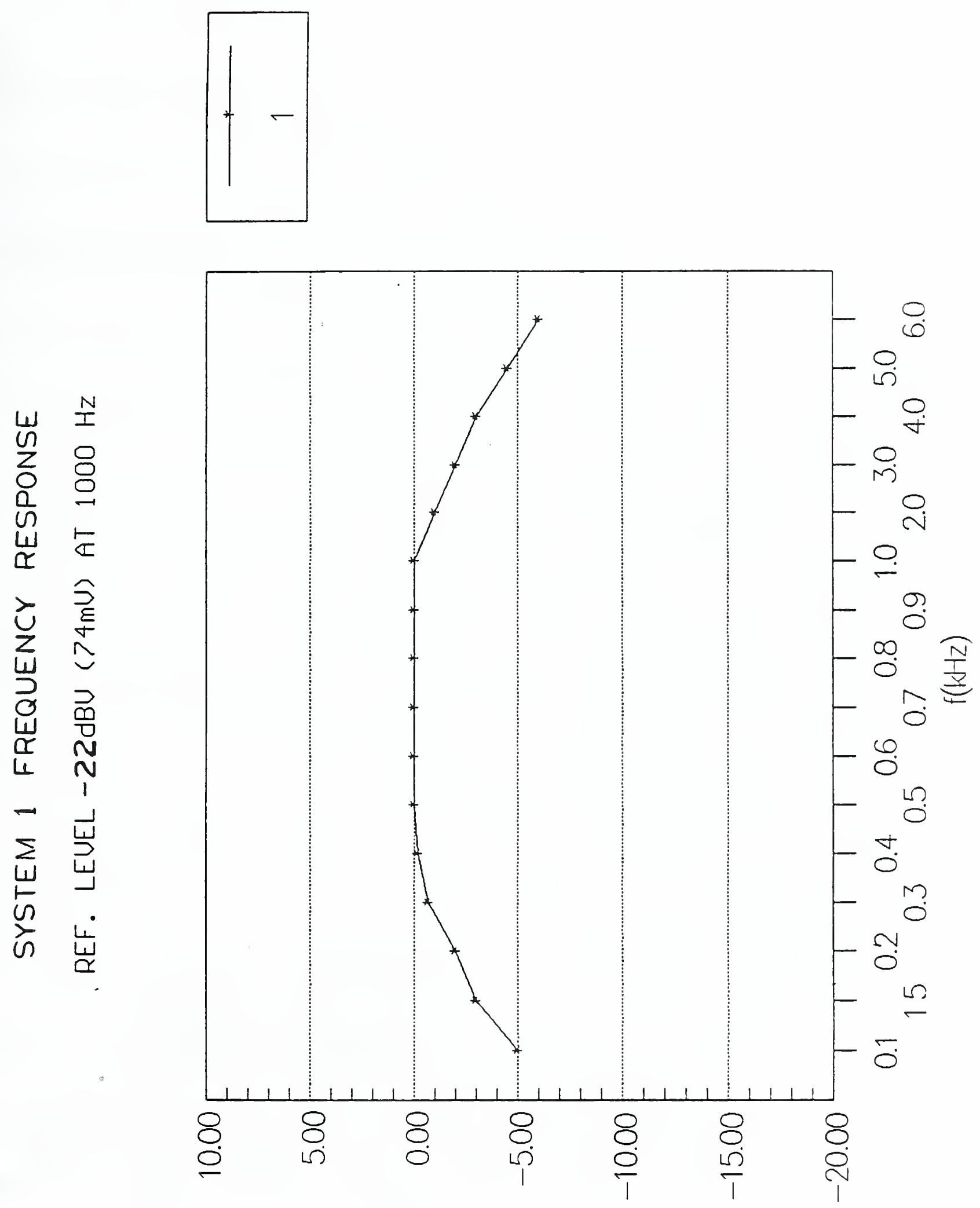

[ap] JSNDOSJY $\exists \wedge I \perp \forall 7 \exists y$ 


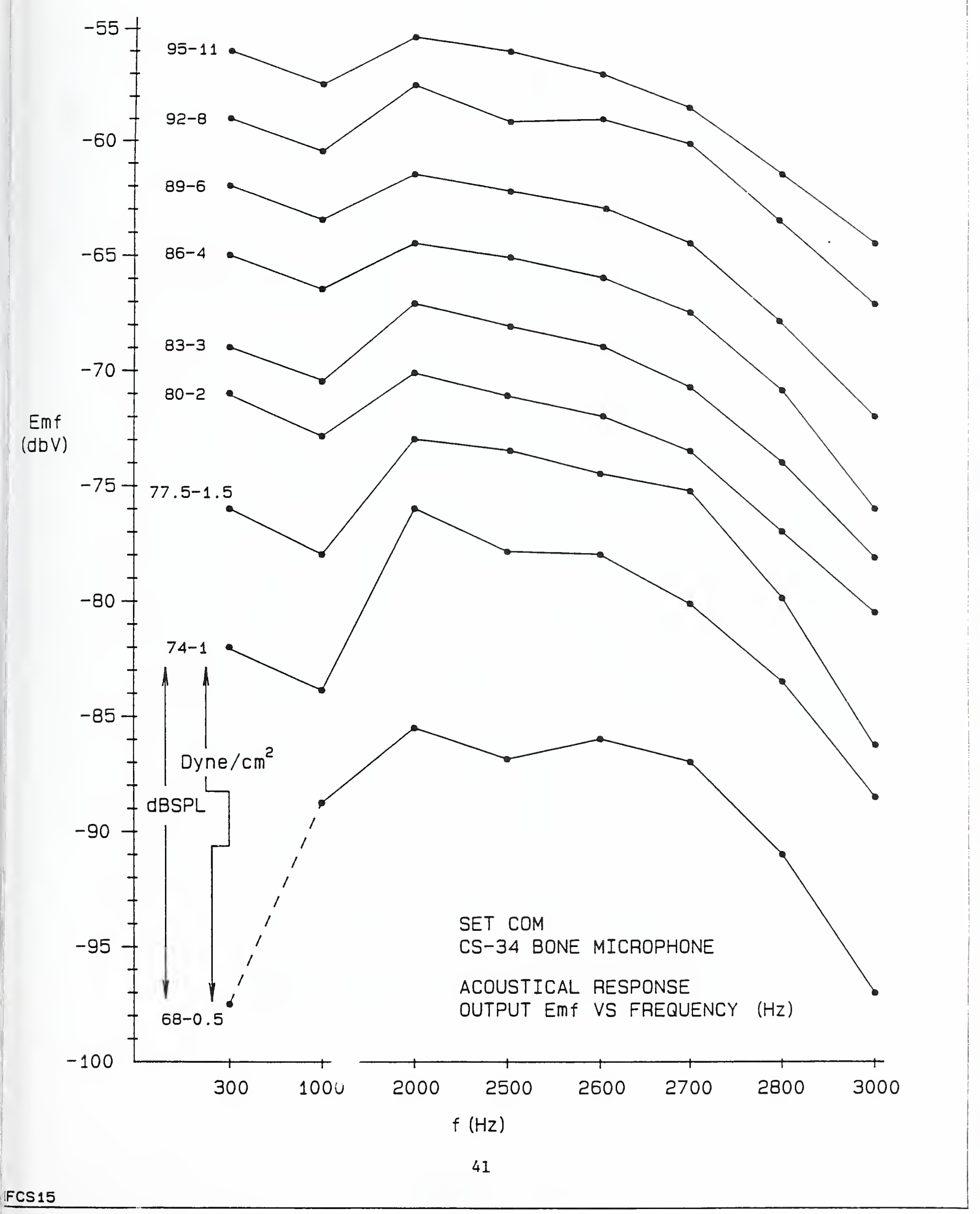


总

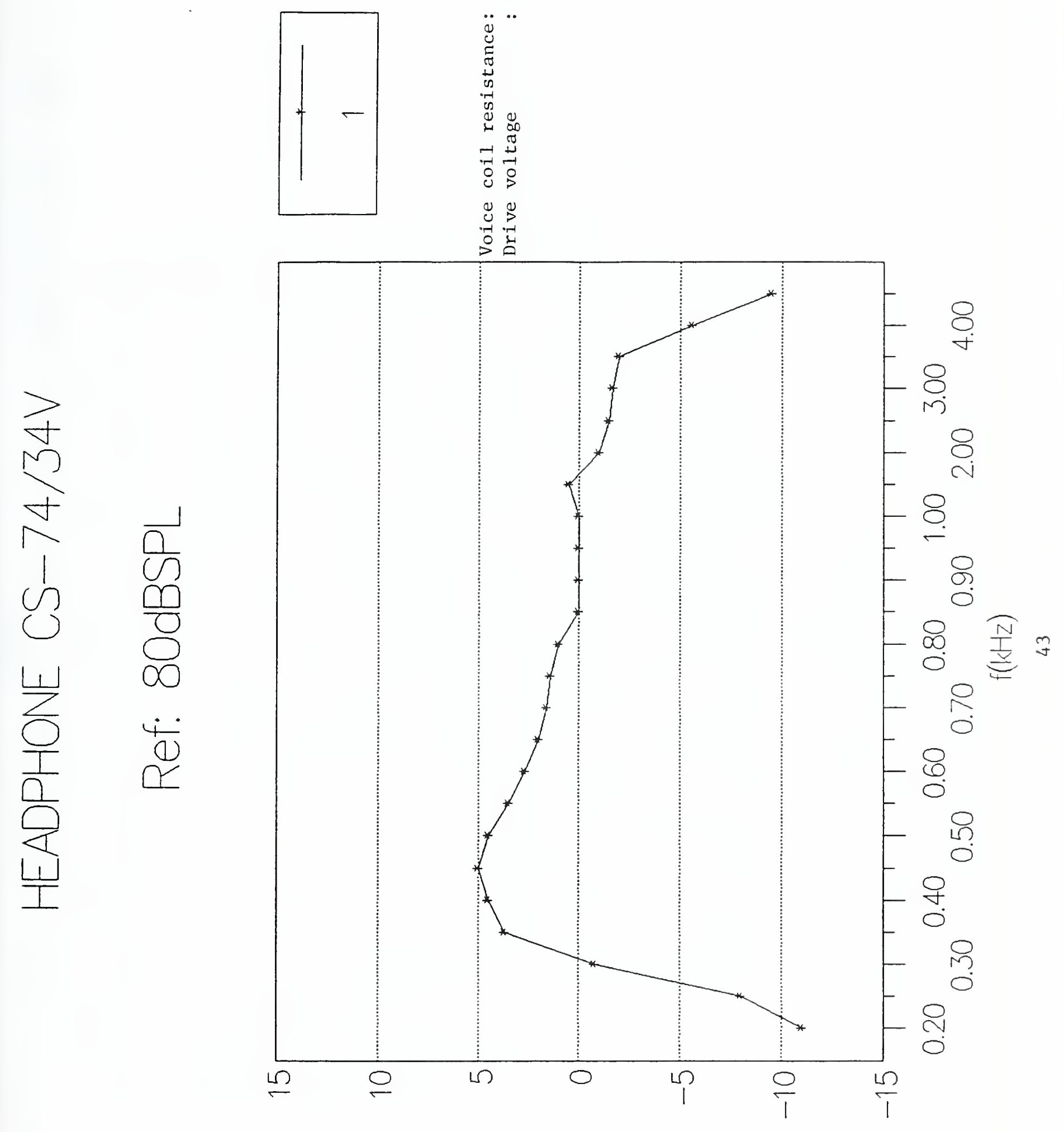




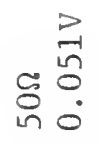

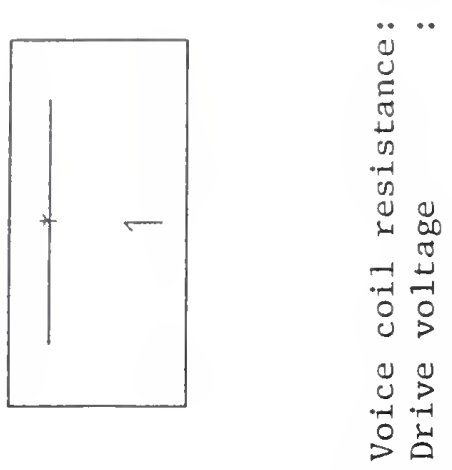

$\frac{7}{4}$

H

$\frac{i}{a}$

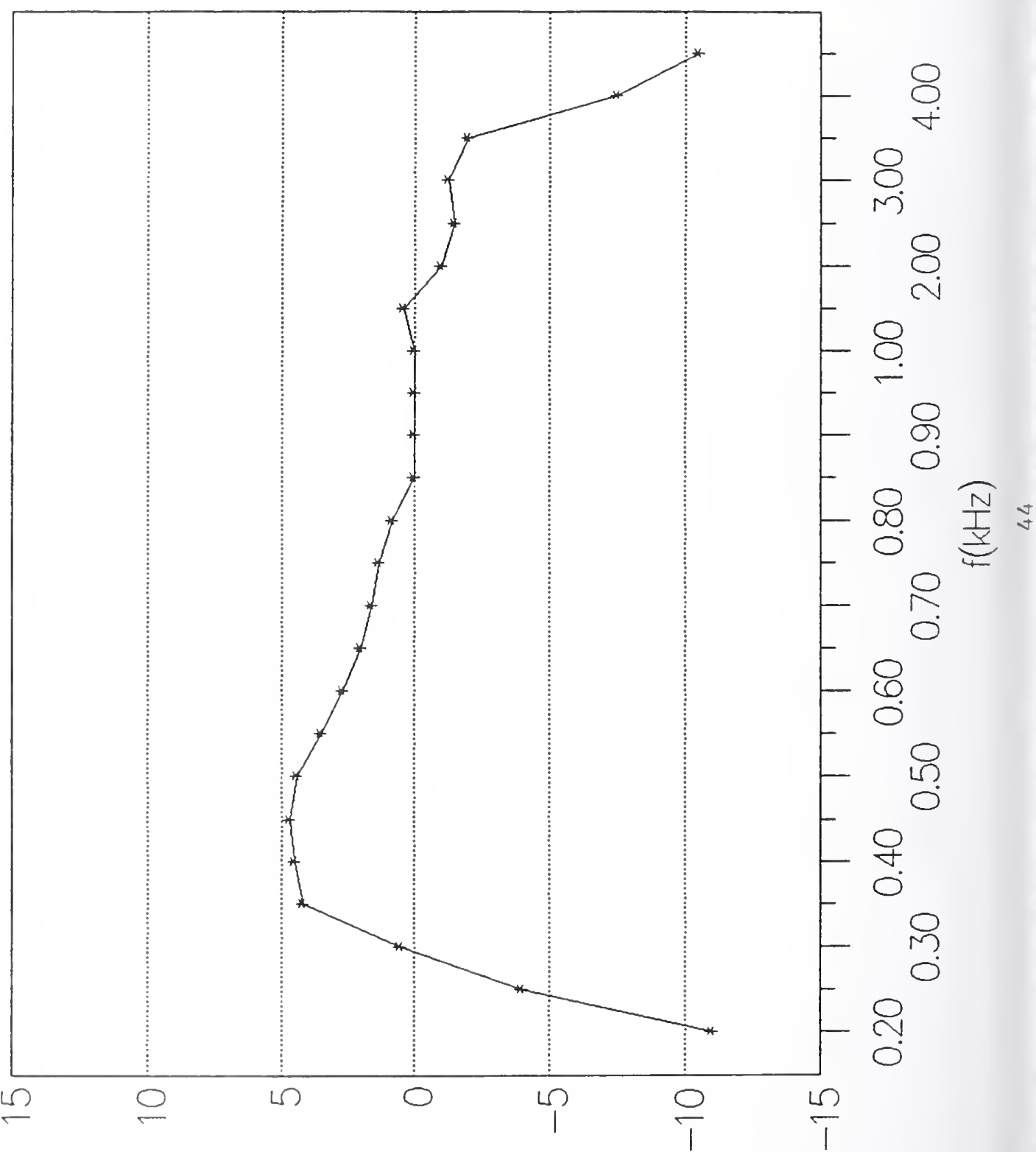

7dSgP 


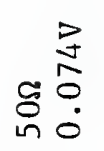
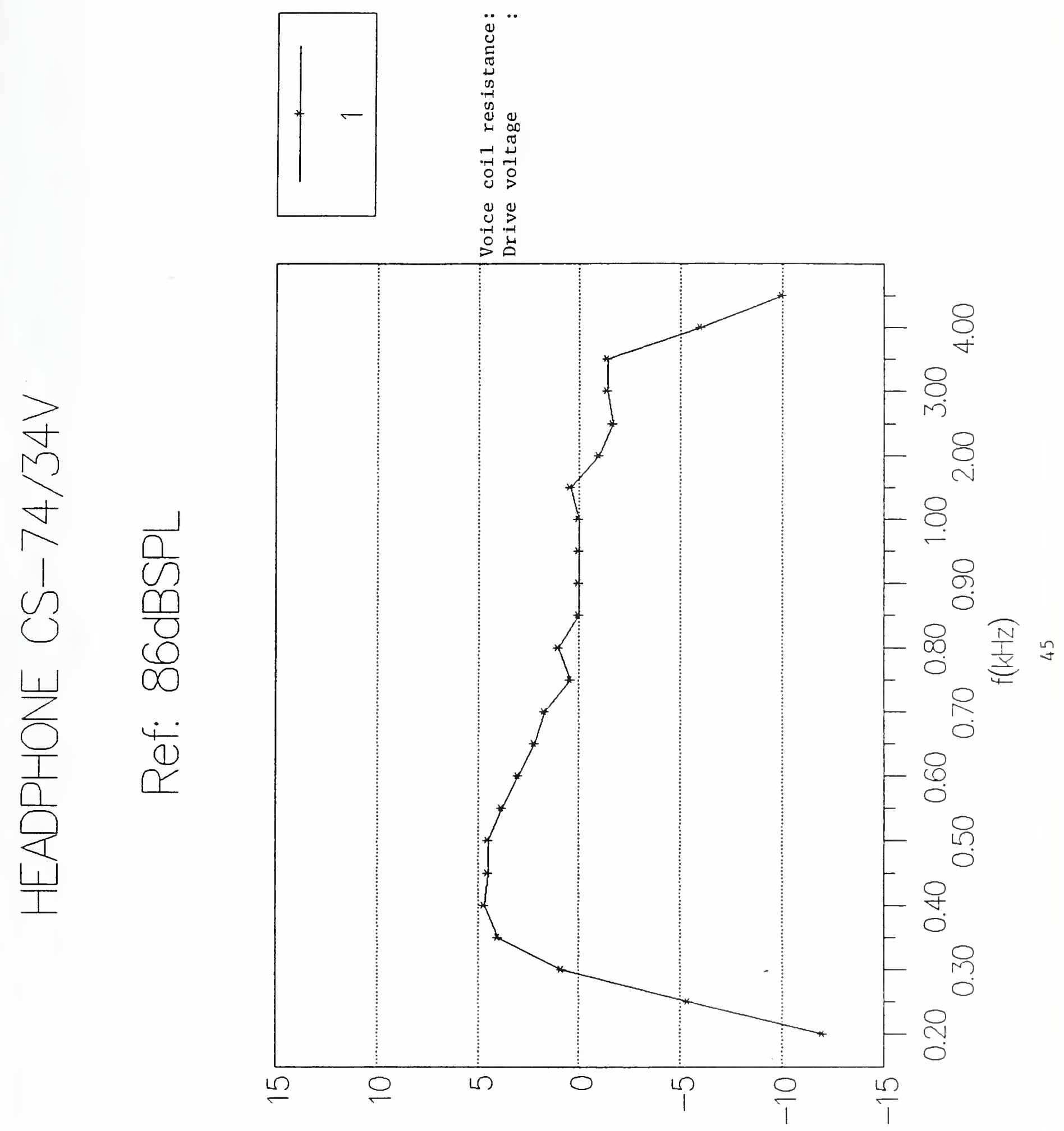
美产

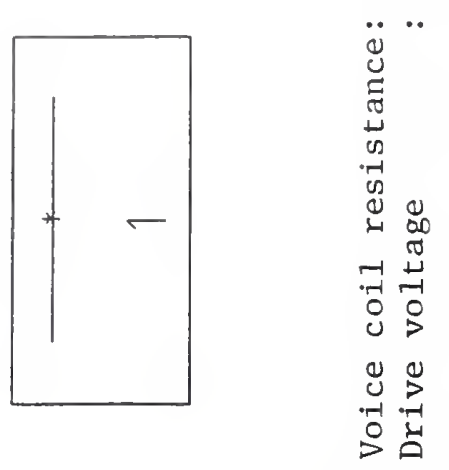

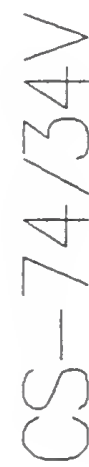
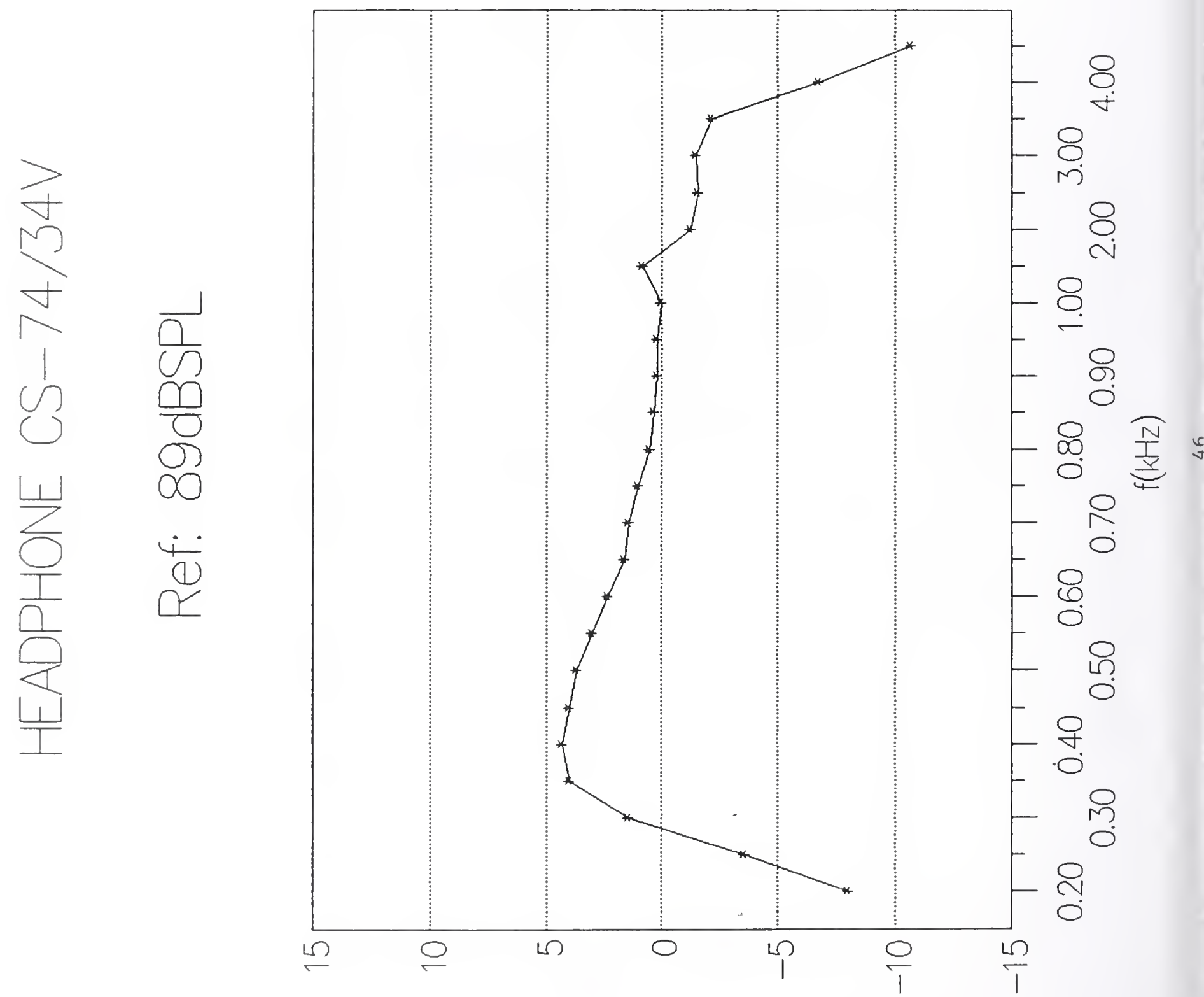
蛋

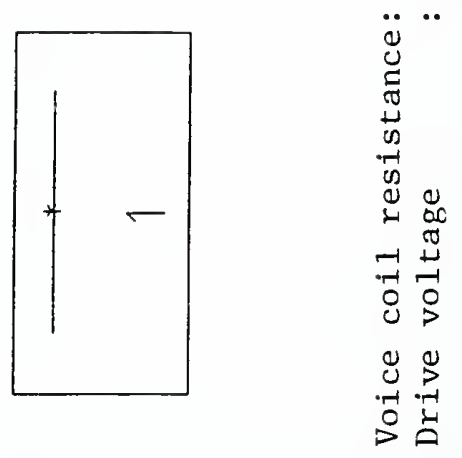

$\frac{7}{4}$

ㄴ

$\frac{1}{0}$
0
0
0
$\frac{1}{0}$
$\square$

$\frac{1}{\square}$

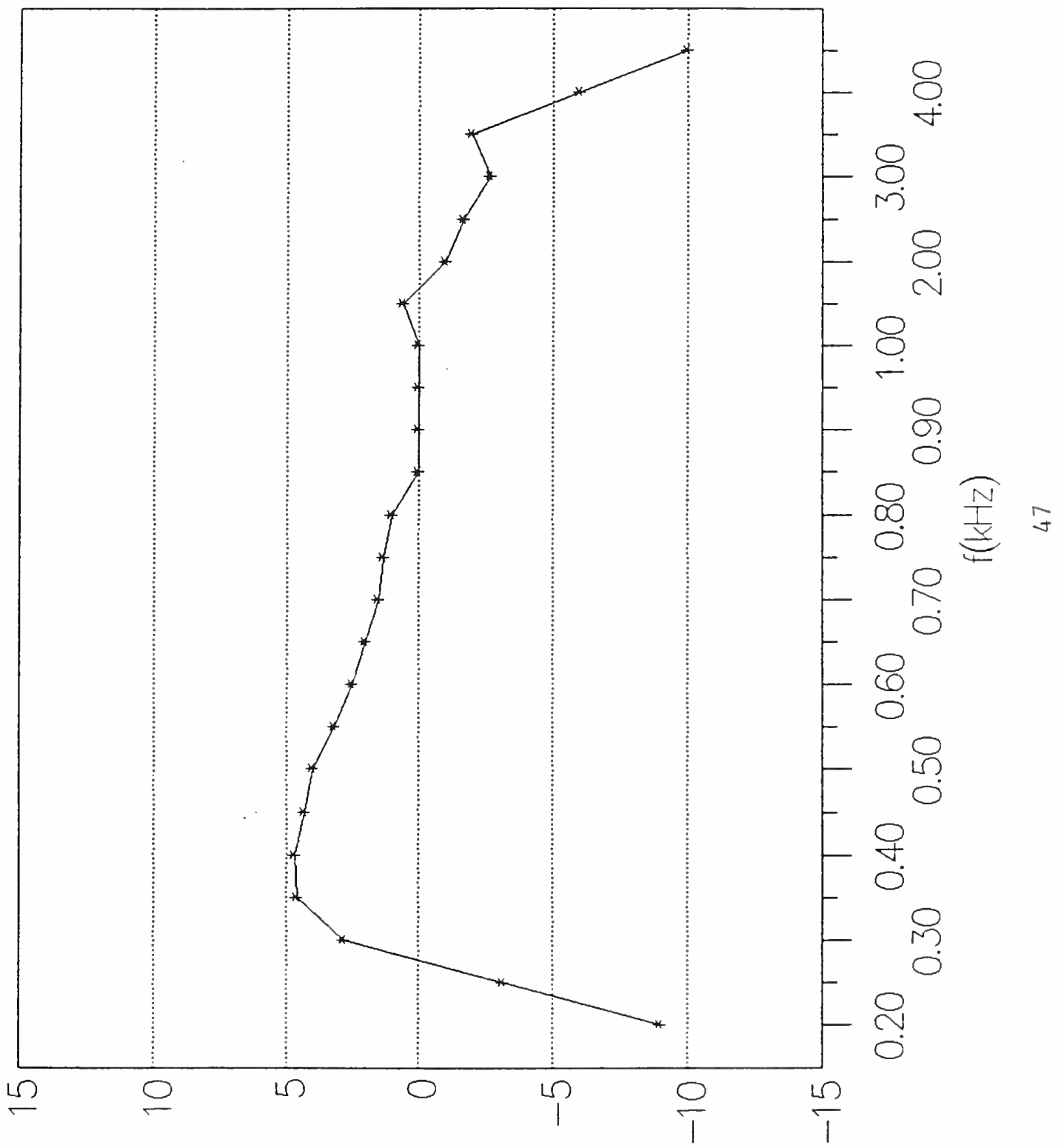


오ํ ํㅜㅇ
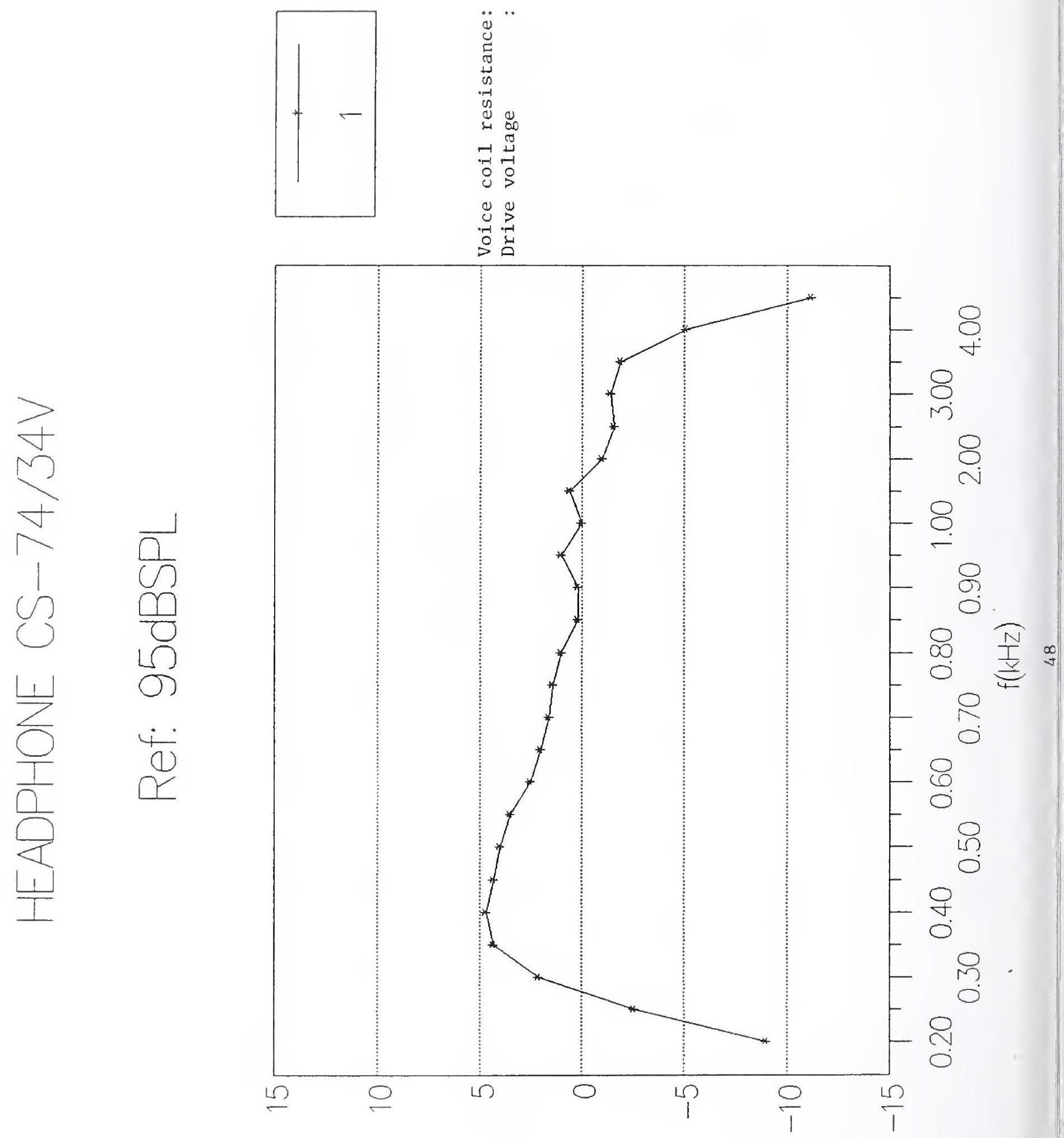
System 2 Test Data 


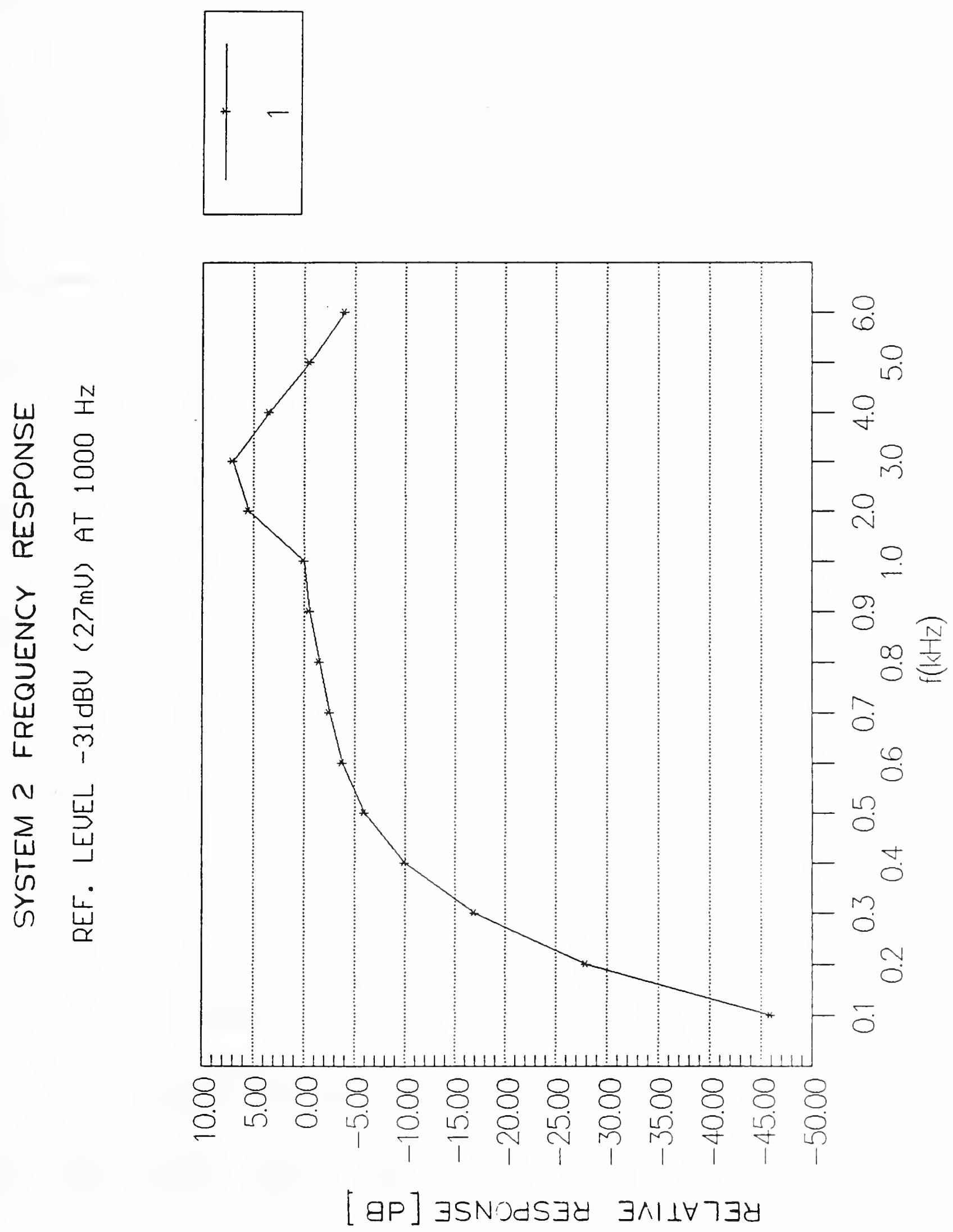


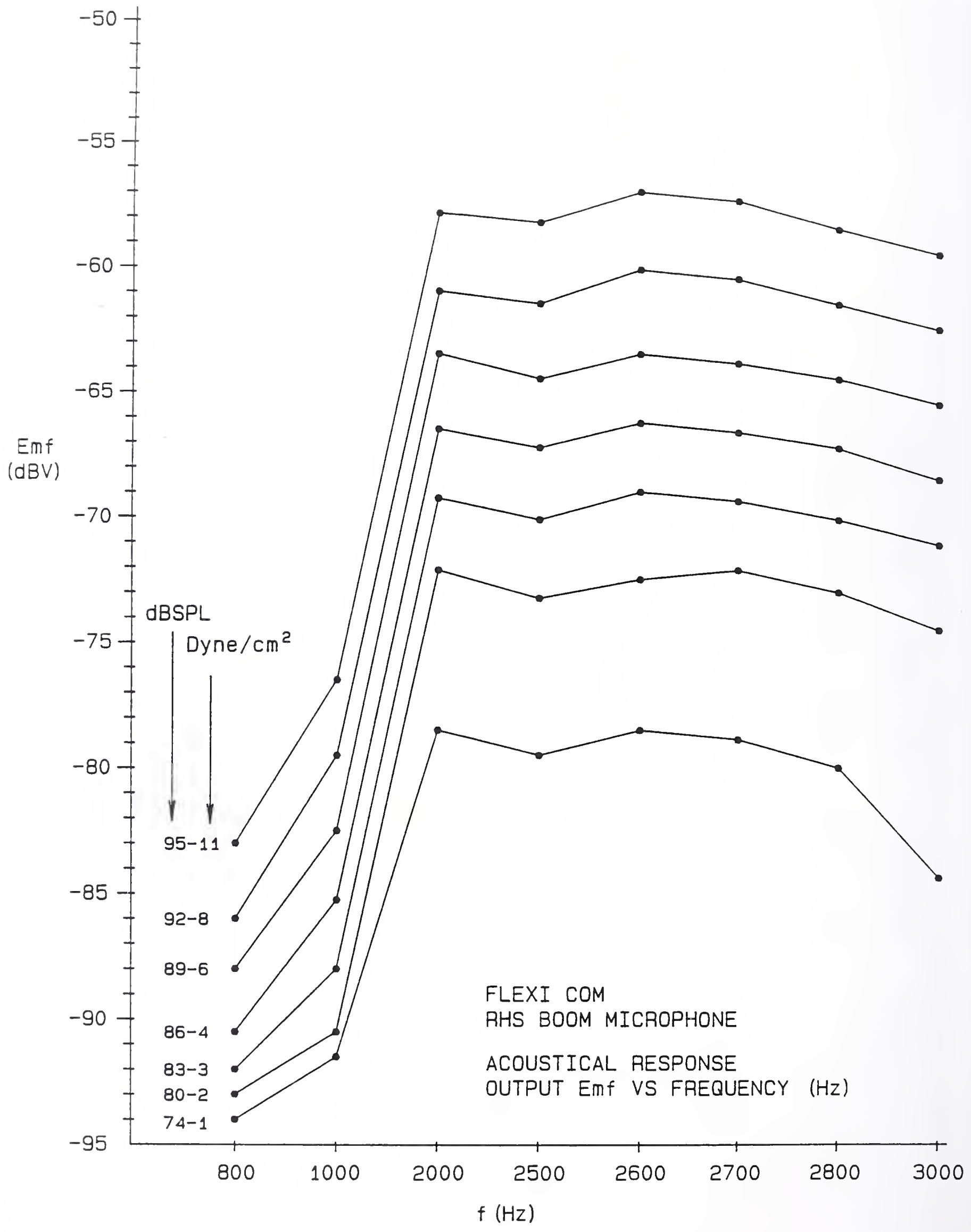




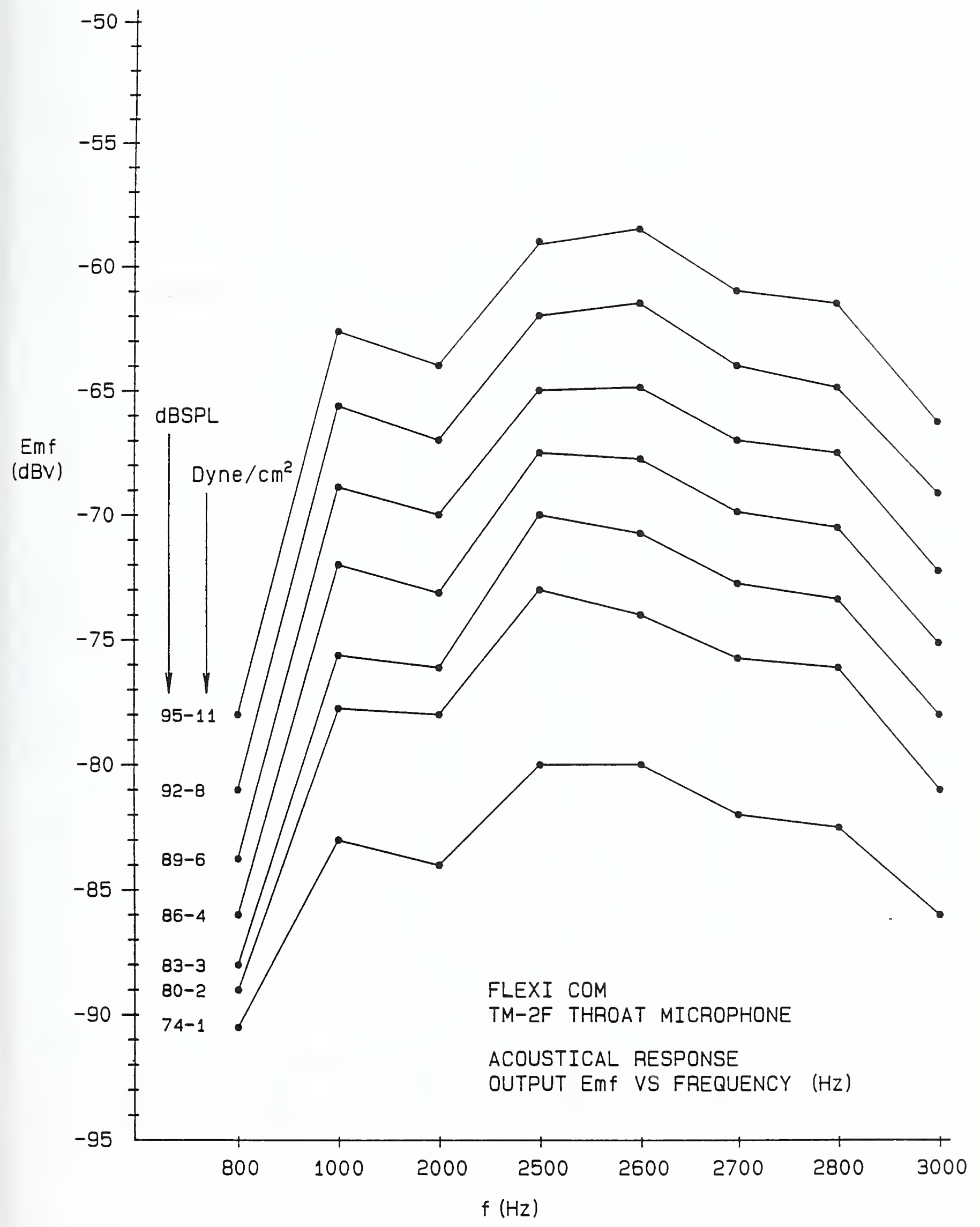


总
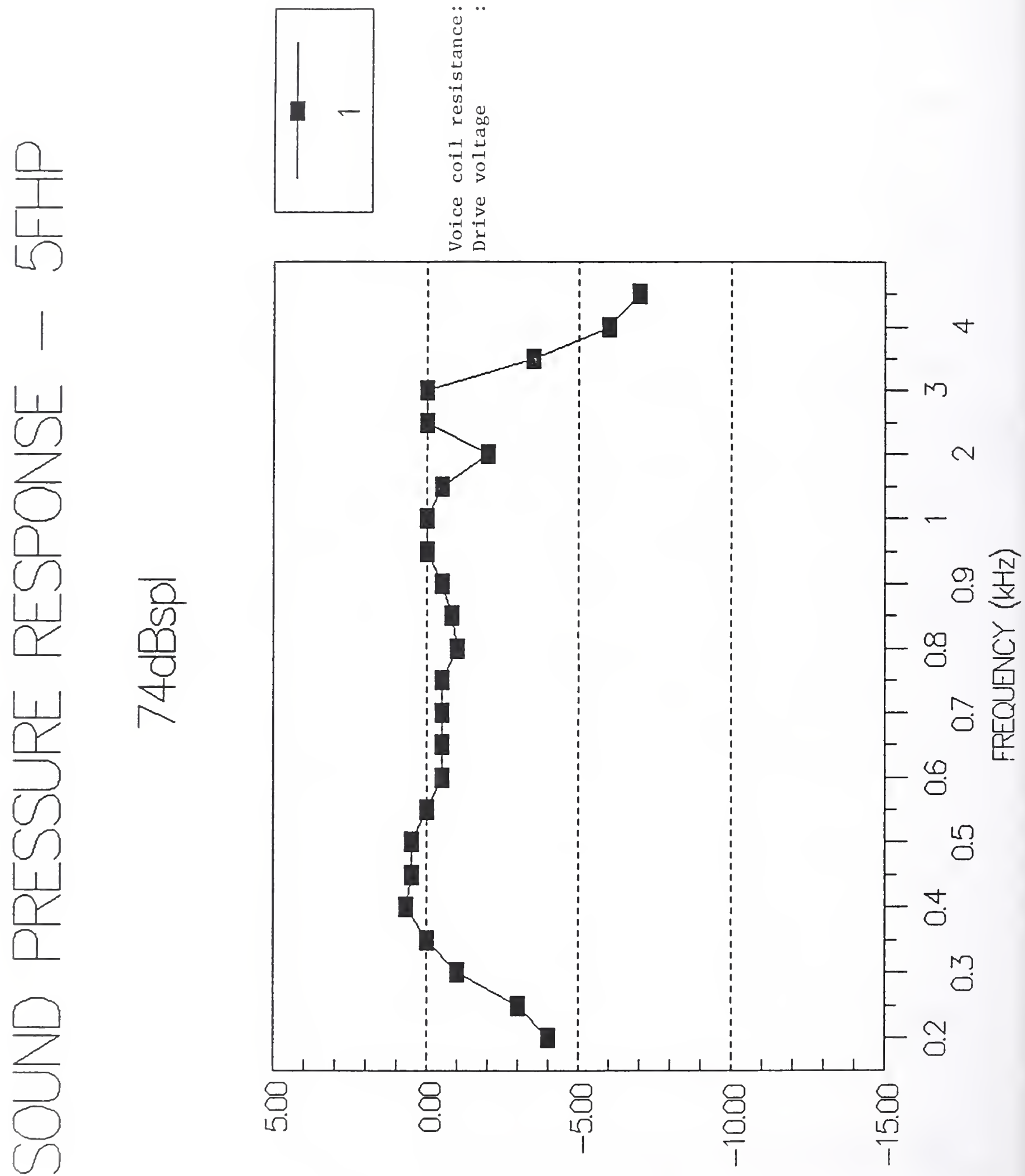
$\frac{9}{\frac{1}{5 \Omega}}$

$\frac{1}{0}$

$\stackrel{L}{\alpha}$

$\stackrel{\square}{\square} \quad \infty$

$\overline{0}$
0
0
0

0

$\Omega$

$\frac{1}{n}$

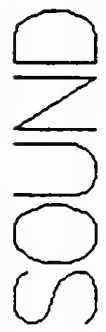

๘气

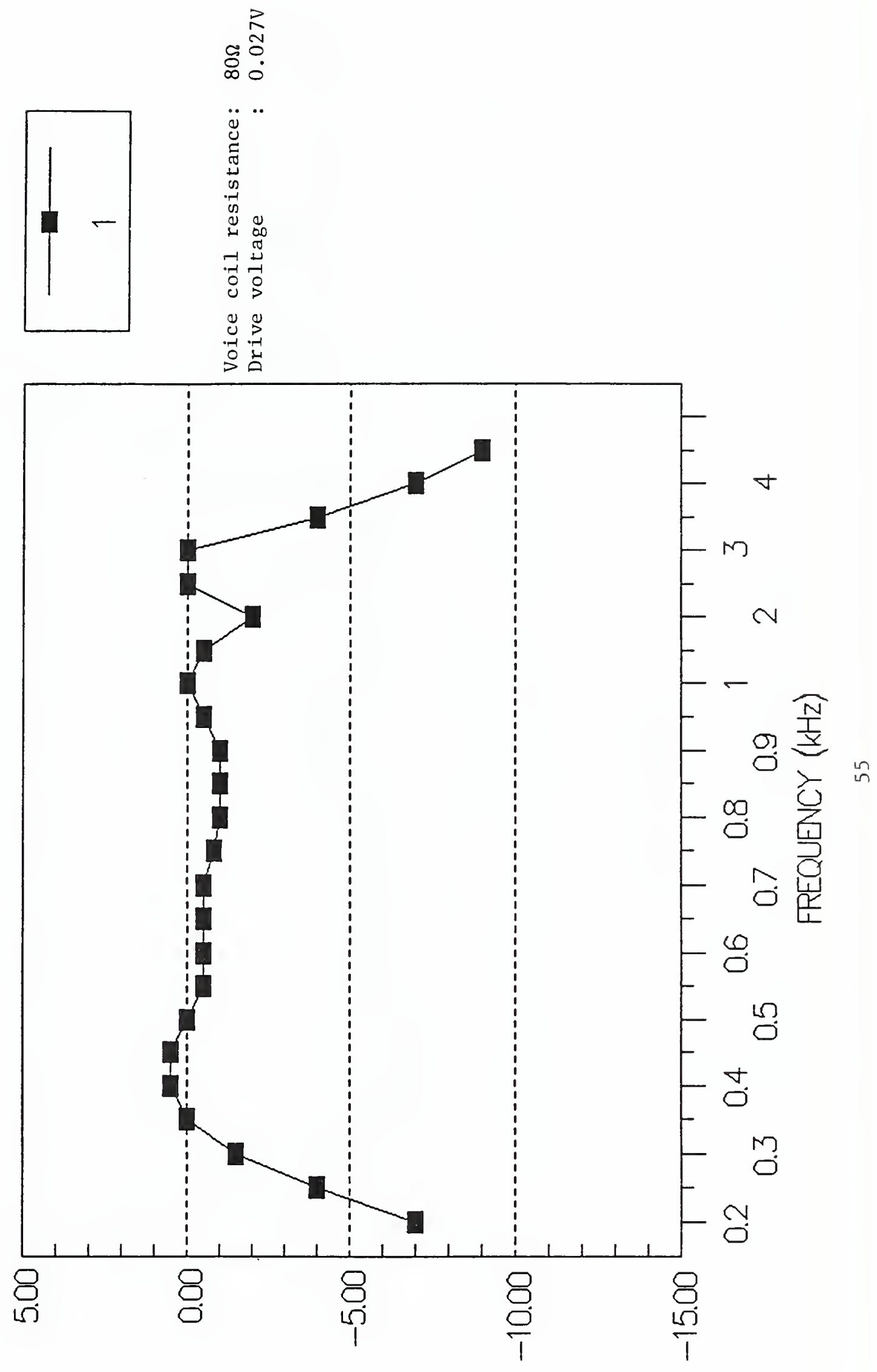

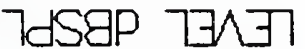




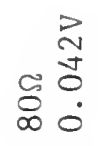
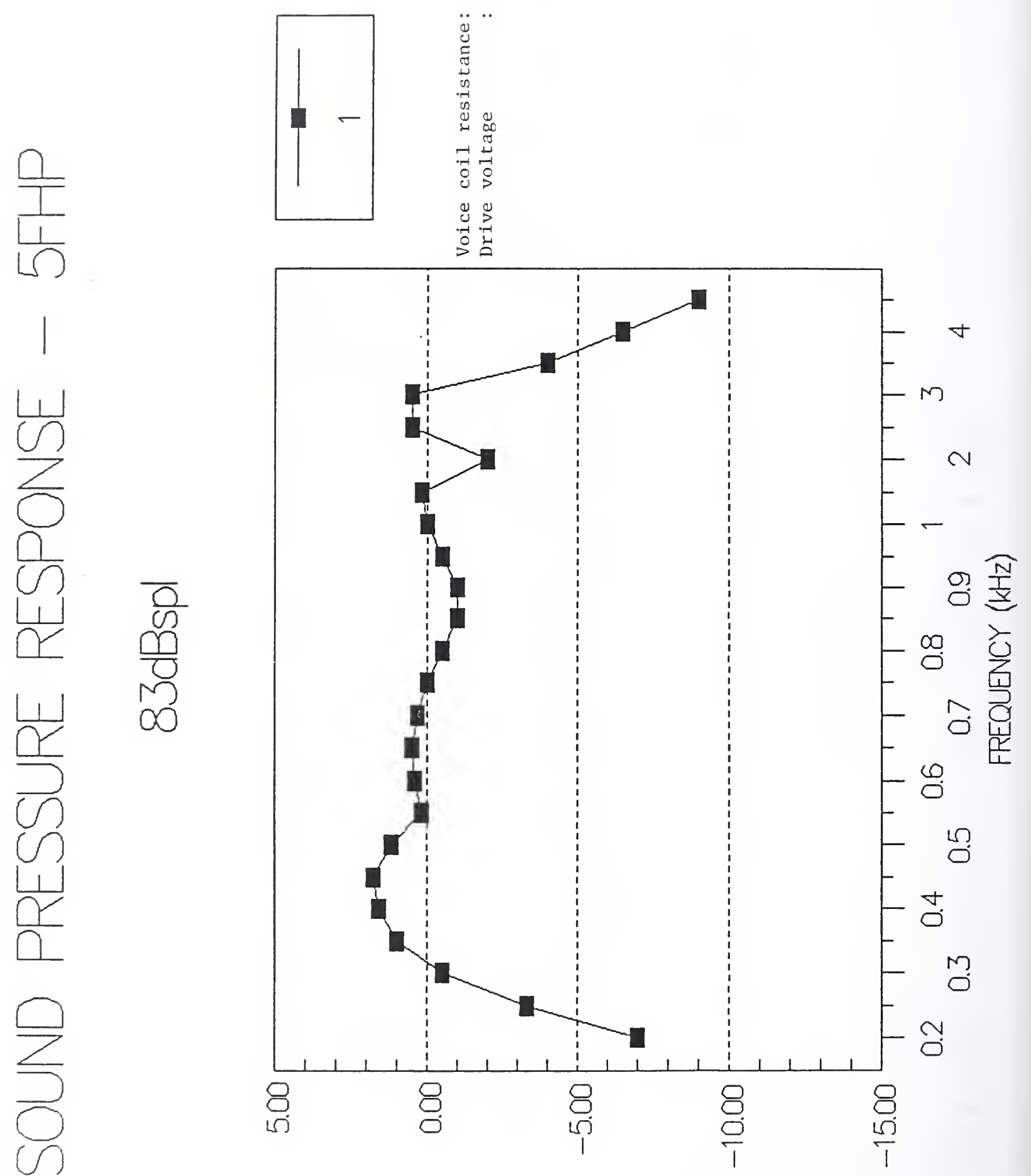


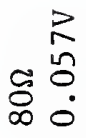

$\frac{\square}{\frac{1}{1 \frac{1}{1}}}$

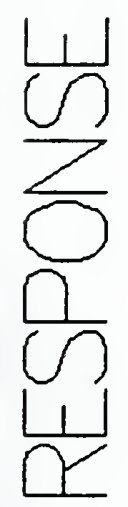

$\stackrel{0}{\mathrm{~N}} \quad 0$

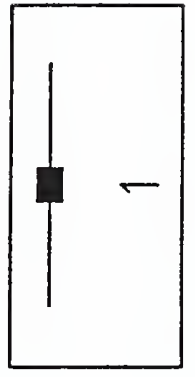

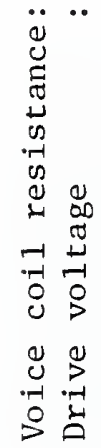

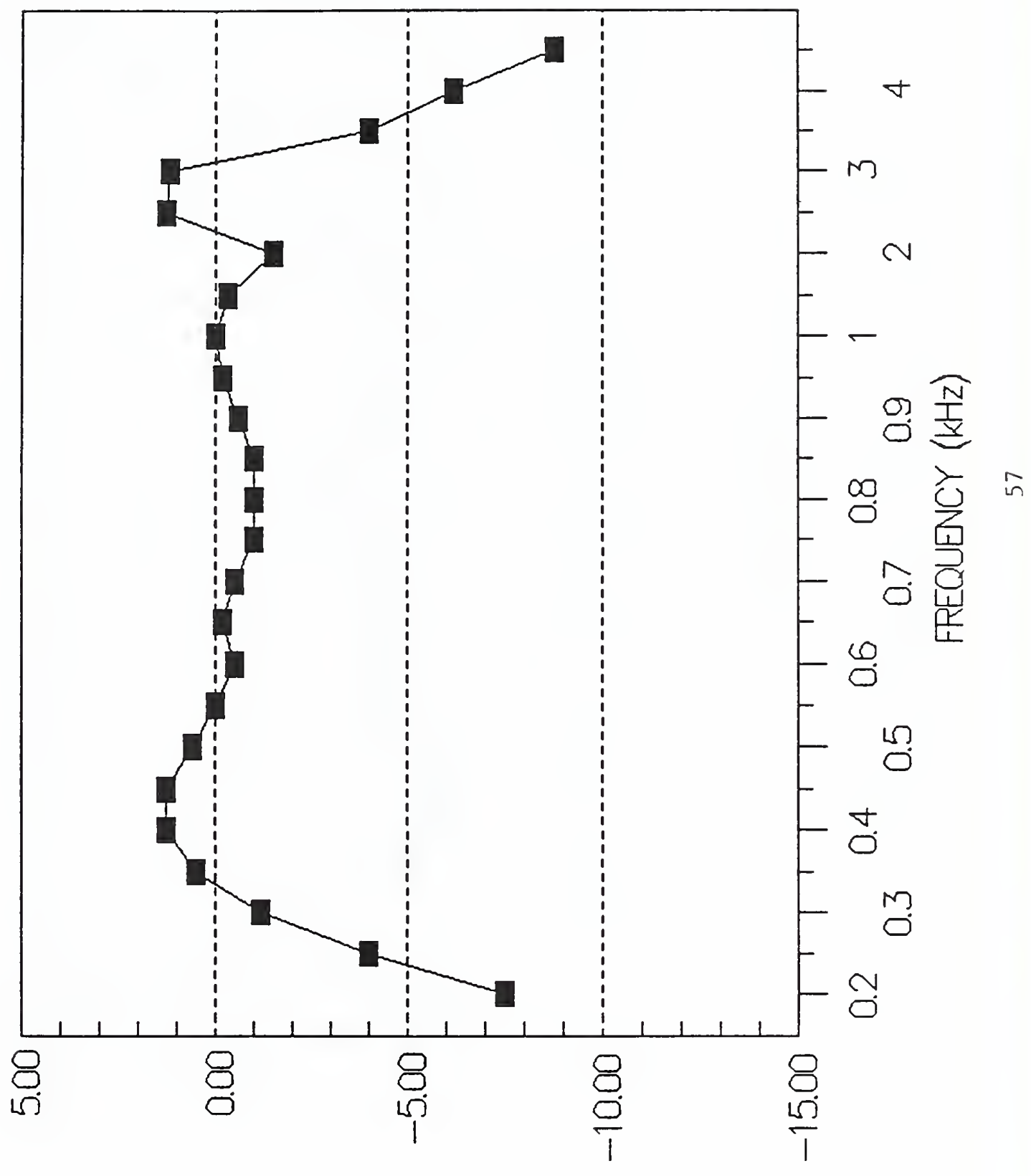


范

$\frac{n}{\frac{1}{5}}$

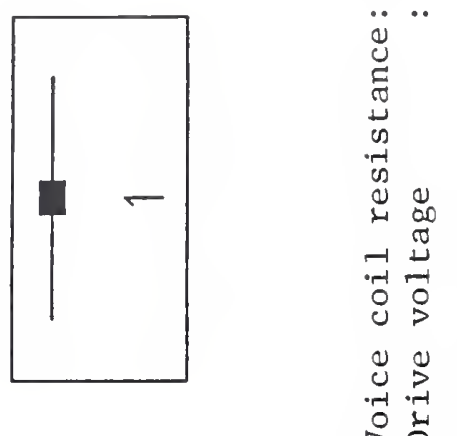

至

$\frac{w}{5}$

남

나

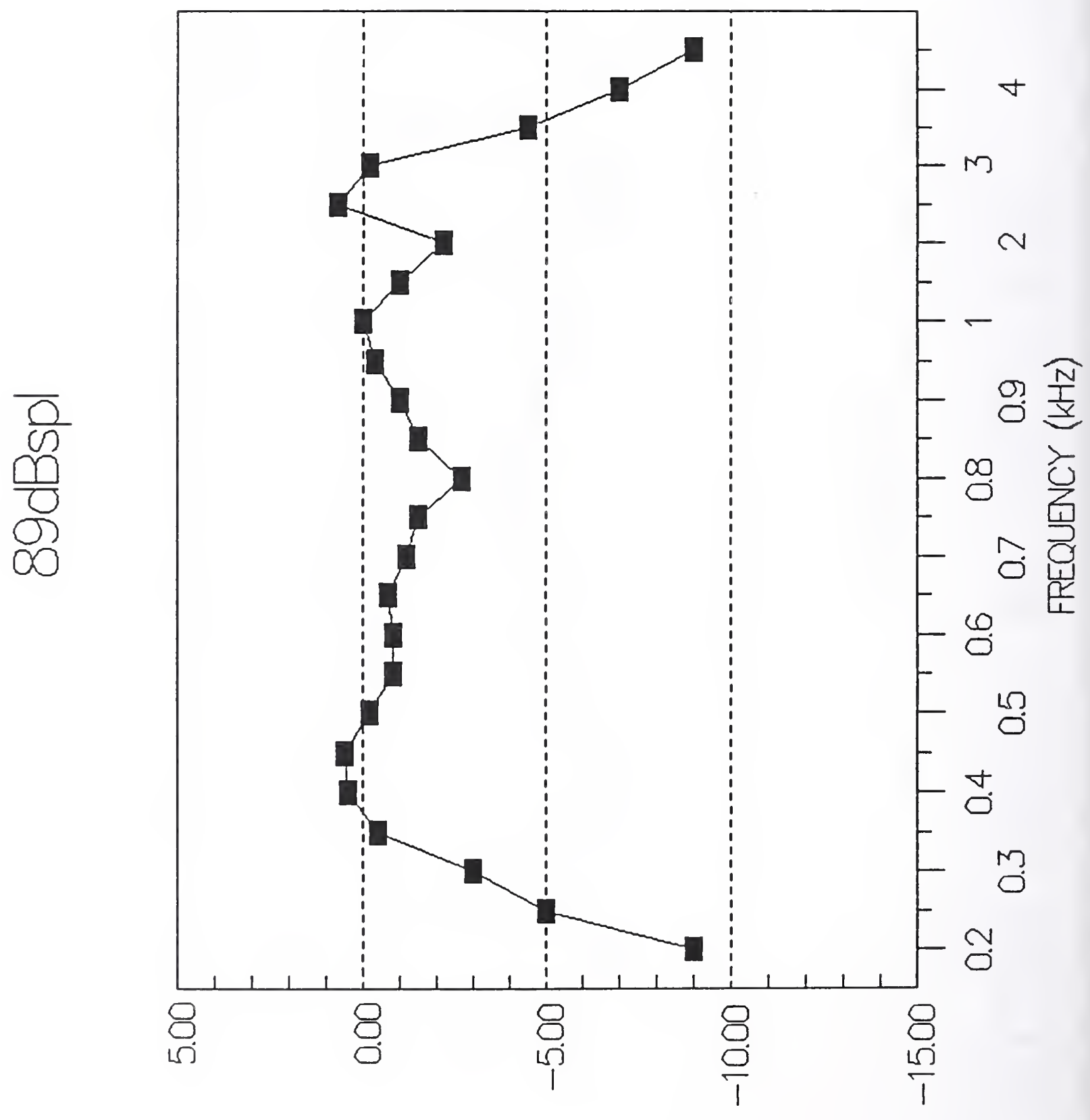

$\frac{0}{c}$
0
0
0

0

$\Omega$

$\frac{1}{\alpha}$

$\square$

$\frac{8}{3}$

7dSgP ךユএت1 
要

$\frac{\frac{a}{1}}{\frac{1}{n}}$

...
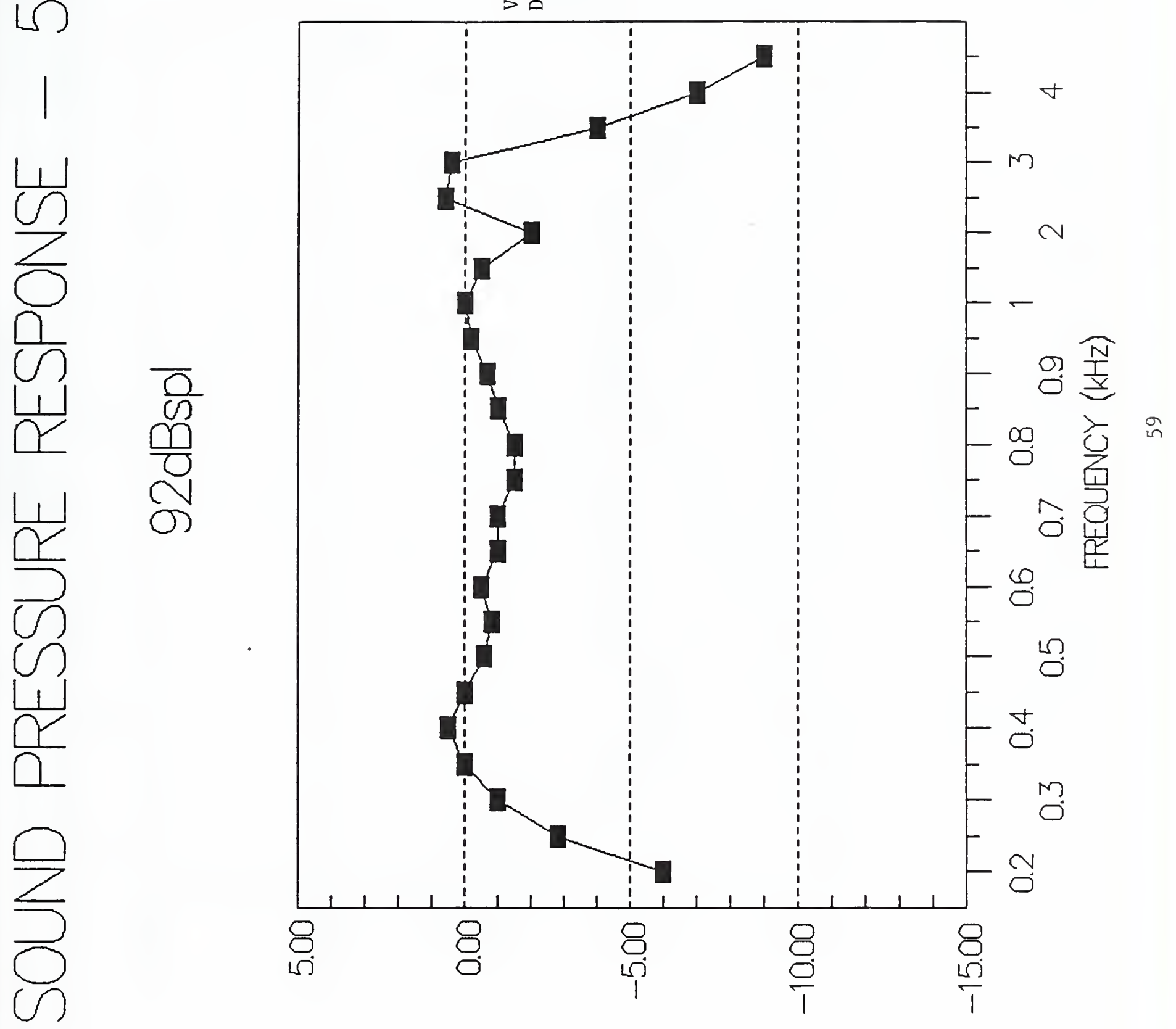


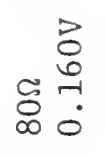

$\frac{a}{\frac{1}{4}}$

$\frac{1}{0}$

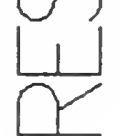

남

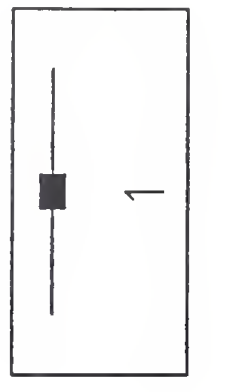

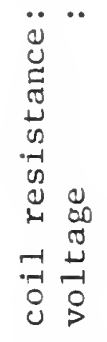

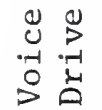

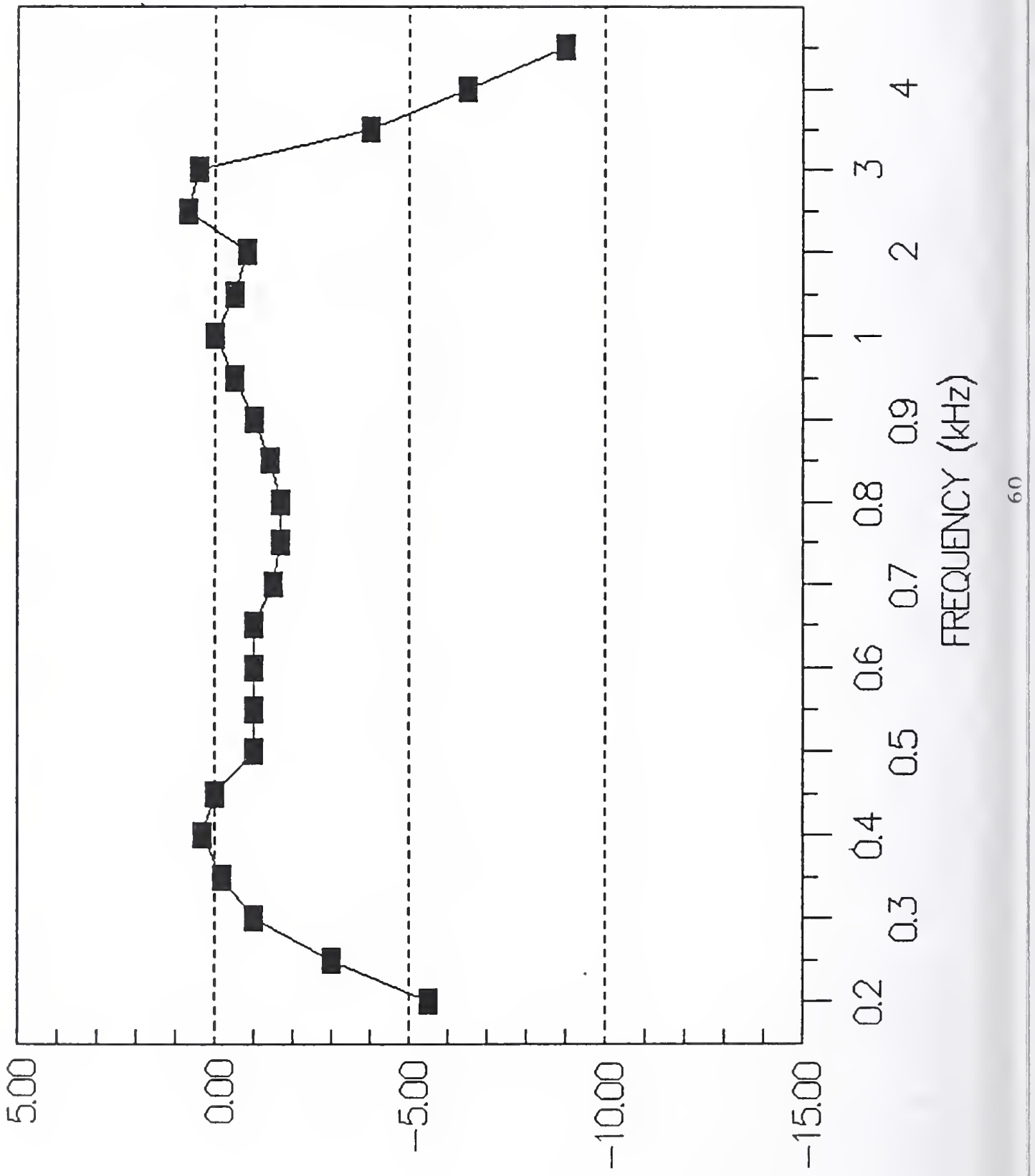


突茎:

$\frac{a}{1} \frac{a}{\square}$

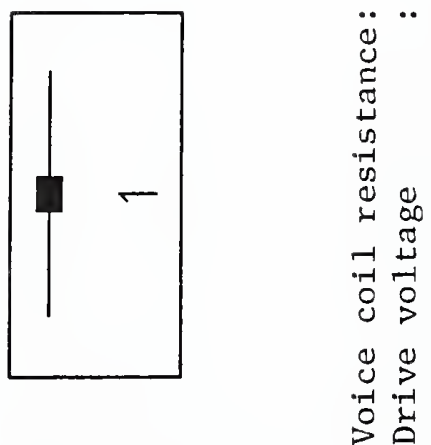

$\frac{w}{2}$
$\frac{1}{0}$
$\frac{0}{n}$

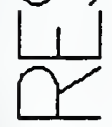

$\frac{1}{1} N$

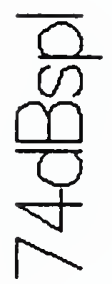

(

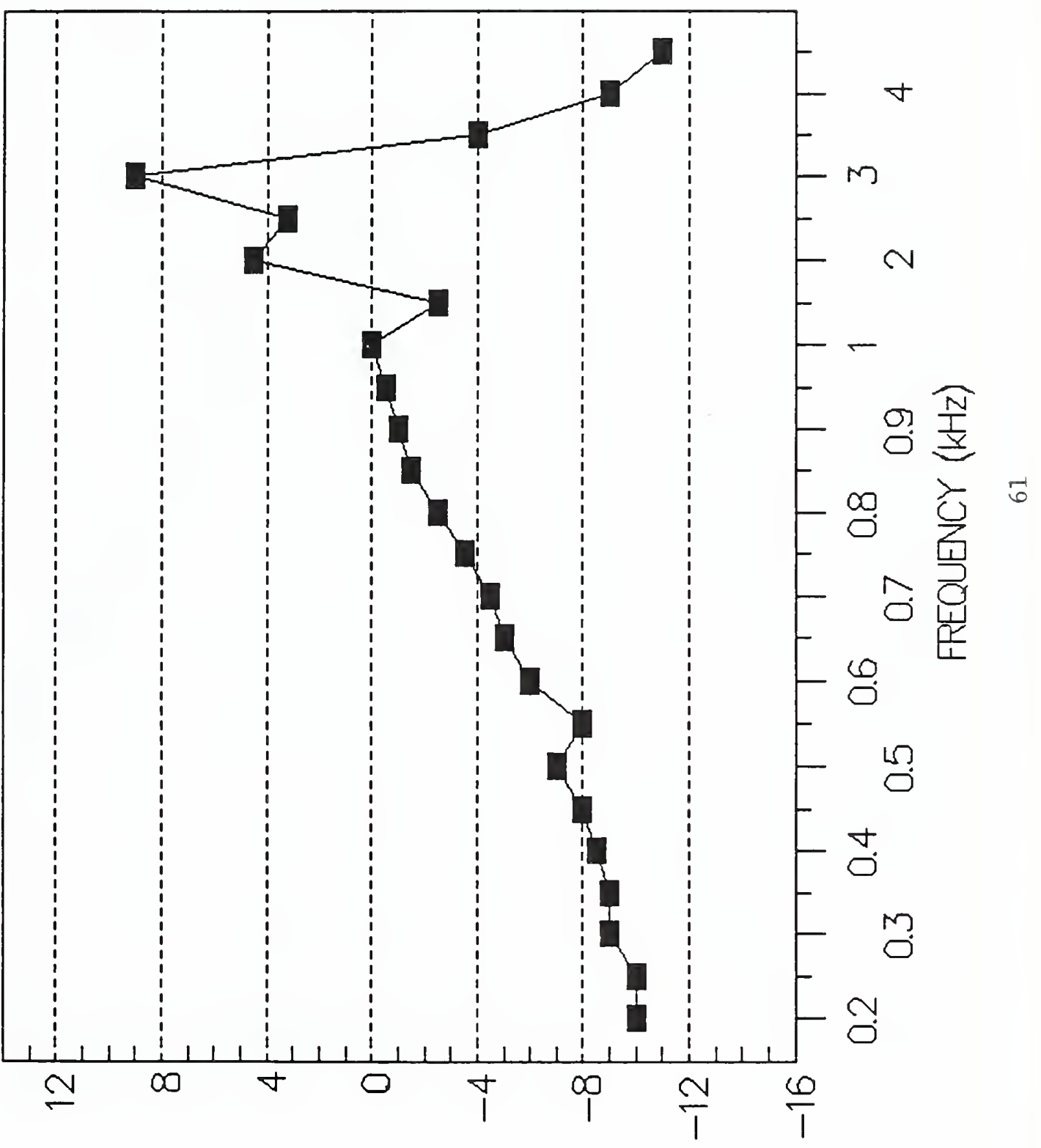


콩

$\frac{0}{\sqrt{10}}$

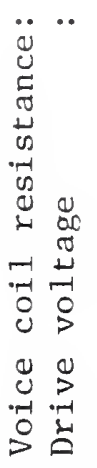

$\frac{w}{3}$

$\frac{1}{\alpha}$

嶎

क

n

$\frac{a}{0}$
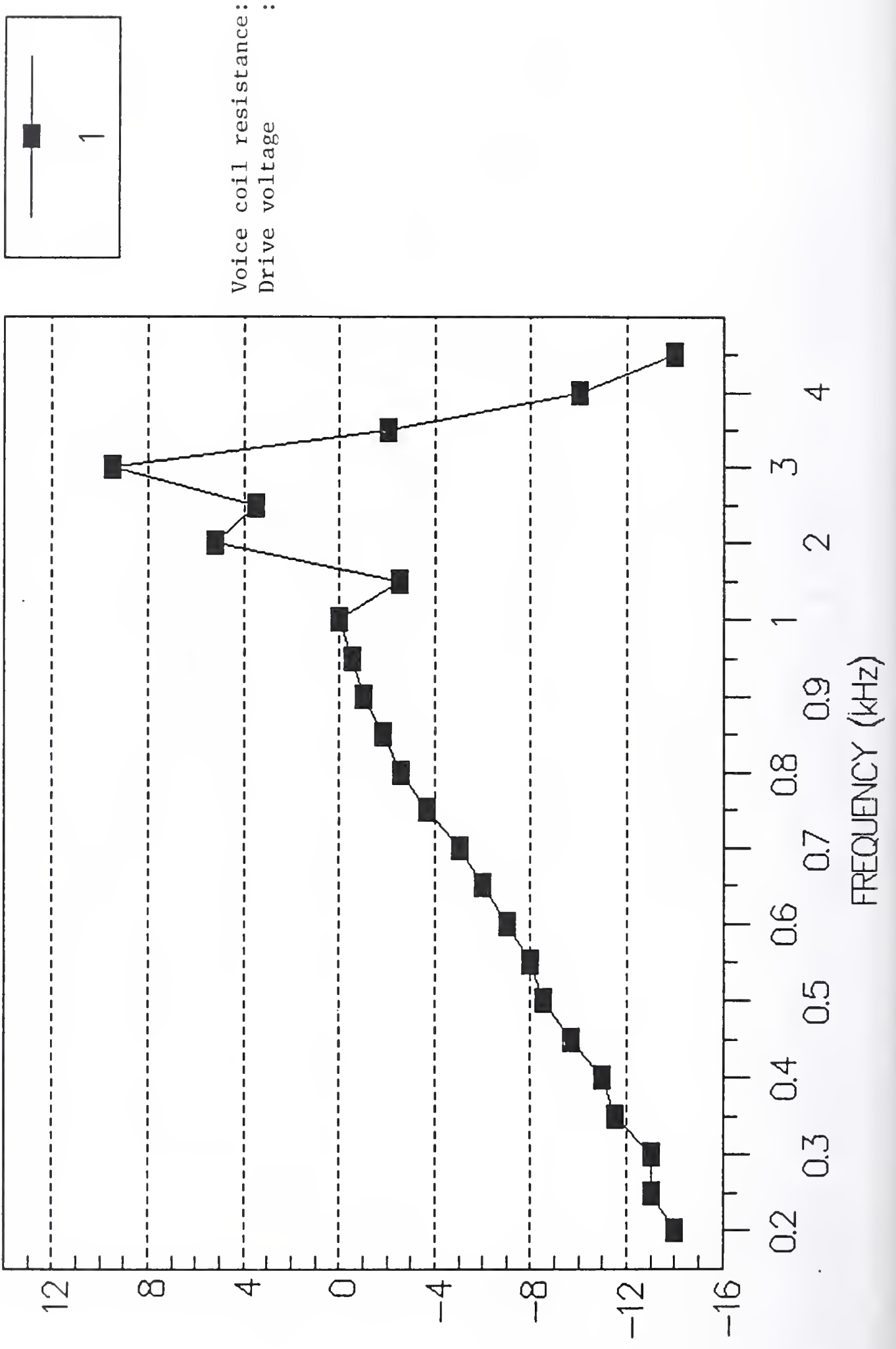

o 
옹ํำ

$\frac{\frac{0}{11}}{\frac{0}{2}}$
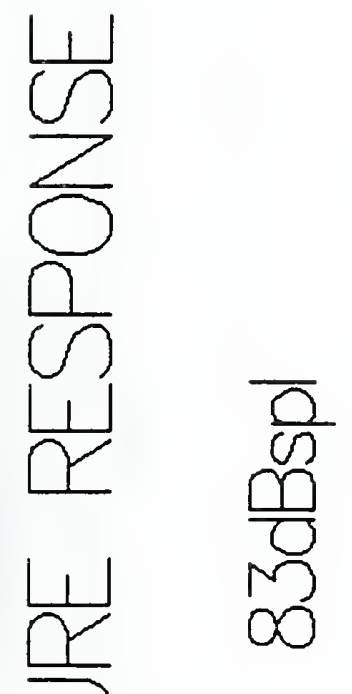
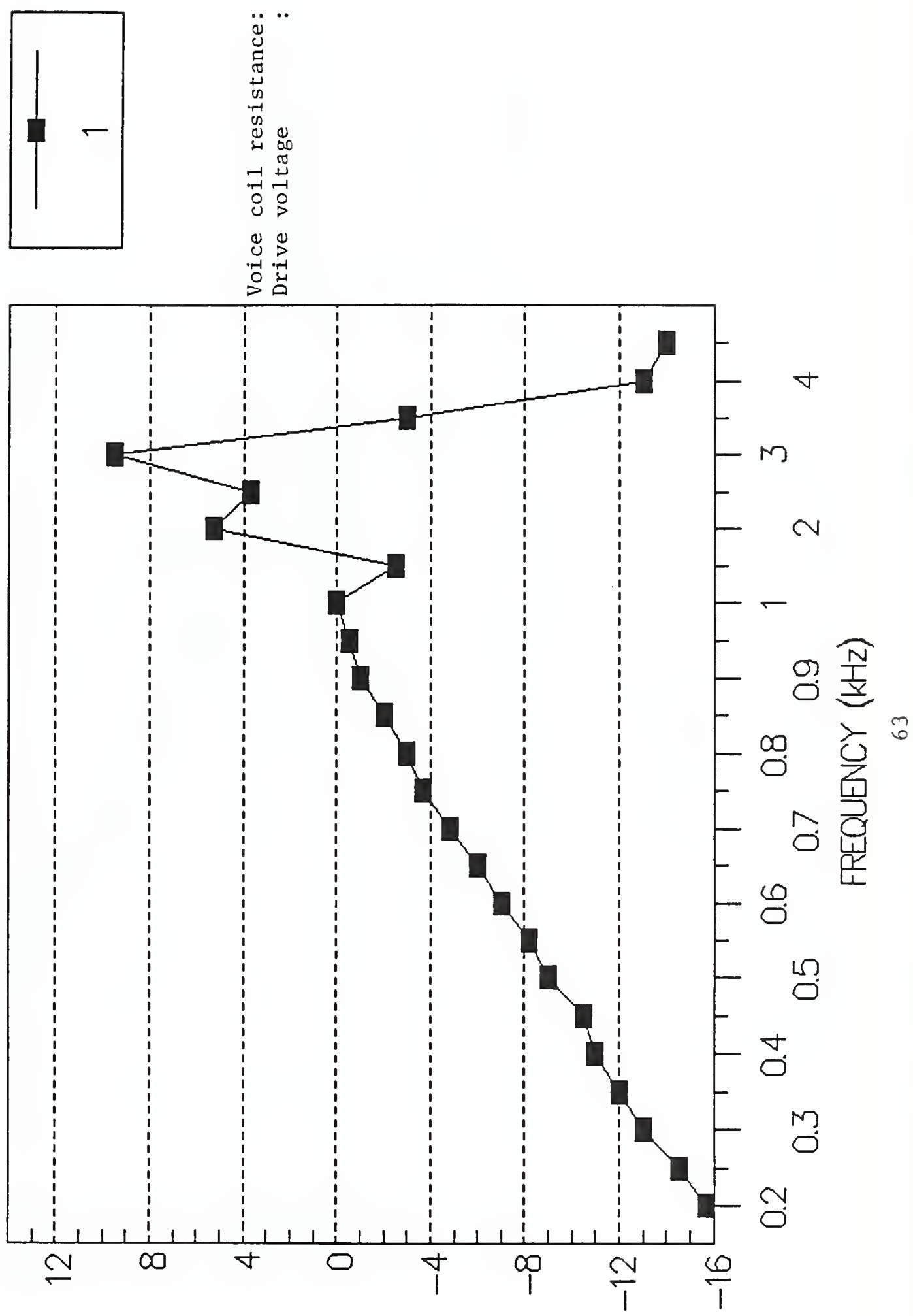
施
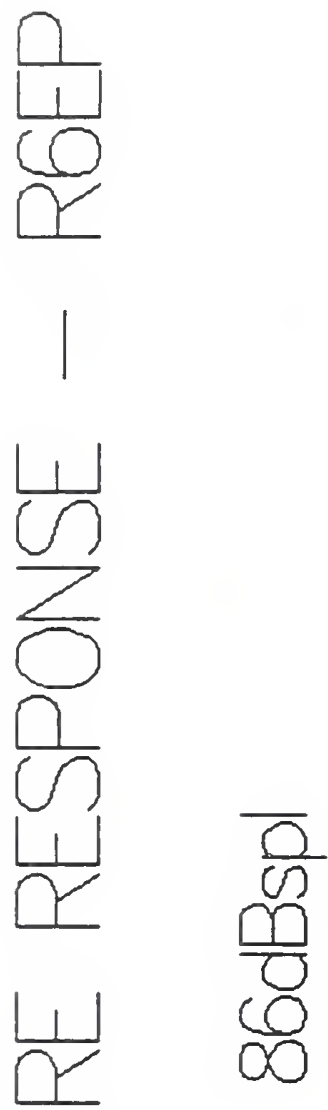

0
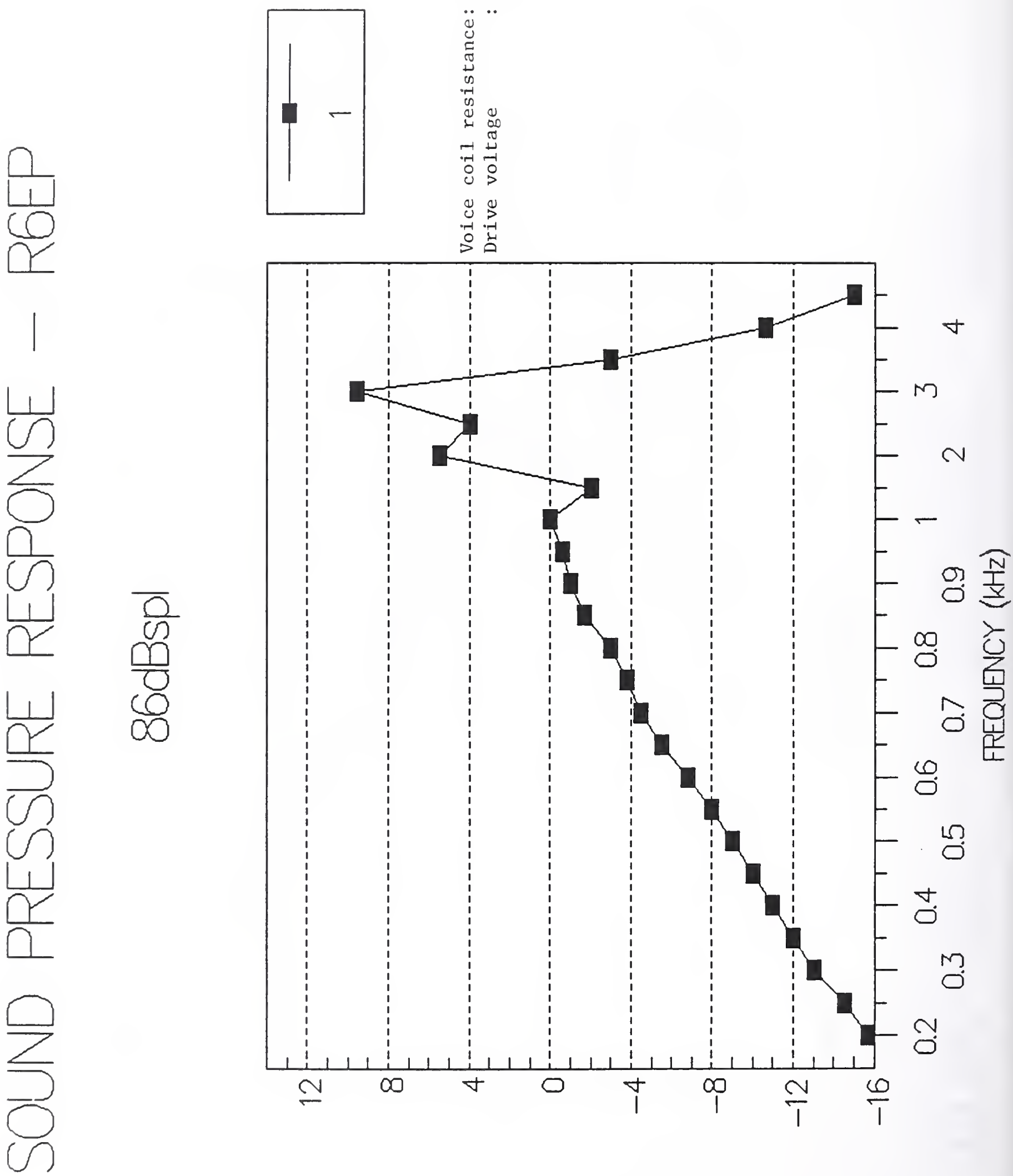
c.

0
0
$\square$

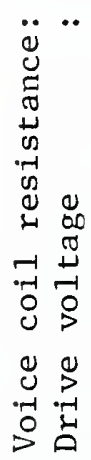

$\square$
0
0

1

L 0

0

0

$\frac{1}{\square}$

$\square$

$\frac{0}{0}$
0
0
0

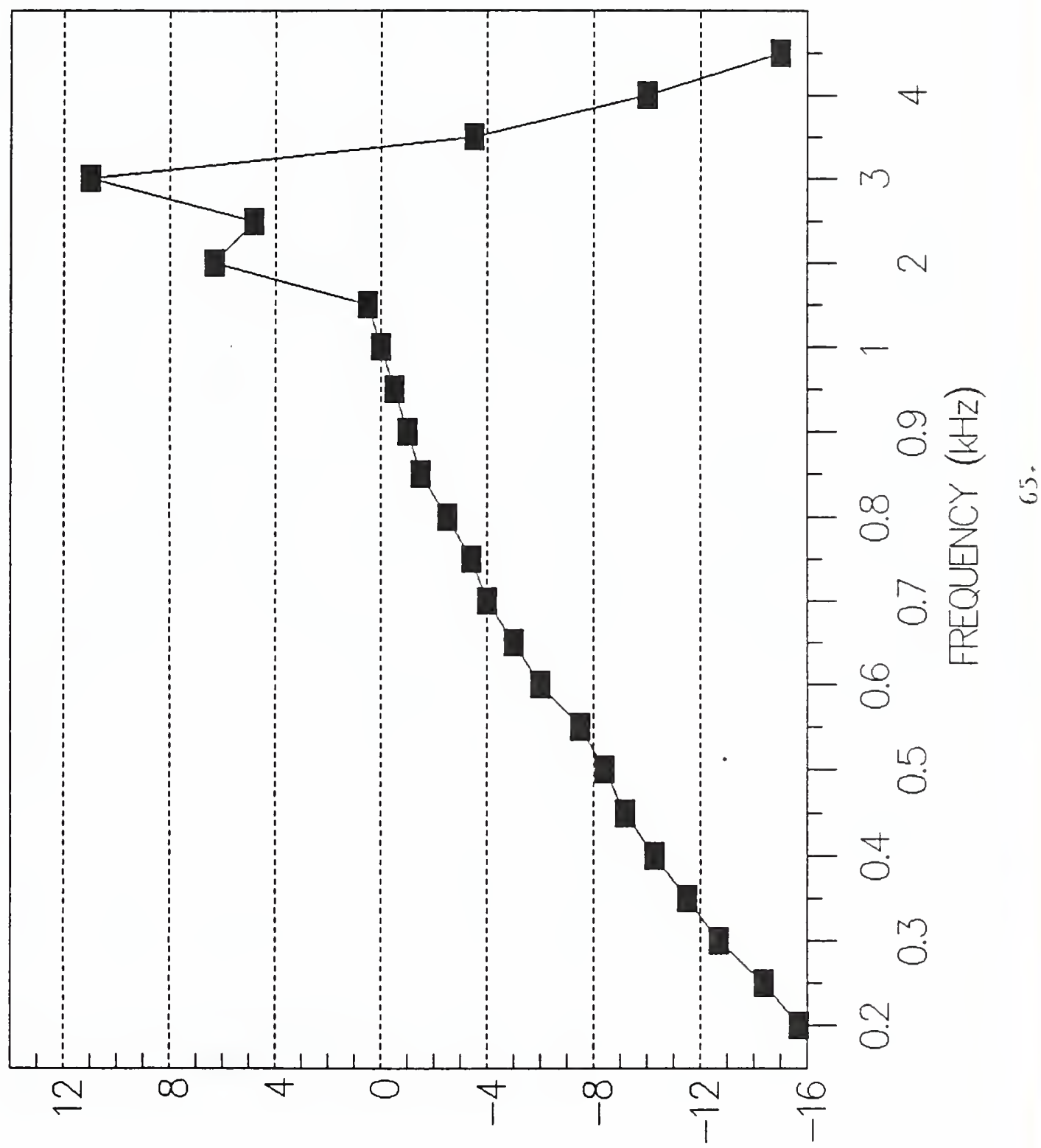




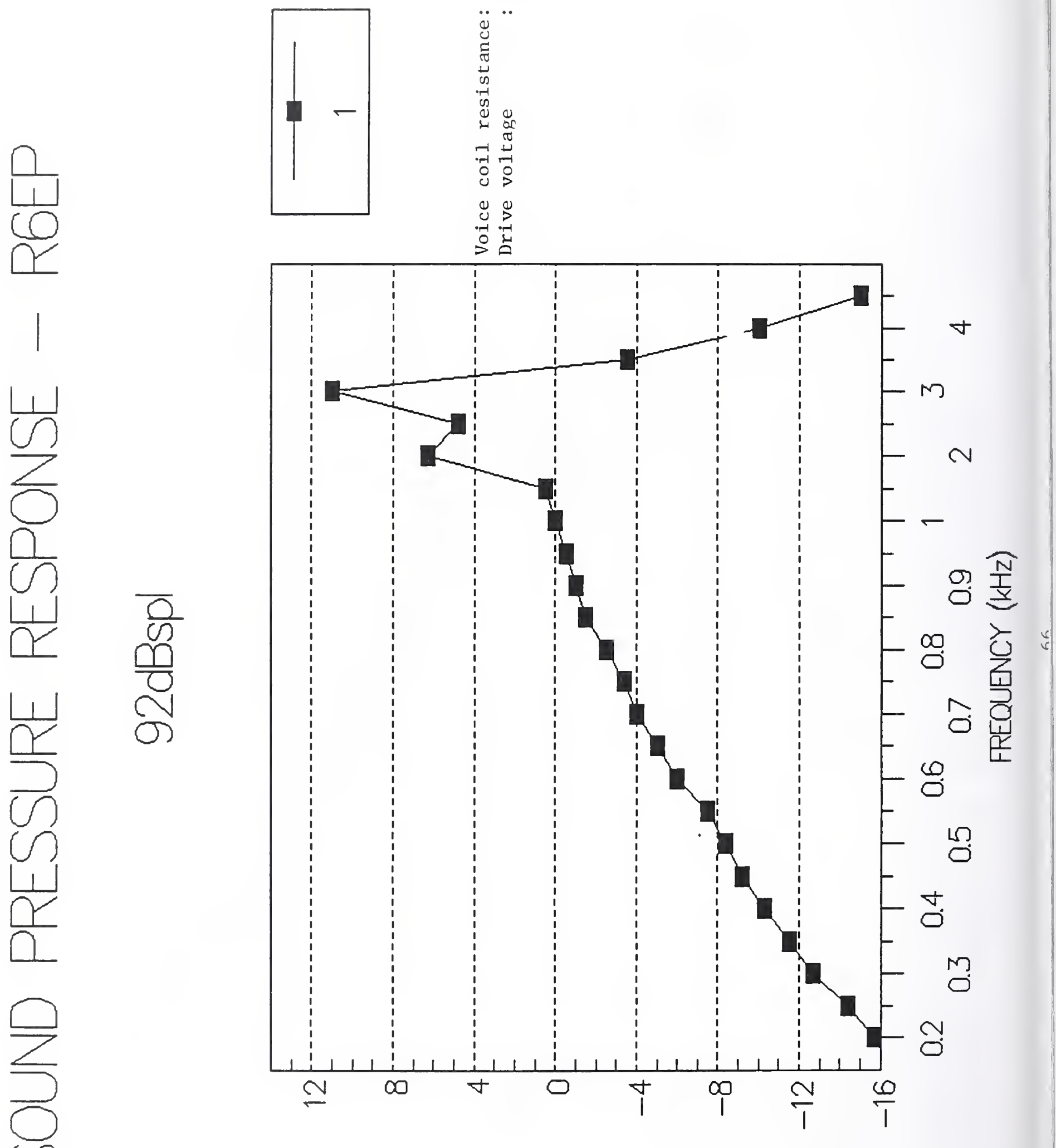

影高 
空

$\frac{0}{11}$
$\frac{0}{6}$

$\frac{1}{0}$

$\stackrel{\leftarrow}{\Upsilon}$

내요
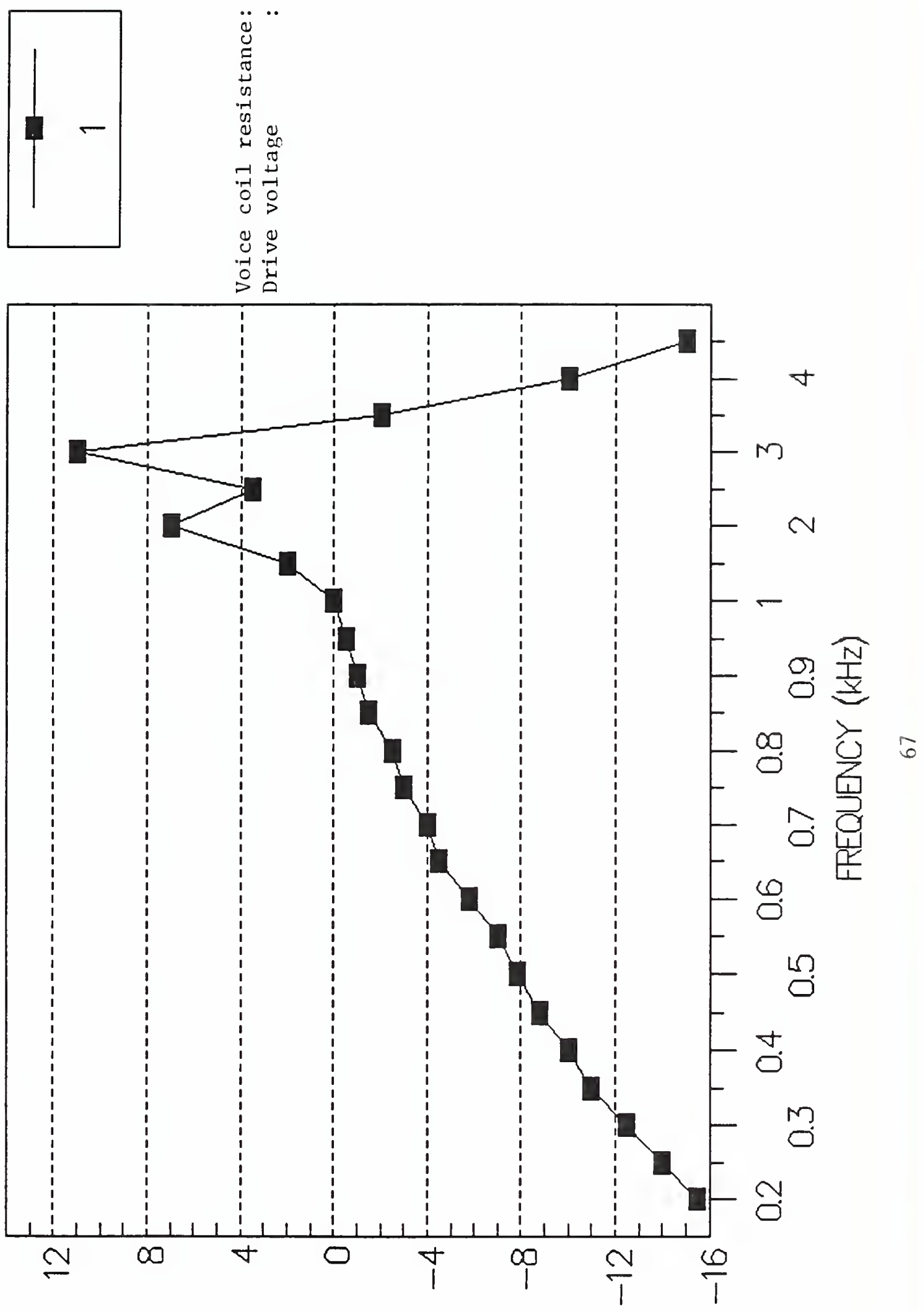


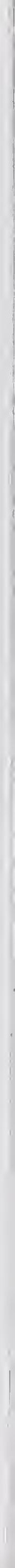


System 3 Test Data 

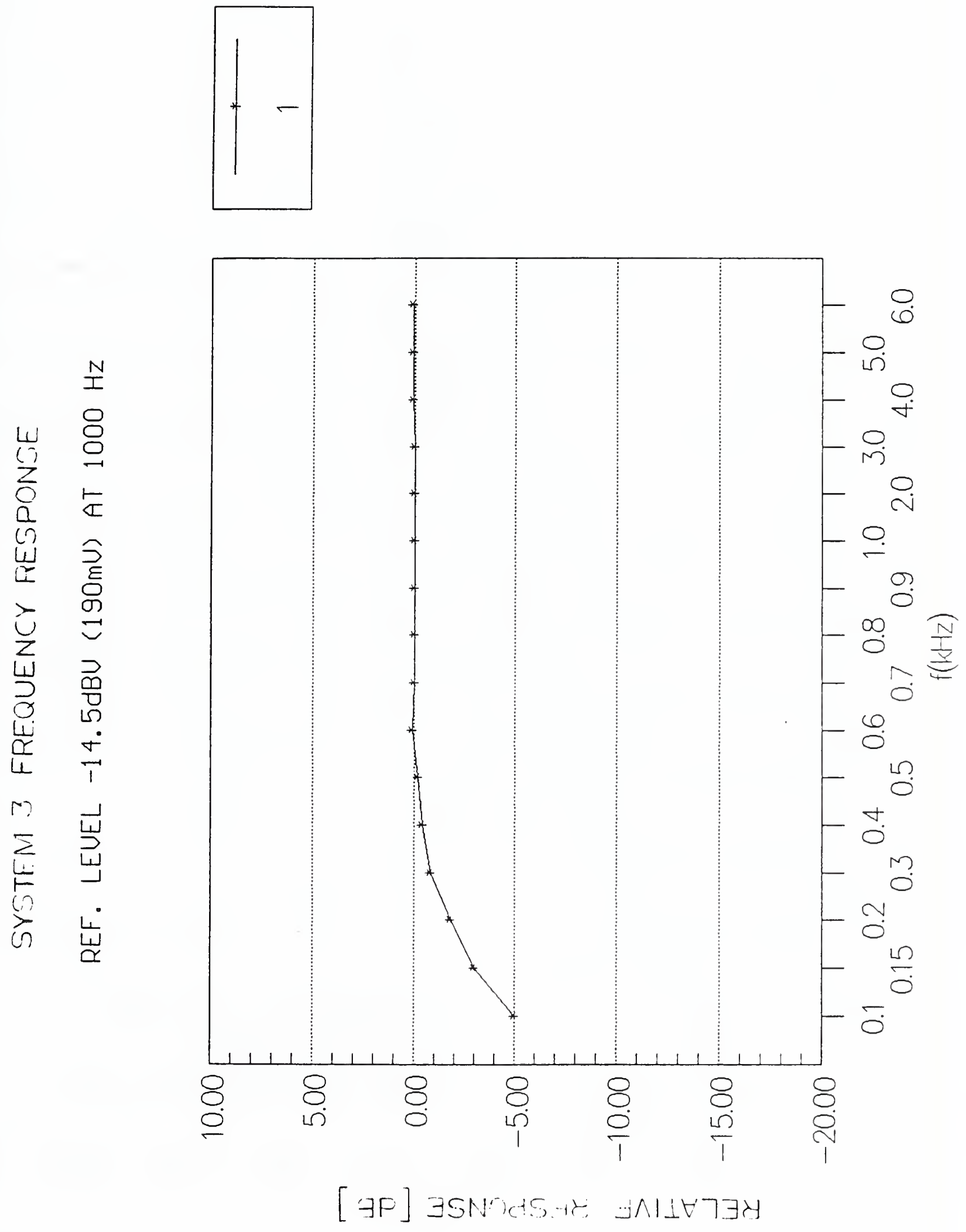


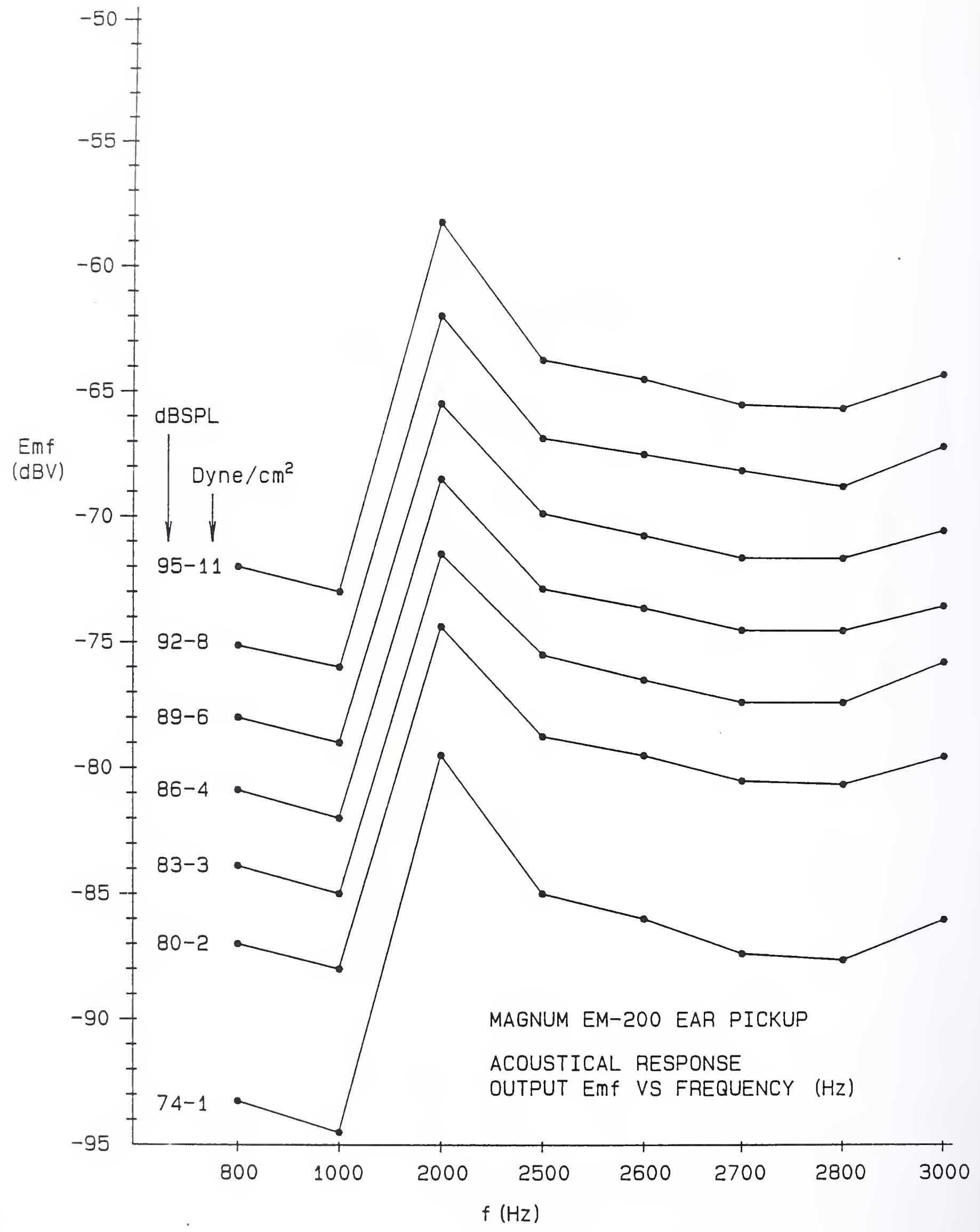




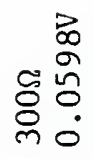
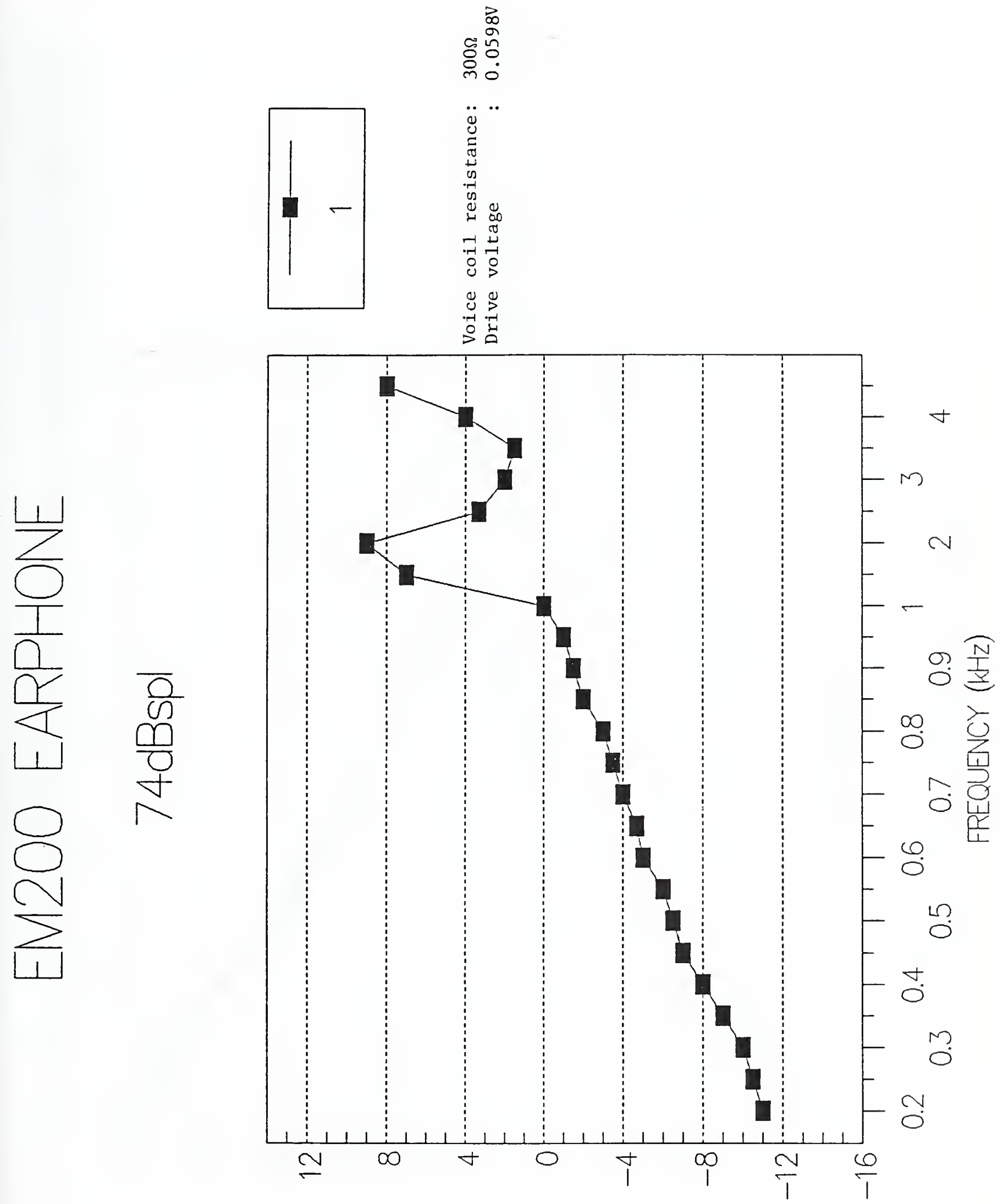


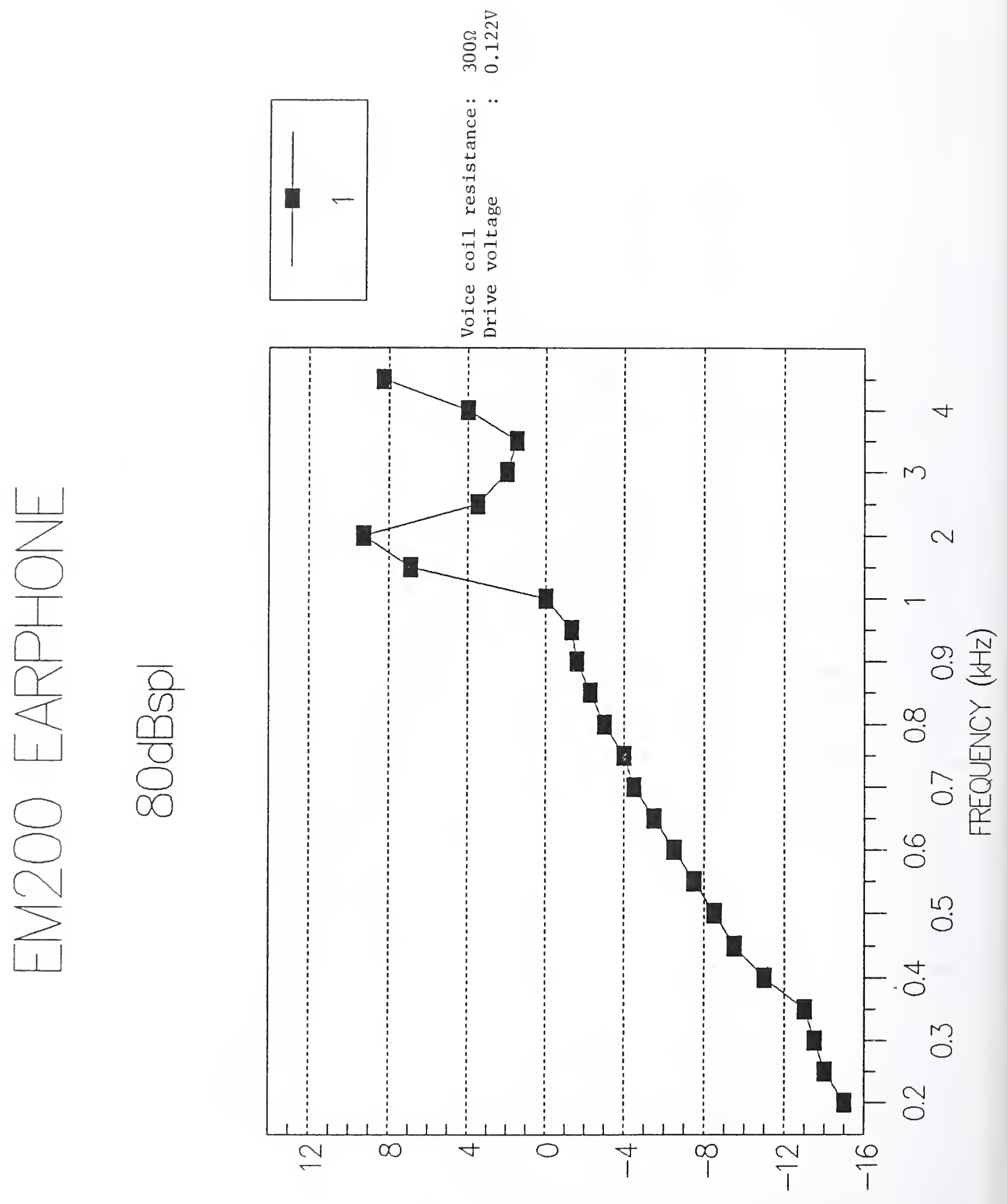


密耪
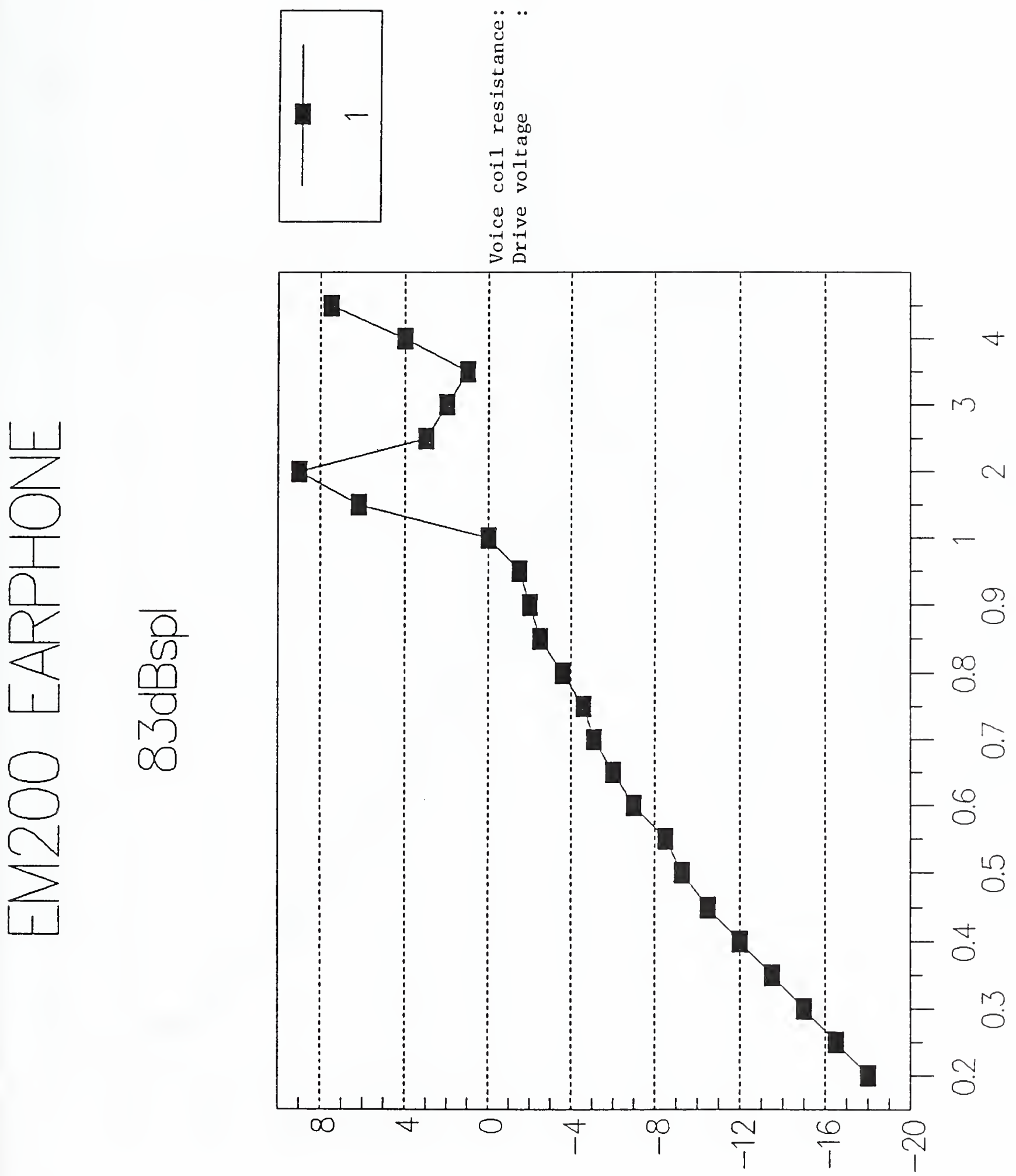
总
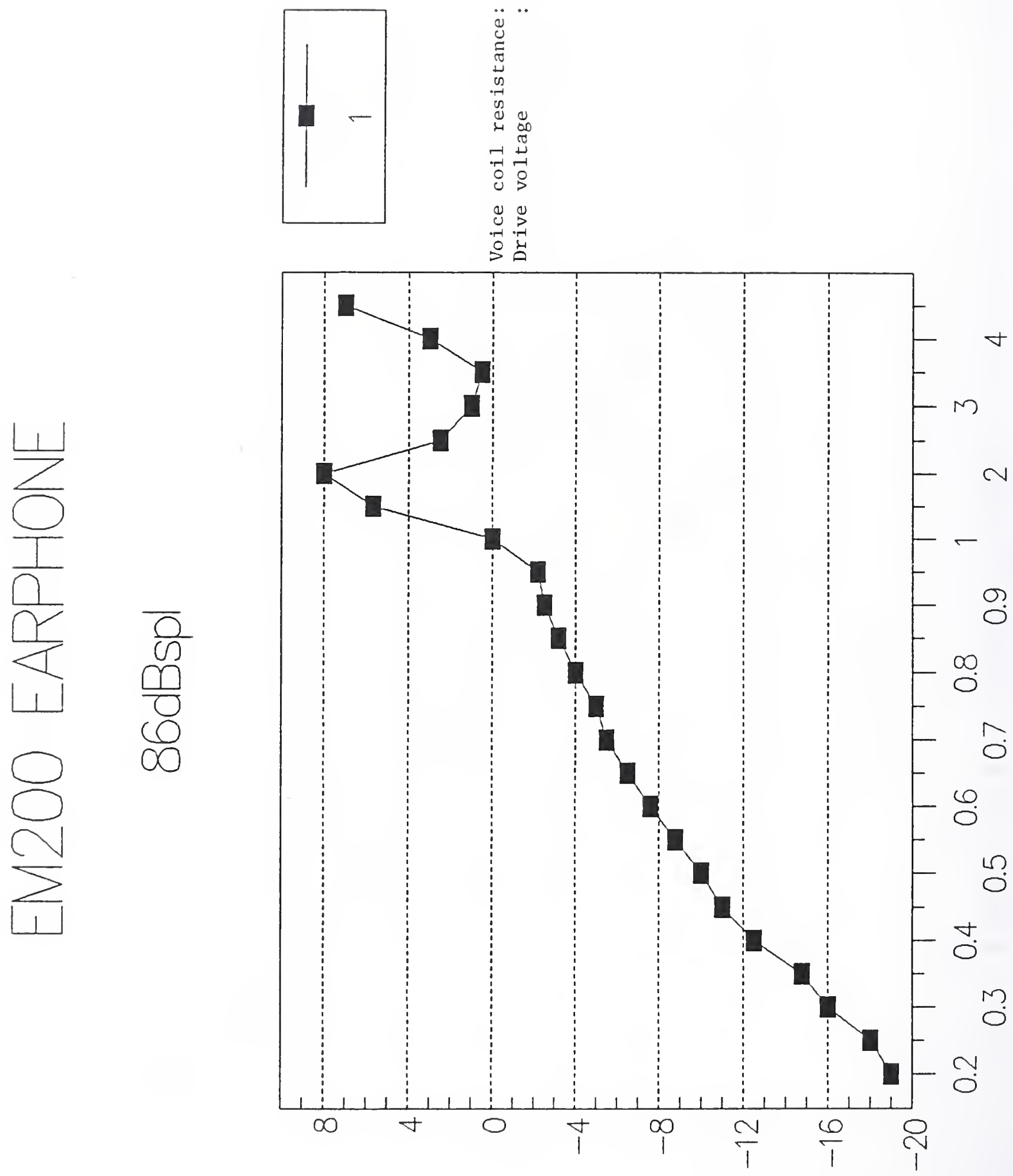
ซू

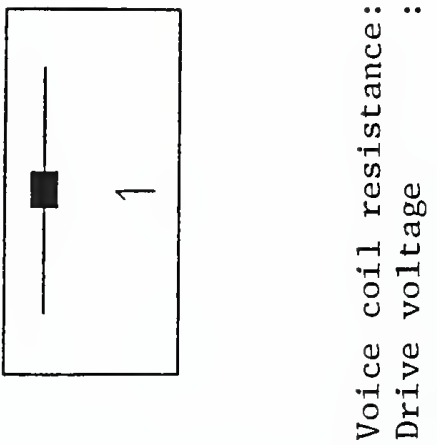

$\frac{\frac{u}{2}}{\frac{1}{\frac{1}{0}}}$

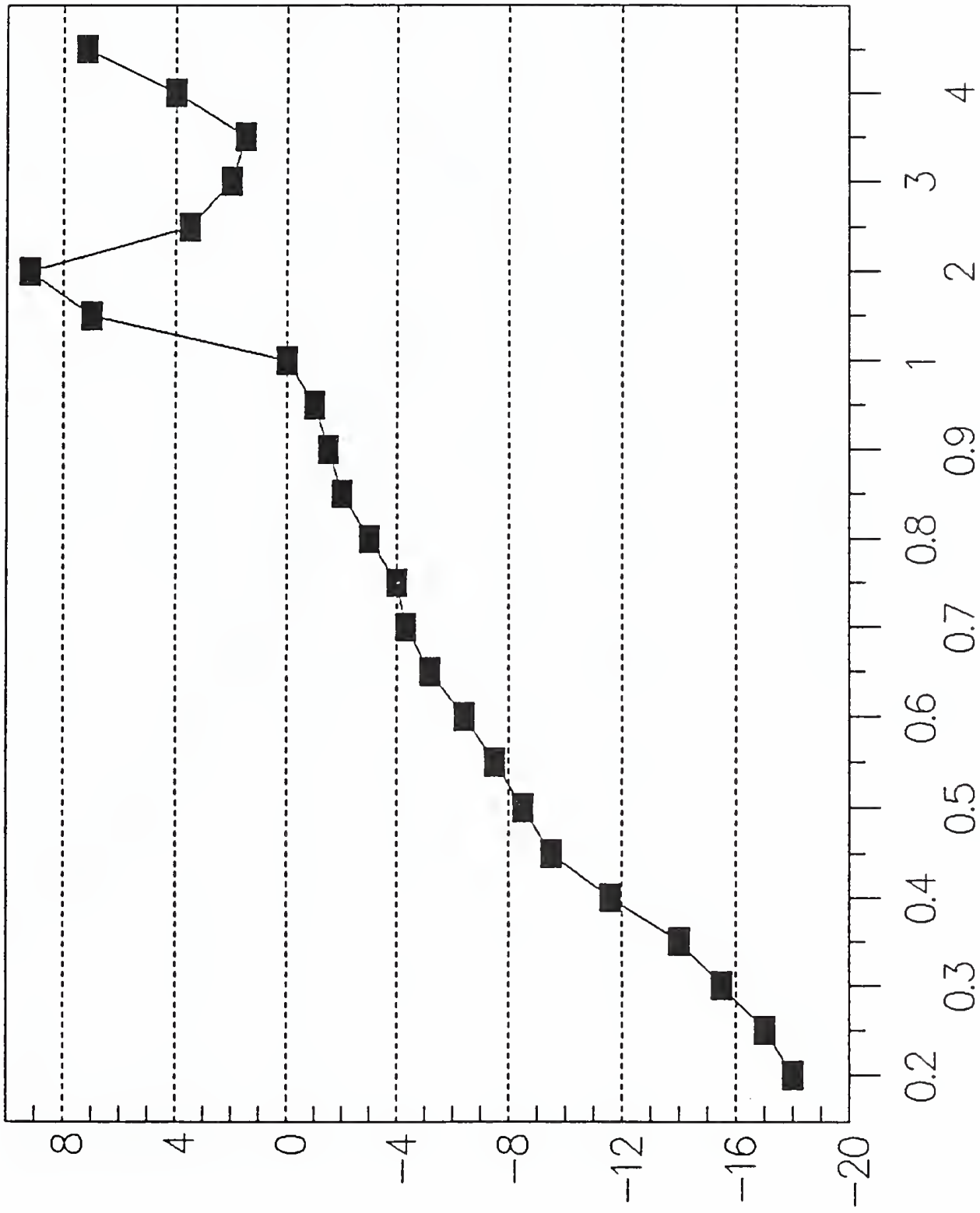


용
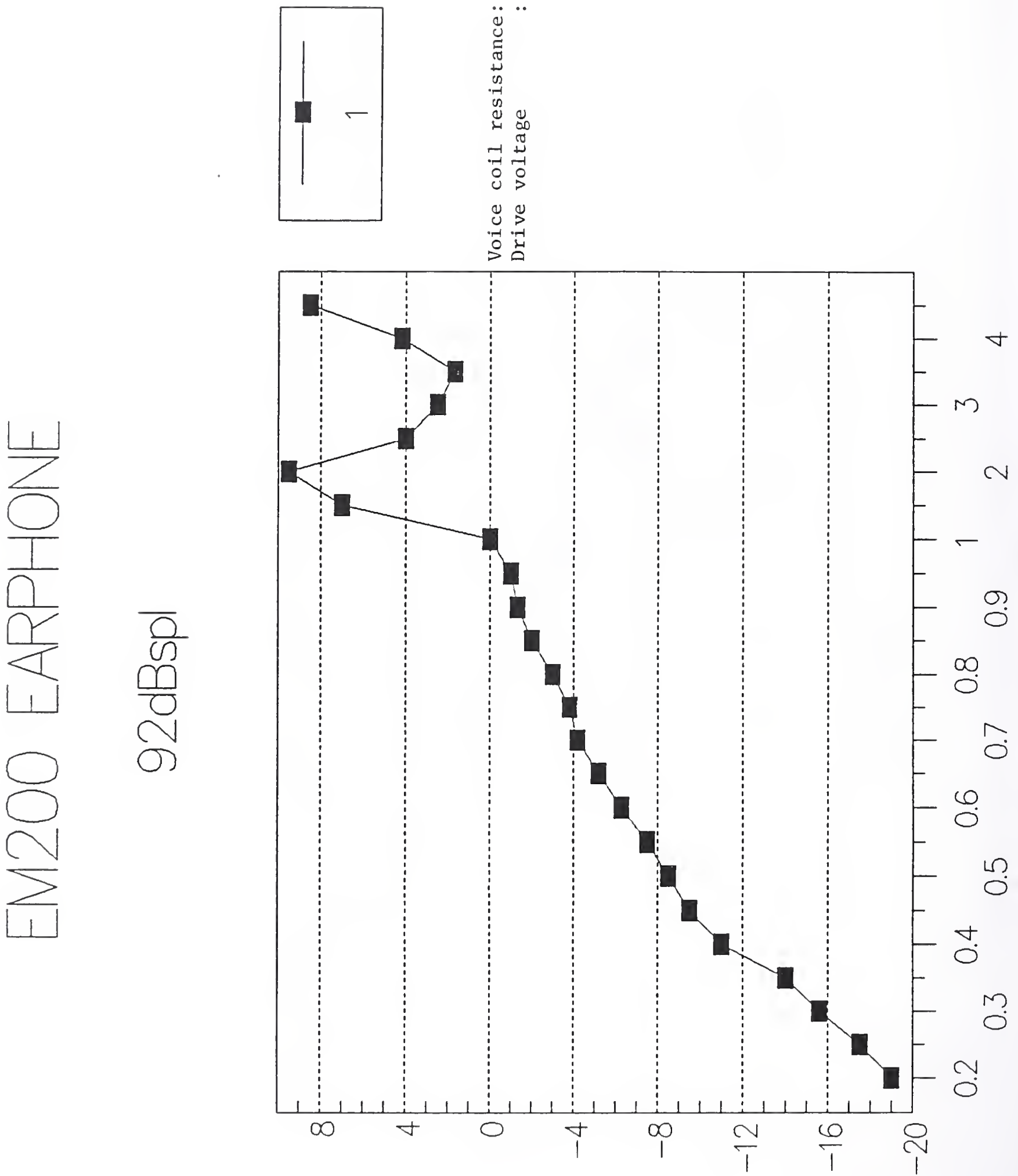


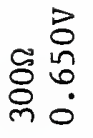
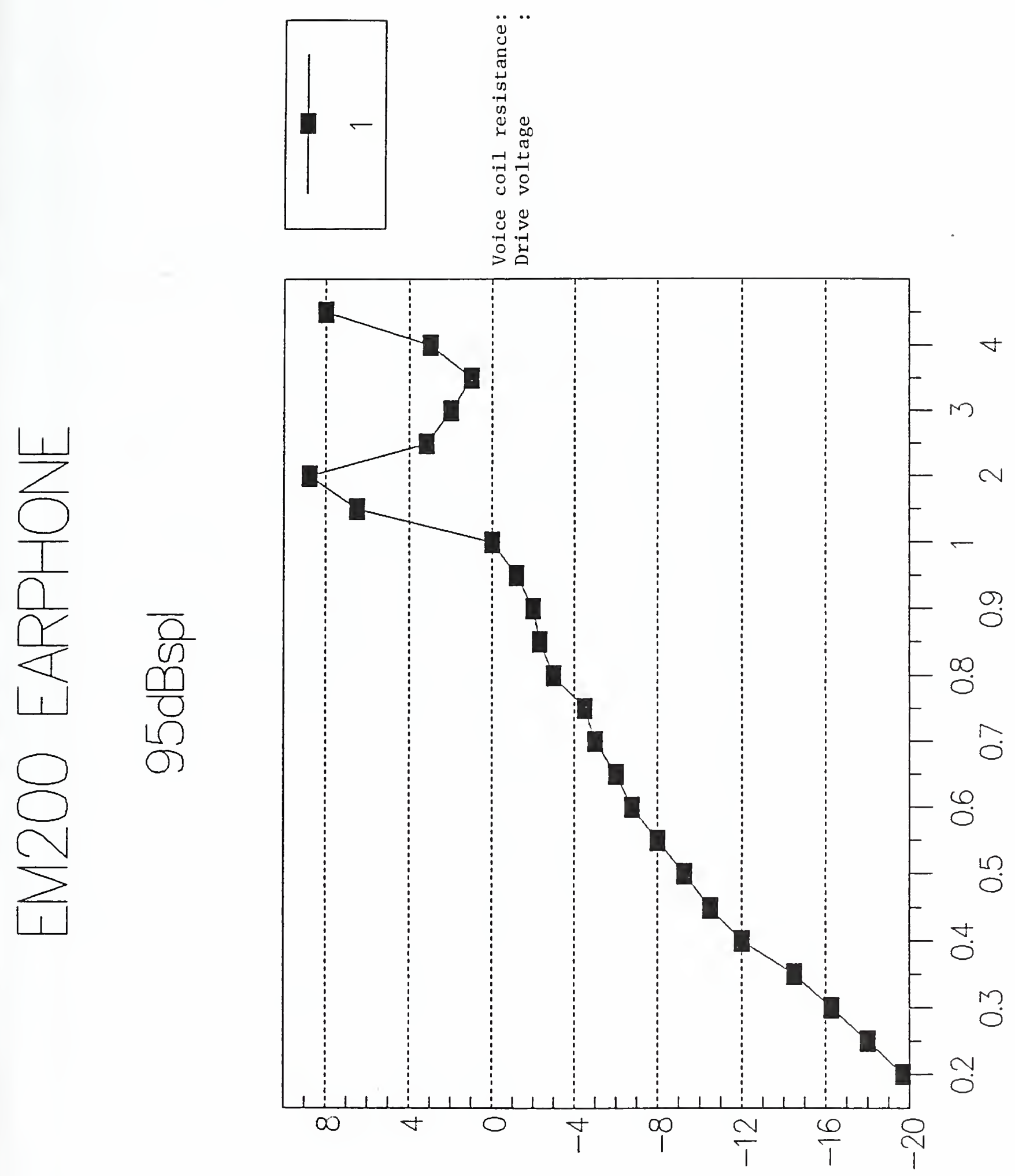
System 4 Test Data 


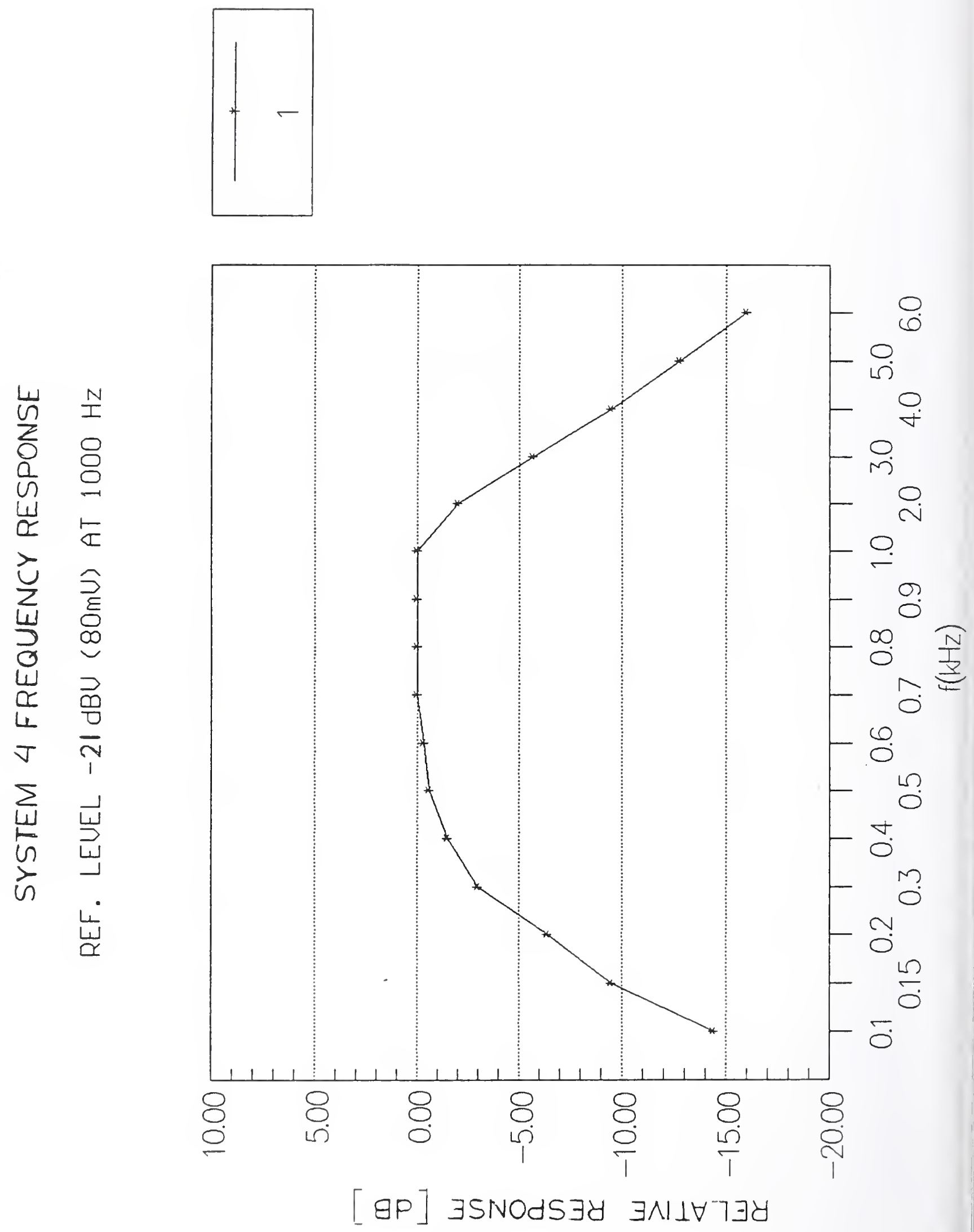


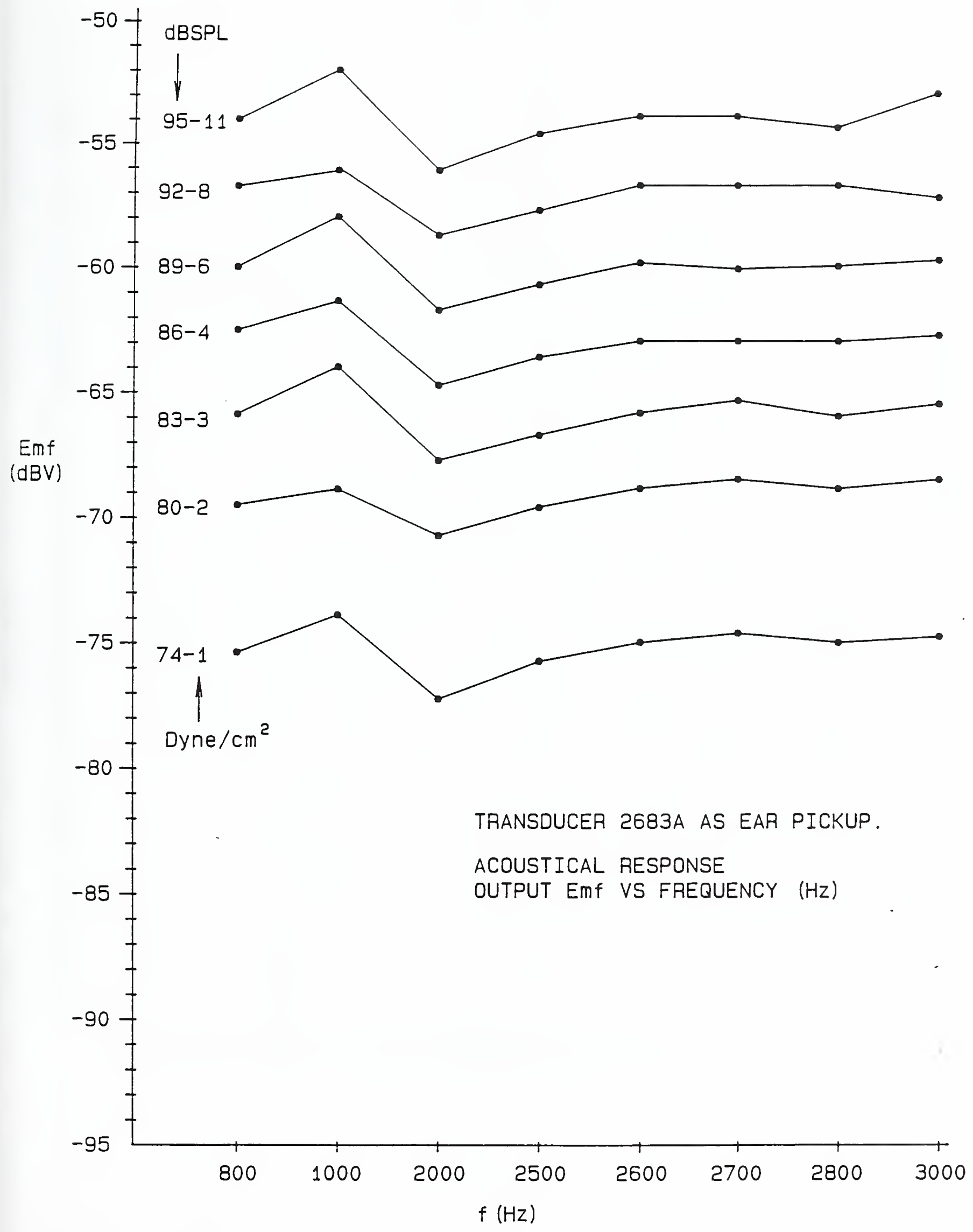


镑

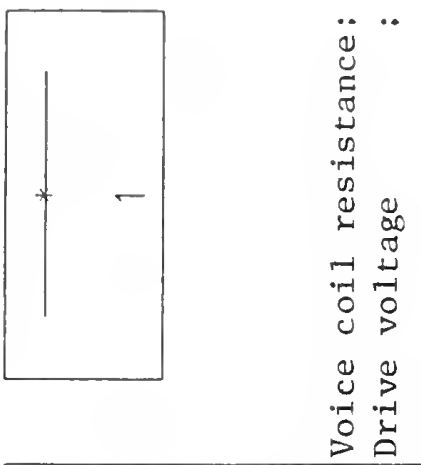

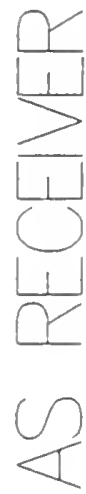

$\begin{array}{ll}\frac{1}{2} & \vec{d} \\ 0 & 0 \\ 0 & 0 \\ 0 & 0\end{array}$

신

$\frac{4}{3}$

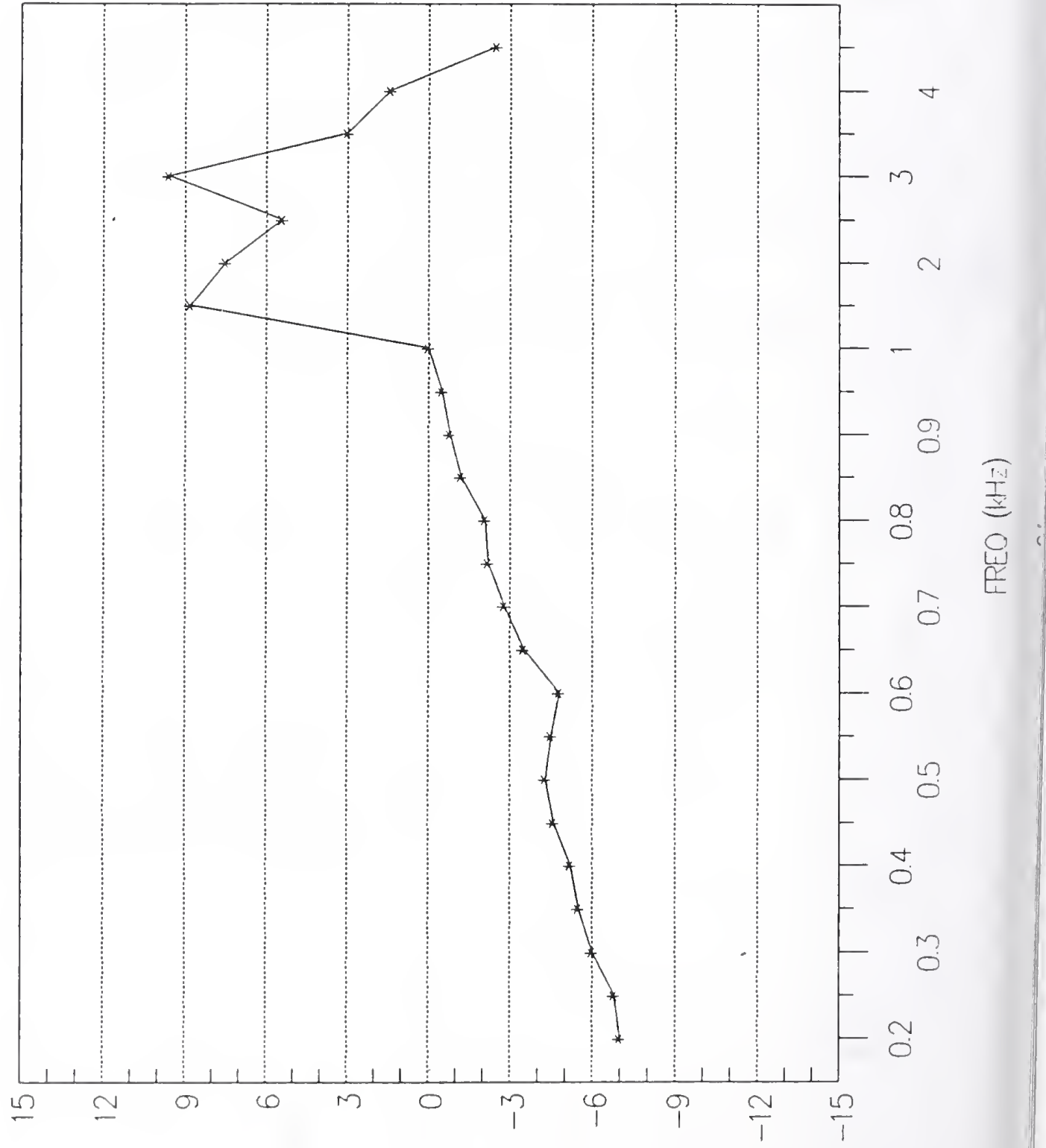


密商

舀

Y

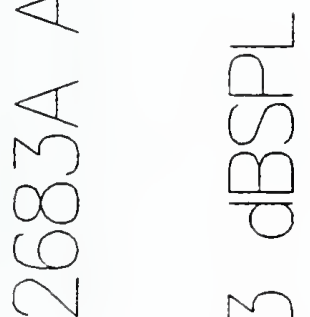

$\begin{array}{ll}\infty & 2 \\ \alpha & \infty\end{array}$

$(1)$

$\frac{7}{2}$

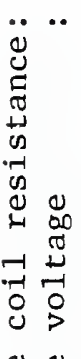

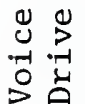

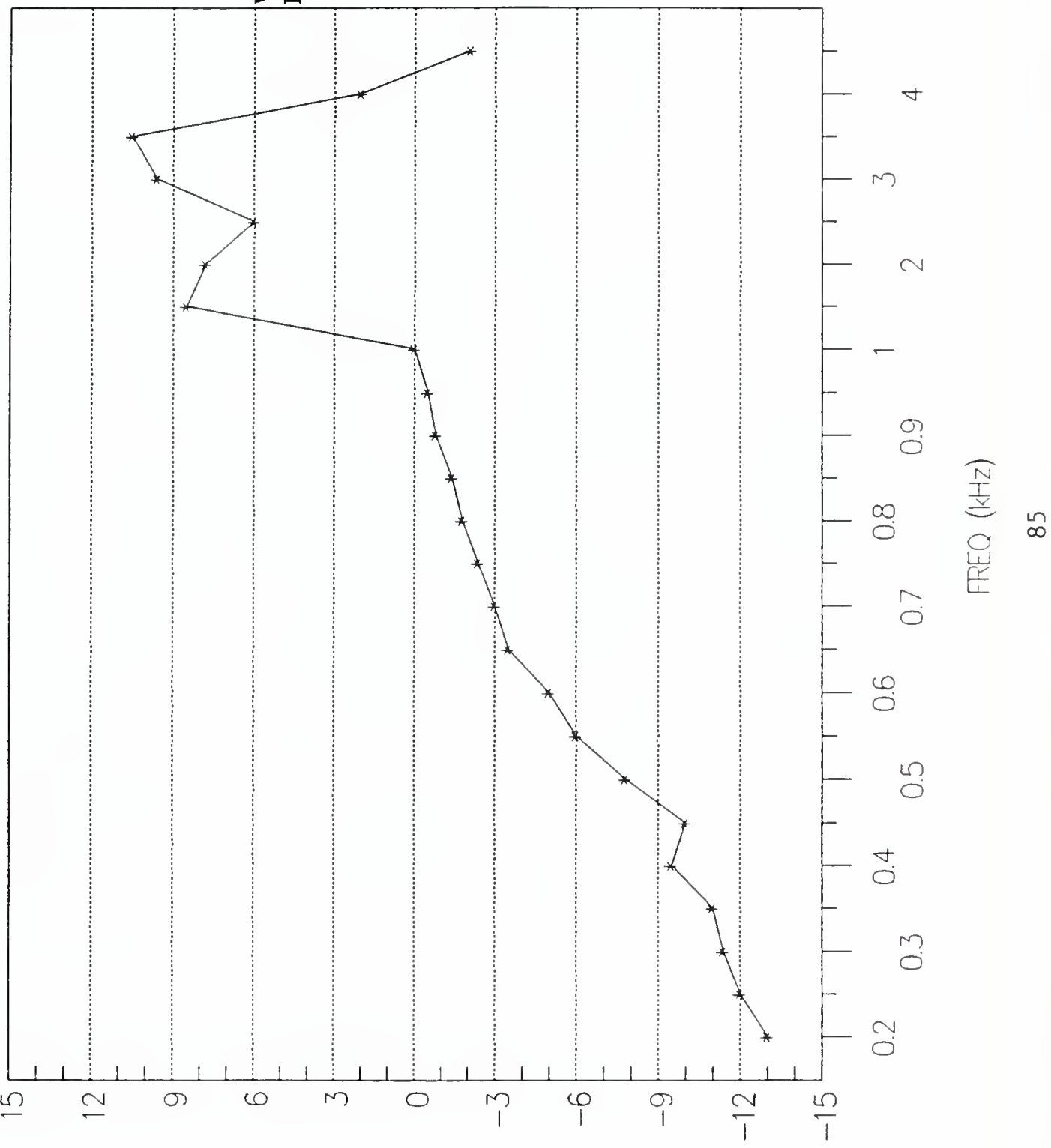


害实

$\frac{r}{w}$
$\frac{w}{d}$
$\frac{1}{\alpha}$
$\frac{1}{\alpha}$

$\begin{array}{ll}\alpha & \vec{n} \\ N & \frac{\pi}{0} \\ \infty & \frac{m}{0} \\ 0 & 0\end{array}$

$\frac{\alpha}{\frac{c}{u}}$
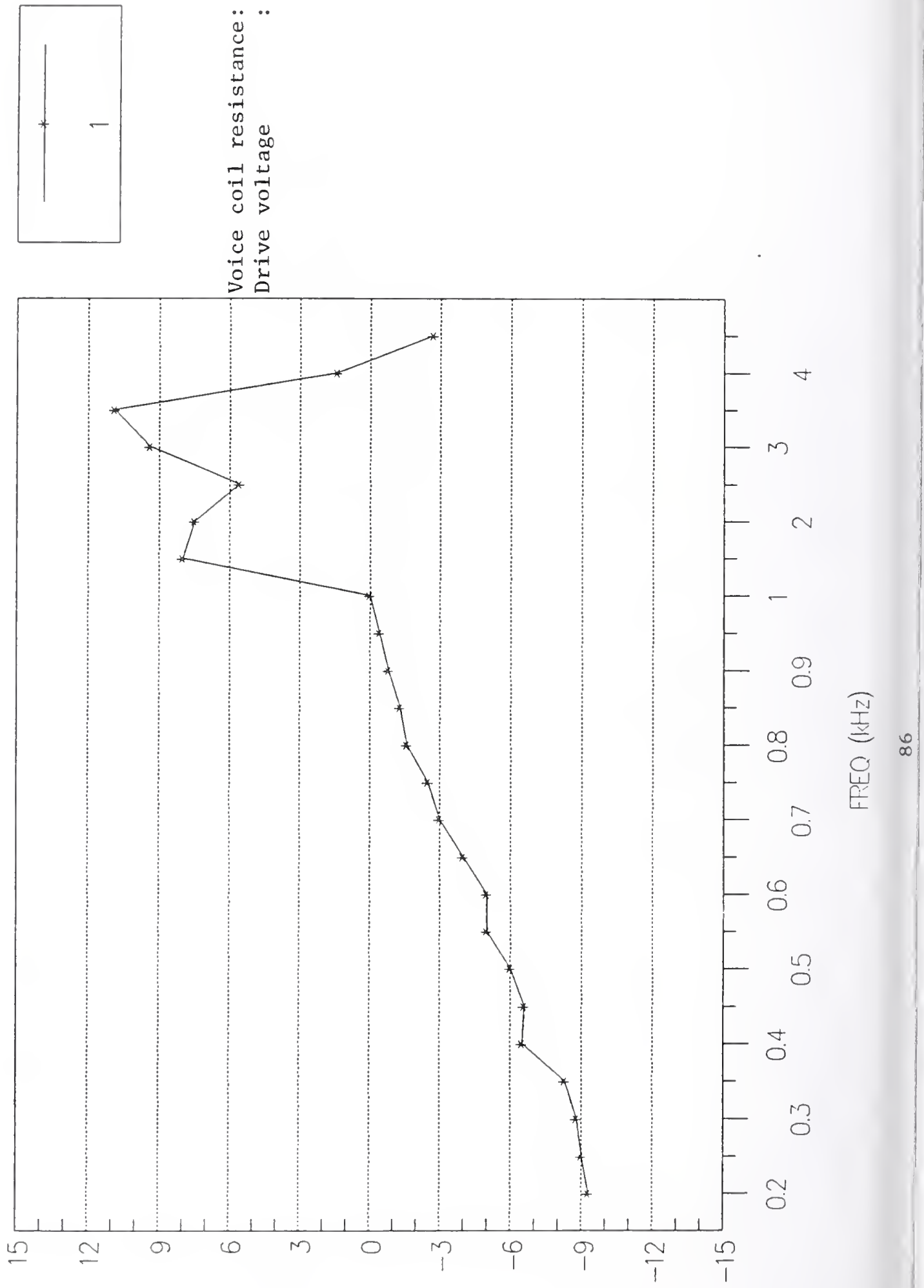
善尊
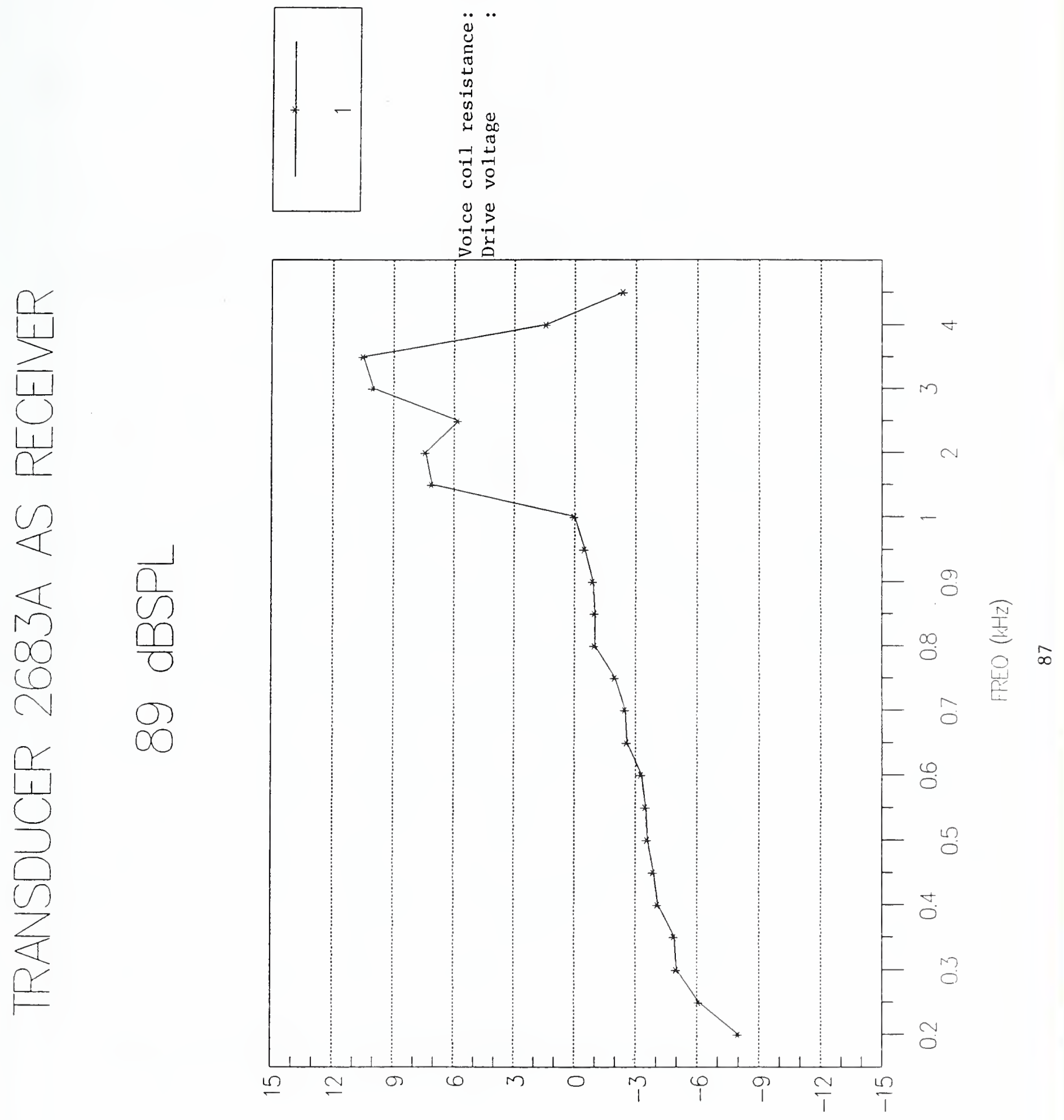
号:
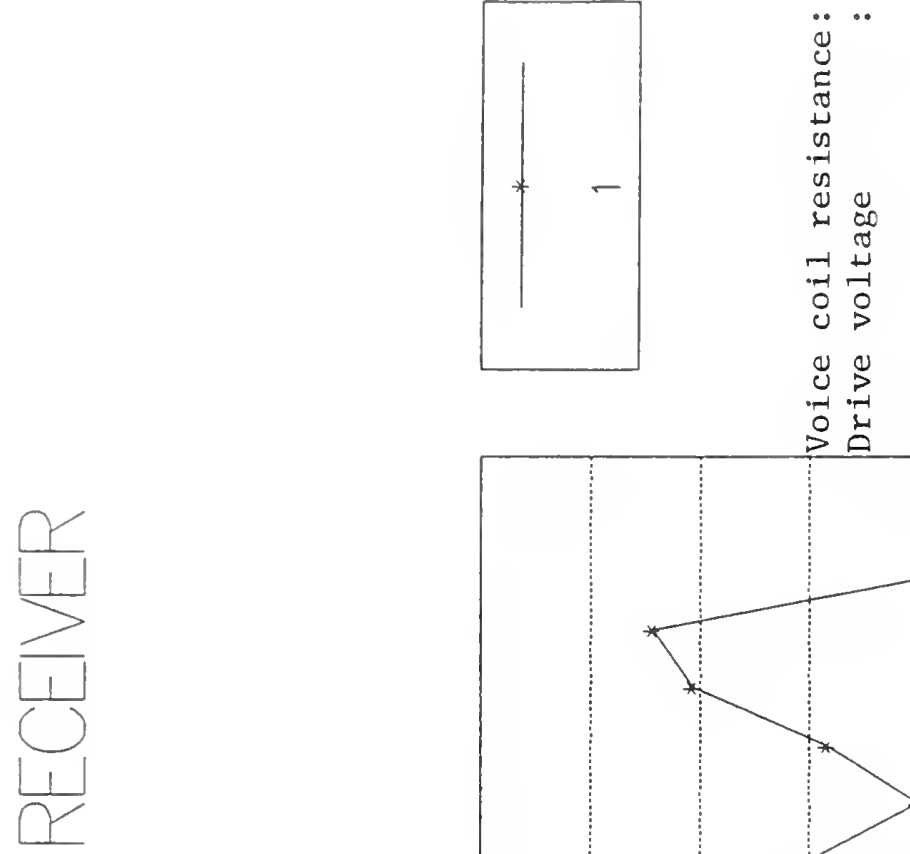

$\mathcal{O}$

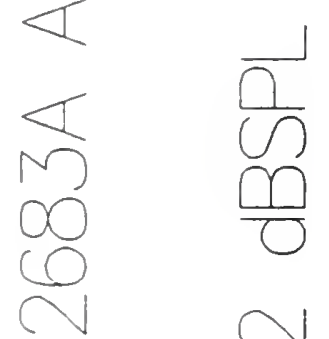

o o

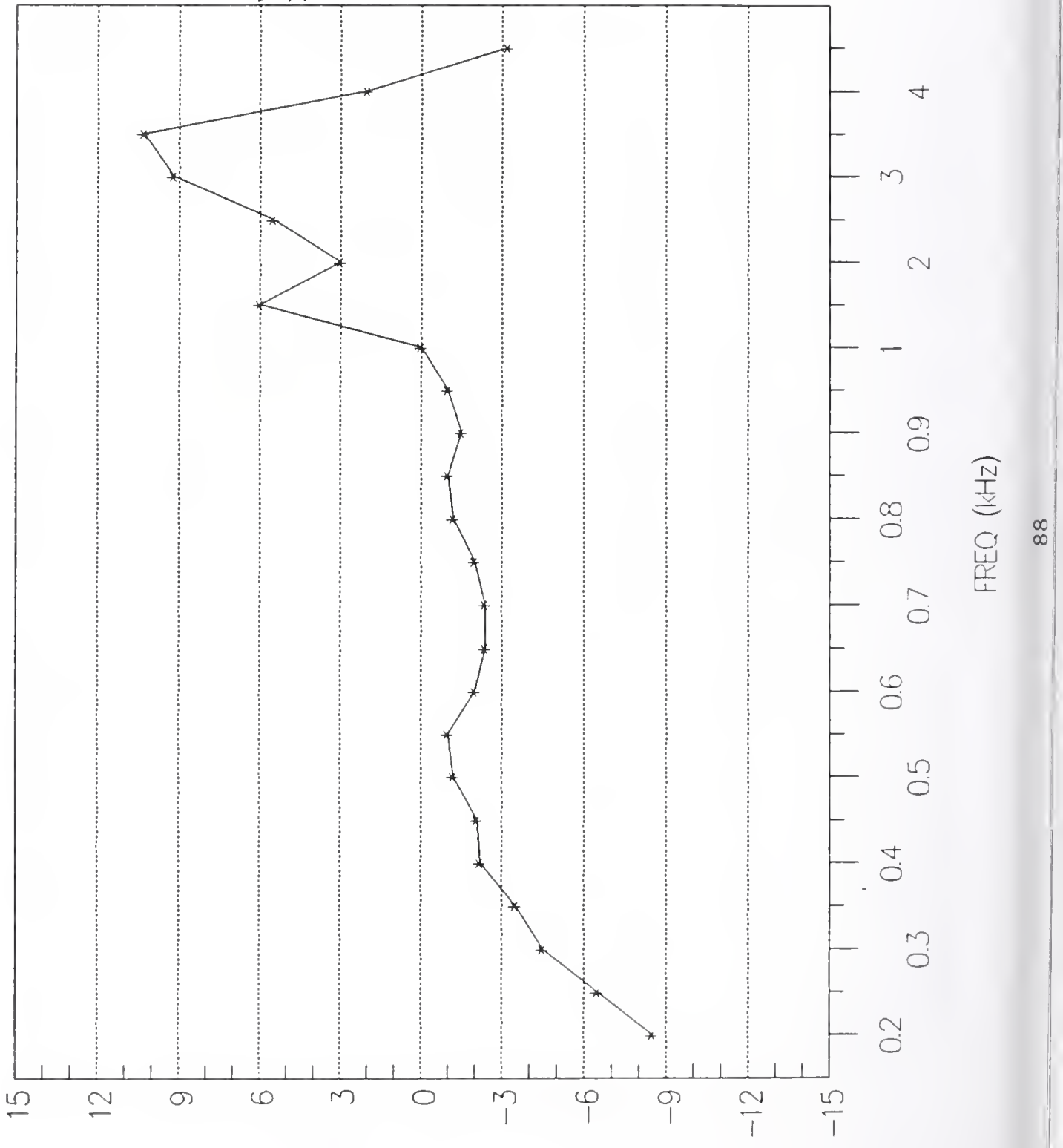


응구

立

是

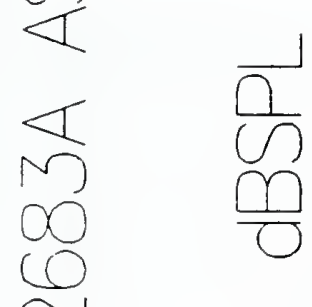

N L

r O

岁
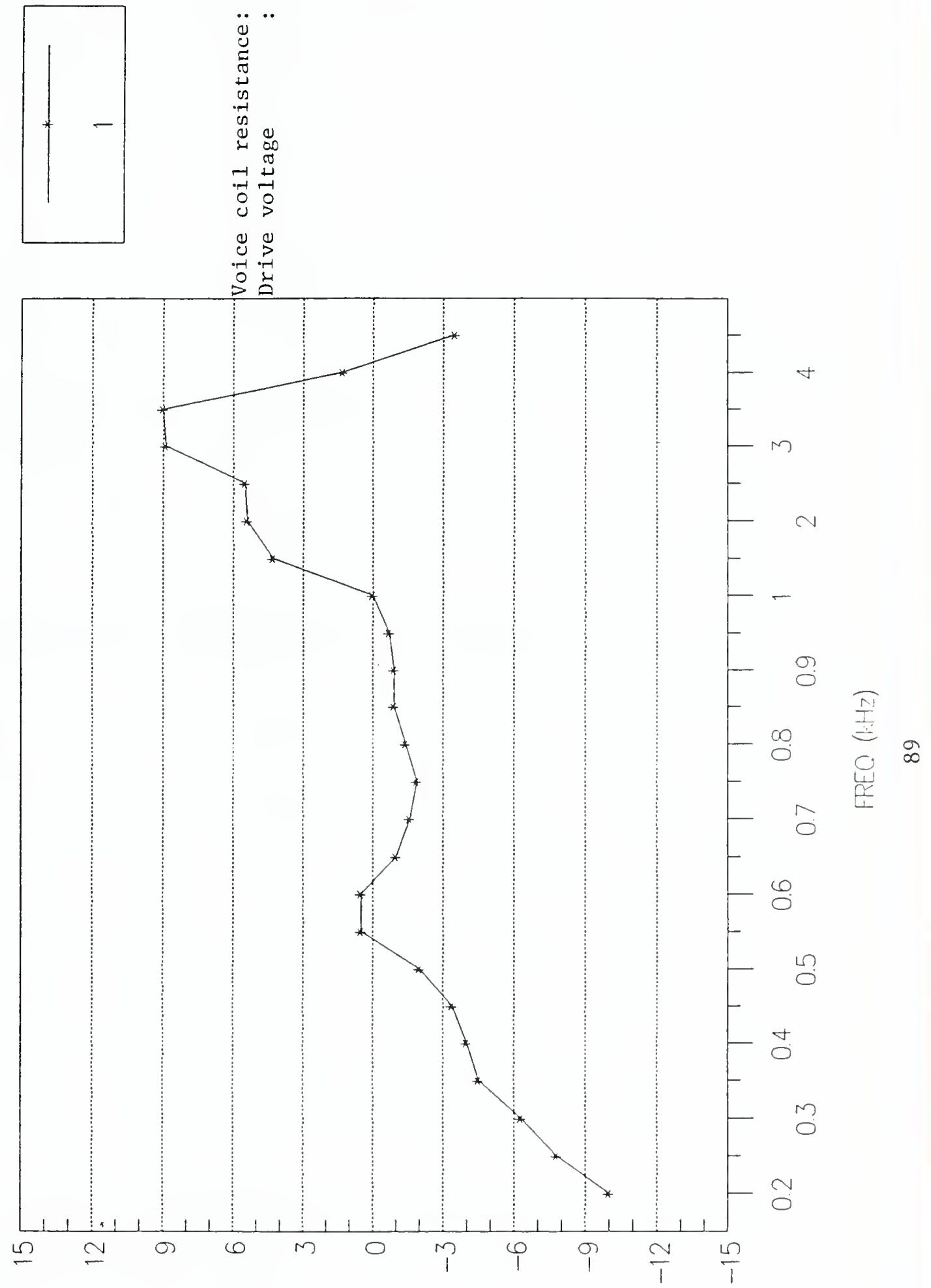


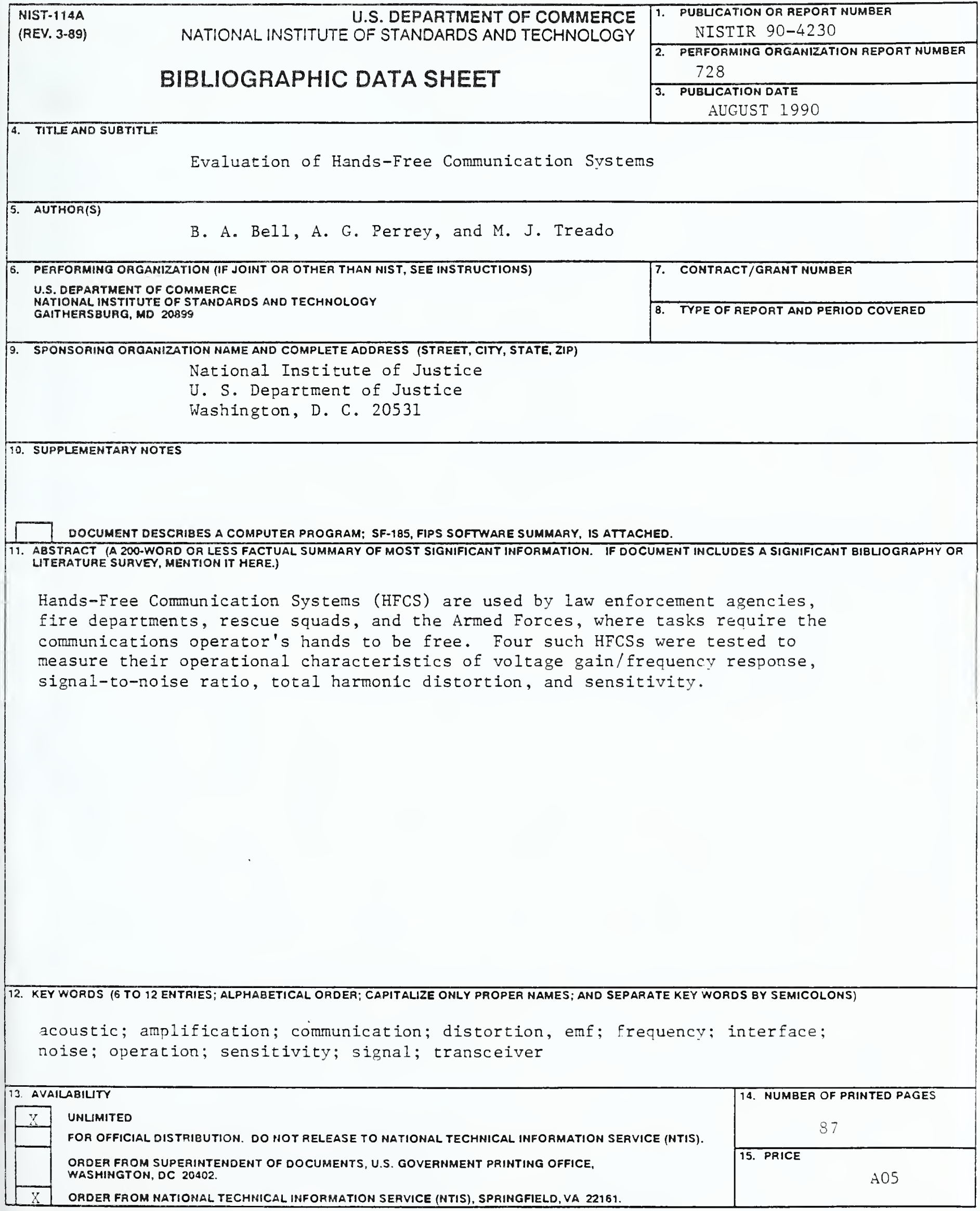



